Florida International University

FIU Digital Commons

FIU Electronic Theses and Dissertations

University Graduate School

$11-1-2018$

\title{
An Exploration of Names in Social and Professional Settings for Persons with Ethnically Identifying Names
}

Paige Whitney Johnson

Florida International University, pjohn004@fiu.edu

Follow this and additional works at: https://digitalcommons.fiu.edu/etd

Part of the Adult and Continuing Education Commons, Human Resources Management Commons, Organizational Behavior and Theory Commons, Personality and Social Contexts Commons, Race, Ethnicity and Post-Colonial Studies Commons, and the Social Psychology Commons

\section{Recommended Citation}

Johnson, Paige Whitney, "An Exploration of Names in Social and Professional Settings for Persons with Ethnically Identifying Names" (2018). FIU Electronic Theses and Dissertations. 3900.

https://digitalcommons.fiu.edu/etd/3900

This work is brought to you for free and open access by the University Graduate School at FIU Digital Commons. It has been accepted for inclusion in FIU Electronic Theses and Dissertations by an authorized administrator of FIU Digital Commons. For more information, please contact dcc@fiu.edu. 


\section{FLORIDA INTERNATIONAL UNIVERSITY}

Miami, Florida

AN EXPLORATION OF NAMES IN SOCIAL AND

\section{PROFESSIONAL SETTINGS FOR PERSONS WITH ETHNICALLY IDENTIFYING}

\section{NAMES}

A dissertation submitted in partial fulfillment

of the requirements for the degree of

DOCTOR OF EDUCATION

in

ADULT EDUCATION AND HUMAN RESOURCE DEVELOPMENT

by

Paige Whitney Johnson 
To: Dean Michael R. Heithaus

College of Arts, Sciences and Education

This dissertation, written by Paige Whitney Johnson and entitled An Exploration of Names in Social and Professional Settings for Persons with Ethnically Identifying Names, having been approved in respect to style and intellectual content, is referred to you for judgment.

We have read this dissertation and recommend that it be approved.

Hyejin Bang

Valentina Bruk-Lee

Sarah Mathews

Thomas G. Reio, Jr., Major Professor

Date of Defense: November 1, 2018

The dissertation of Paige Whitney Johnson is approved.

Dean Michael R. Heithaus

College of Arts, Sciences and Education

Andrés G. Gil

Vice President for Research and Economic Development and Dean of the University Graduate School

Florida International University, 2018 
(C) Copyright 2018 by Paige Whitney Johnson

All rights reserved. 


\section{DEDICATION}

My life is an adventure with many playing important roles along the way. I thank them all and this is for each of them, including my mother, Barbara H. Johnson, M.Ed. That child who sprayed colored water at the living room wall to demonstrate how far a sneeze could travel for my middle school science fair project and got lost in books until I was satisfied that I knew and understood the answers I sought, is now the adult who can help others to understand.

To my supporters near and far, who have quietly cajoled, loudly encouraged, brainstormed, counseled, fed and distracted: I am grateful for each of you, more than you shall ever know. Thank you for checking in, for asking questions and for being interested in this work as it has transformed into what it is today.

This quiet (and not so quiet) patience and encouragement to continue asking the difficult questions and looking for the answers has allowed me to reach this point in my formal education and I am truly grateful. Education gives you options in how you live, work, and interact. As a woman of African descent, we can never have too many options. Thank you. 


\section{ACKNOWLEDGMENTS}

Dr. Thomas G. Reio, Jr., words have not yet been created that can adequately express my appreciation for you. You always know just when to check-in, to nudge, to be available, to distract, to champion, to be human and kind. By its very nature, doctoral study can be lonely but I never actually felt like I was alone because I knew that you were always there.

To Drs. Bang, Lee and Mathews, your participation and suggestions have created stronger research and a better researcher. I am thankful to each of you.

To El pagnier, Elizabeth, Hazel, Haki, Kenyeta, Jia, Heidi, Cory, Hillary, Simone, John, Mercedes, Manichahn (Jade), April and Nicole, thank you so much for sharing your wisdom with me on such a deeply personal topic. Every detail of your perspectives and experiences served to enlighten and educate and I am deeply grateful for your trust and openness.

Dr. Maria Elena Villar (MEV), you are "good people" in every sense of the world. You never turn a person away even when you have 92 projects due in 20 minutes and you take the time to provide a kind word and inquire as to each person's well-being. These intangibles do not show up on a resume or often win awards but are so very appreciated. This is for you, as well.

To Mrs. Merle Inasi, you have cajoled, provided pep talks, pushed, pulled, distracted, sourced participants, listened, fed, explained, educated and pushed me to enjoy and explore the wonders that the world holds. Your contributions are too numerous to count and more appreciated than you know. 
To Ramces Marsilli, of FIU Libraries, thank you for the guiding hand and injecting some levity into what can be an arduous process.

To Dr. Linda Bliss, thank you for sharing your knowledge and pushing me to figure out what I wanted to find out and how to ask. Whenever I crack open my Bogdan and Biklen textbook, I remember you fondly.

To Jonathan Abdullah, you were my first foray into interviewing on this subject way back in our research class and you set the foundation. I look forward to collaborating with you upon both our graduations. You're almost there!

To Dr. Tonette Rocco, you provided the initial push when I began this program and started playing with the idea of conducting research on naming. I have not forgotten the lessons you imparted. Thank you.

To Dr. Joshua Collins, you read some of my earliest drafts when I was a first semester doctoral student and provided invaluable feedback when I really had no idea what I was doing. Thank you.

To my unicorns, also known as my siblings, Marlon, Amanda, Christopher and Kayla, each of you is special in your own way and you definitely embody the names that you were given. Own it and love it always! 


\author{
ABSTRACT OF THE DISSERTATION \\ AN EXPLORATION OF NAMES IN SOCIAL AND PROFESSIONAL SETTINGS \\ FOR PERSONS WITH ETHNICALLY IDENTIFYING NAMES \\ by \\ Paige Whitney Johnson
}

Florida International University, 2018

Miami, Florida

Professor Thomas G. Reio, Jr., Major Professor

The overarching purpose of this collected papers dissertation was to explore the perspectives and experiences related to names in social and professional settings for persons with ethnically identifying names. The first paper was an integrative literature review. The second paper was a qualitative study utilizing the phenomenological approach. Both studies utilized self-presentation theory, while Study \#2 added social penetration theory and social identity theory. Self-presentation theory posits that people put forth a public face to show that they possess desirable characteristics to observers. Social penetration theory is centered on the concept of self-disclosure and the notion that people carefully construct their level of disclosure based on the interaction and how they wish it to proceed. Finally, social identity theory puts forth that people categorize others to determine with whom to align themselves and whom to exclude. These theories undergirded the studies and directed the inquiry. 
Study \#1 reviewed literature to determine if names and self-presentation were studied within HRD. Only one study was found. The extant literature was largely quantitative, focused on job market reactions to applicant names, and assumed characteristics. Overall, the studies were focused on how best to present an applicant based on their name and the possible consequences of self-presentation in undesirable categories (e.g., minority applicants with unique or ethnic names). The literature indicated that applicants best presented when they utilized names that indicated nonminority ethnicity (e.g. White).

Study \#2 explored the opinions, experiences and behaviors of interview participants with ethnically identifying names related to social identity, self-presentation and social penetration. This study consisted of interviewing 15 people of either Asian, African, Caucasian or Latino/Hispanic ethnicity. Findings suggested that names did matter to the participants and that their behaviors and opinions related to their selfpresentation and self-disclosure were colored by their experiences as someone with an ethnically identifying name; both professionally and socially.

Overall, the findings of these studies are a starting point into the HRD literature to inform organizational research and practice. Additional research is needed to create a more comprehensive picture of the issues involved and work towards best practices and interventions. 


\section{TABLE OF CONTENTS}

CHAPTER

PAGE

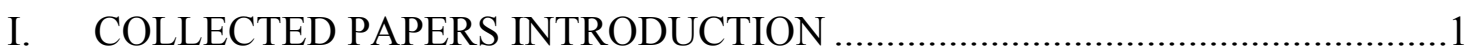

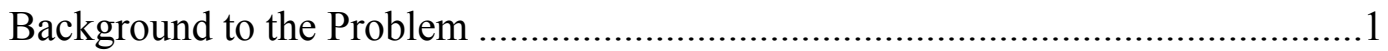

Conceptual Background for Collected Papers .......................................................

Effects of Names: Supporting Empirical Research ............................................15

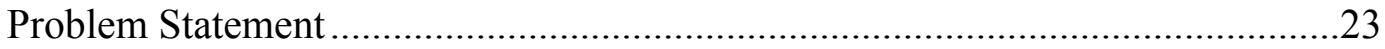

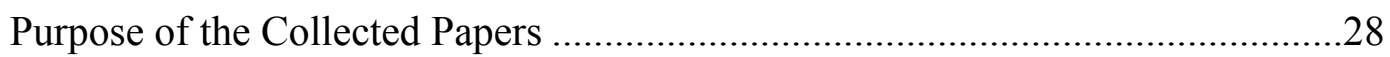

Description of Collected Papers.......................................................................28

Structure of Collected Papers Dissertation ............................................................35

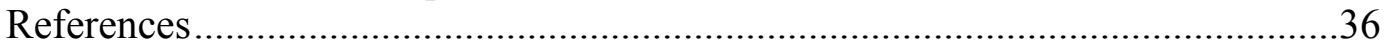

II. STUDY \#1, NAMES AND SELF-PRESENTATION IN THE WORKPLACE:

AN INTEGRATIVE LITERATURE REVIEW ...............................................41

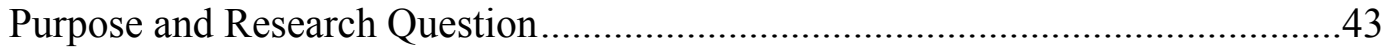

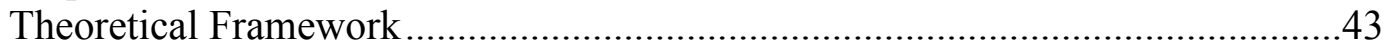

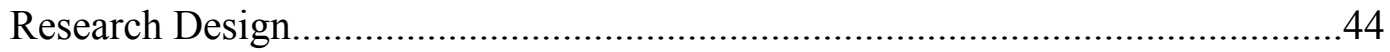

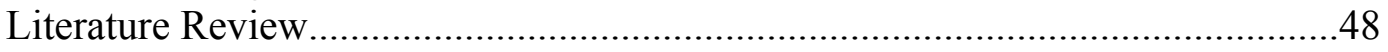

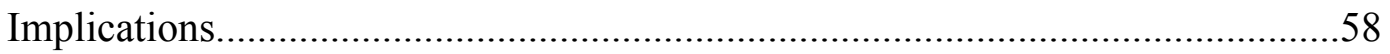

Future HRD Research .............................................................................5

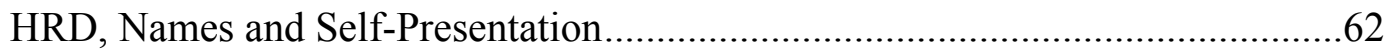

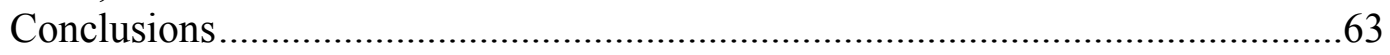

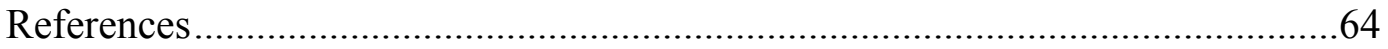

III. STUDY \#2, NAMES AND EXPECTATIONS: WHAT ORGANIZATIONS NEED TO KNOW ABOUT PEOPLE WITH ETHNICALLY IDENTIFYING NAMES

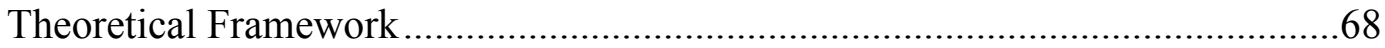

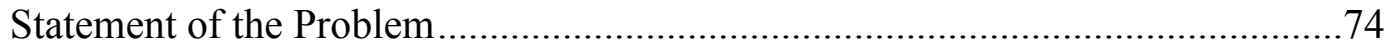

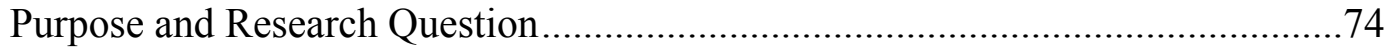

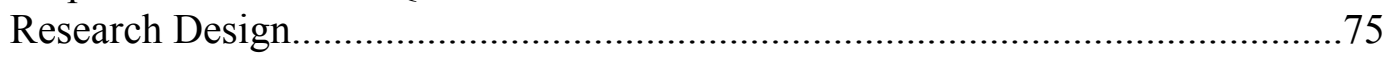

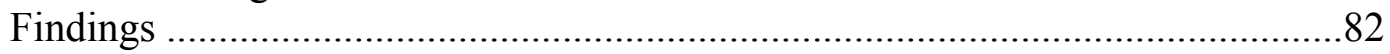

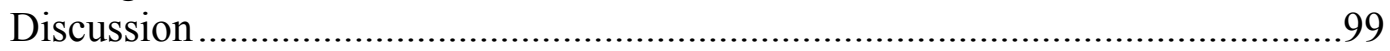

Implications for Theory, Research and Practice ...............................................100

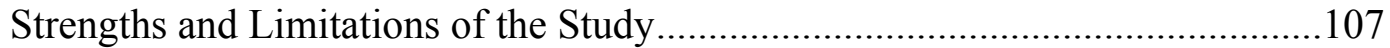

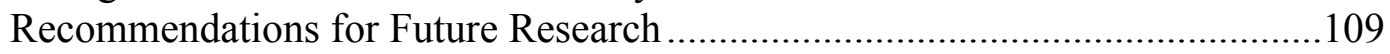

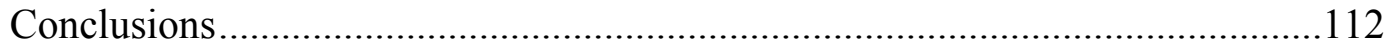

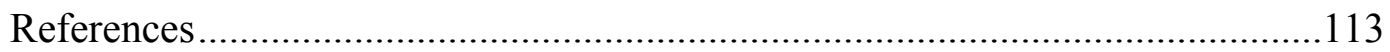




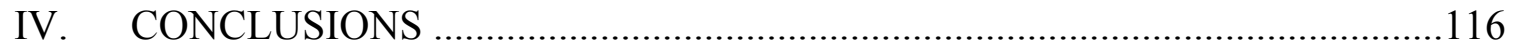

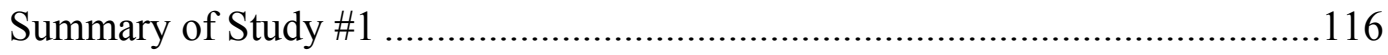

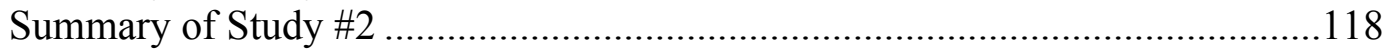

Findings Related to Overarching Purpose of Collected Papers Dissertation........121

Overarching implications ...............................................................................122

Emerging Themes for Possible Future Research ..................................................125

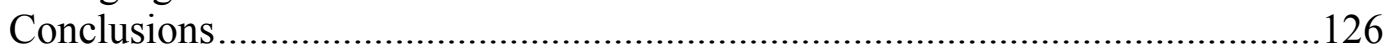

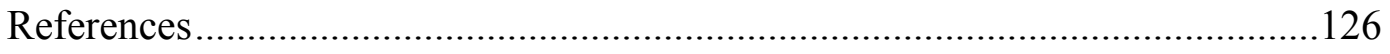

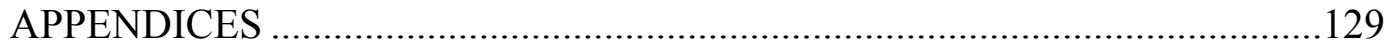

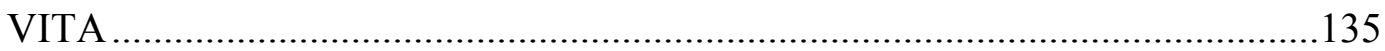




\section{COLLECTED PAPERS INTRODUCTION}

This collected papers dissertation explored the perspectives and experiences related to social identity, self-presentation, and social penetration in social and professional settings for persons with ethnically identifying names. The background to the problem, theoretical framework, supporting empirical research, problem statement, and overarching purpose as well as the proposed collected papers, and structure of the collected papers are presented.

\section{Background to the Problem}

Names and the Selection of Names

The "Why”, "Who” and "What" of Names

Names provide a mechanism to describe and associate, alluding to and connecting with attitudes, life experiences, assumptions, concepts and feelings. The impact of a name on a business, a University, a product or a child can determine the success of the business, the pedigree of the University, the popularity of a product and the ability of the child to relate to and conform to society. Tschaepe (2003) noted that,

first naming is not only significant, but performs a very specific function within language use that implies dynamics of power and identity insofar as the first name not only grants one a specific identity as a language user, but also directs who that person is and who will be through the name's physiognomy and reference to the world (pp.67-68).

When a child's name is chosen, there are various factors that can be considered: familial influences, popular culture, religious considerations, gender, geographical location, ethnicity, etc. The family name is largely pre-determined, but the first name is a 
singular experience, personal to the parent or grandparent. Parents and grandparents, if consulted, bring a substantial amount of thought and care to the name selection process (Edwards, 2008). The giving of the name, however, is only the first step in the process of naming. A second part of the process includes the sharing of that name through interpersonal interaction and the frames of reference associated with the name.

Throughout the United States, up through the 1960s, there was little distinction between the names chosen for White children and Black/African-American children (Fryer \& Levitt, 2004). Between 1970 and 1980, however, a shift unique to Blacks in the types of names given to their children took place (Fryer \& Levitt, 2004). Among other minority populations such as Asian and Hispanic, this shift was less pronounced with only a slight change noticed between 1961 and 1978 (Fryer \& Levitt, 2004). Hispanic names, however, shifted slightly away from those of Whites in the 1990s (Fryer \& Levitt, 2004).

From 1917-2016, some of the most common names chosen for females were Mary, Patricia, Jennifer, Elizabeth, Linda and Barbara, with Mary appearing the most over the last 100 years (United States Social Security Administration, 2017). For males, from 1917-2016, some of the most common names were James, John, Robert, Michael, William and David with John appearing most often (United States Social Security Administration, 2017).

Further research on naming trends reviewed 325 million names of persons in the United States and concluded that in the United States parents are now less likely to select a "common name" for their child (Twenge, Abebe \& Campbell, 2010). Prior to 2010, 
$40 \%$ of boys in the United States received a name from ten of the most common names and after 2010 less than 10\% received a common name (Twenge et al., 2010). The numbers for female children are similar with $25 \%$ previously receiving one of the ten most common names; currently the number is less than $8 \%$ (Twenge et al., 2010). Possible reasons for these name disparities are changes in immigration, a push to select names reflective of ethnicity/cultural heritage, and a desire to select names that are unique and reflect and encourage individuality (Twenge et al., 2010).

\section{Ethnically Identifying Names}

Ethnicity can be defined as, "a dynamic set of historically derived and institutionalized ideas and practices that allows people to identify or be identified with groupings or people on the basis of presumed (and usually claimed) commonalities including language, history, nation or region of origin, customs, ways of being, religion, names, physical appearance, and/or genealogy or ancestry (Moya, \& Markus, 2010). Ethnically identifying names are those that can aid in the assumption of group membership and associated personal characteristics. Ethnically identifying names can indicate if a person is of African, Spanish, Asian, Caucasian, Arabic or Persian descent, among others.

\section{Effects of Names: Stereotyping and Microaggressions}

Names can provide clues to a person's gender, ethnicity, nationality, social status, race and/or racial makeup (Young, Kennedy, Newhouse, Browne \& Thiessen, 1993). This ability to associate names with racial and ethnic distinctions can then link to 
perceived characteristics and stereotypes; both positive and negative. These stereotypes can be triggered through the basic information of a person's name (King, Madera, Hebl, Knight \& Mendoza, 2006) and link directly back to the history of race relations in the United States, specifically prejudice and racism. This affects not just daily interactions, but employment and other attitudes and behaviors that drive decision-making (Sigelman \& Tuch, 1997). In considering names and their contexts, exploring concepts related to names and naming becomes necessary. First, the concepts of stereotypes, stereotyping, positive and negative stereotypes and occupational stereotyping will be explored. Then, an exploration of model minorities will follow. Finally, a review of microaggressions will provide additional levels of context.

\section{Stereotypes}

Although the word stereotype has been around since ancient Greece, it was first used in a psychological paradigm by Walter Lippman in 1922. A stereotype can best be defined as a formed impression of an individual guided by subjective psychological responses and opinions held of that individual's group membership (e.g., ethnicity, race, gender) which aid in identification and categorization (Czopp, 2008; Lippman, 1922; McGarty, Yzerbyt \& Spears, 2002). This characterization of stereotypes rests on the belief that they are highly influential, but limiting creating understanding without any substantive education for support of such understanding (Lippmann, 1922). Stereotyping, then, is tied to the assumption that a particular group has a collection of descriptive characteristics. 


\section{Positive and Negative Stereotyping}

Negative stereotypes particular to Blacks and other minority groups of varying race and ethnicity include references to lack of ambition, poor work ethic, lack of intelligence, laziness and criminality (Sigelman \& Tuch, 1997). Positive stereotypes, while applicable to all, are often attributed to minorities too. Unlike negative stereotypes which most often have a negative connotation, positive stereotypes as defined are, "subjectively favorable beliefs about members of a social group that directly or indirectly connote or confer domain-specific advantage, favorability, or superiority based on category membership,” (Czopp, Kay \& Cheryan, 2015, p. 451).

While comments including and perpetuating positive stereotypes can often be intended as laudatory, comments such as those stated by former CBS football commentator Jimmy "The Greek" Snyder during a television interview can have the unintended consequence of minimizing the individual's identity outside of the social group to which they are seen to represent and encapsulate (Czopp, 2008). Snyder stated, "The Black is the better athlete, and he practices to be the better athlete, and he's bred to be the better athlete because this goes way back to the slave period. The slave owner would breed this big Black with this big Black woman so he could have a big Black kid. That's where it all started," (Czopp, 2008; Uhlig, 1988, pp. 47).

Positive stereotypes tend to be perceived as being more acceptable in that the stereotype, in the form of a compliment is not meant to be an insult, and as such no offense should be taken. While positive stereotypes are meant to be favorable compliments by those who express them, the recipient may see the positive stereotype as 
a method to detract from their existence, except as it relates to their membership in a specific group (Czopp et al., 2015). The use of positive stereotypes, much like negative stereotypes, is values-based and indicates what the "complimenter" finds acceptable or unacceptable about the receiver of the compliment or insult. Their use of the stereotype, then, becomes a mixture of judgment and ill-conceived praise or scorn with possible wide-reaching psychological effects for both the receiver and the giver who may not understand the underlying issues associated with the stereotype (Siy \& Cheryan, 2013).

Although there have been improvements in the racial climate of the United States and in perceptions and attitudes in recent decades, disparaging associations of minority groups remain steady and create a climate of racial hostility that also serve to influence thinking on other issues of racial importance, like equal opportunity (Booker, 2015; Sigelman \& Tuch, 1997).

\section{Occupational stereotyping}

An understanding of occupational stereotyping, the "preconceived attitude about a particular occupation, about people who are employed in that occupation, or about one's suitability for that occupation,' is important in the context of names (Lipton, O’Connor, Terry, \& Bellamy, 1991, p. 129). If anyone involved in the employment process holds negative viewpoints about groups and individuals based on their group membership, they may also have predetermined notions of whom would best fit and not fit into the open position and the organization as a whole (Fiske \& Taylor, 1991). One such example is landscapers of Spanish descent who may have difficulty gaining other 
gainful employment in fields not associated with horticulture and agriculture (King et al., 2006; Powell \& Butterfield, 2002).

\section{Model Minority}

A form of positive stereotype, specifically related to persons of Chinese and Japanese ancestry within the United States, is known as the Model Minority. "Model Minority” is a label created in 1966 in reference to Japanese Americans and their achievements that should serve as a model for other ethnic and racial minorities (Wong \& Halgin, 2006). The concept that Asian Americans have created the standard by which all other minorities will be judged is borne out through frequent depictions in the media where Asian Americans are considered to be paragons of virtue through their lawfulness, prosperity, academic ability and facilities in mathematics and science (Wong \& Halgin, 2006). A study undertaken in 1997 by researchers Oyserman and Sakamoto to determine the opinions on Asian Americans to the Model Minority label indicated strong feelings towards the label (51.7\% negative and $15.9 \%$ ambivalent), which the interviews supported (Wong \& Halgin, 2006). The idea of identity played a large role in the research regarding the Model Minority label, with follow-up interviews providing detail of how the label tied directly to the cultural norms and expectations of the ethnic group as a whole and the individual's ability/desire to be tied/judged by a group image (Wong \& Halgin, 2006).

As Asian Americans feel strongly about the label and some may wish not to be judged by it, the Model Minority label has consequences. From an academic standpoint, Asian American students experience some of the same difficulties as other minorities and 
may struggle with issues of identity, independence, expectation and the pressure to live up to the image inherent to the Model Minority label (Wong \& Halgin, 2006). In that Asian American students are expected to perform well, the pressure to meet those expectations and falling short, can create a deep belief that they have tarnished the reputation of all Asian Americans as opposed to an individual setback that only affects the student (Wong \& Halgin, 2006). There is an assertion, borne out in research, that the positive stereotypes associated with the Model Minority label produce more negative consequences than positive (Maddux, Galinsky, Cuddy \& Polifroni, 2008).

\section{Microaggressions}

Microaggressions are any subconscious beliefs, casual comments, attitudes, and interactions that evidence and perpetuate unintended discrimination towards the receiver based on their group membership (Pierce, 1970; Pierce, Carew, Pierce-Gonzalez, \& Willis, 1978). As such, microaggressions are thought to be a way in which racism and discrimination are covertly expressed. These microaggressions manifest themselves in words, action, glances, inaction (e.g., lack of inclusivity in workplace), etc., and can be both verbal and nonverbal (Sue, Capodilupo, Torino, Bucceri, Holder, Nadal, \& Esquilin, 2007). Examples of microaggressions include expressing to someone that they are a credit to their race or telling an African American that they are articulate (Sue, Capodilupo, \& Holder, 2008), expressing to an Asian American that they have a fine grasp of the English Language (Sue et al., 2008) or becoming visibly wary and clutching onto a handbag when an African American comes near (Nadal, Sriken, Davido, Wong \& McLean, 2013). 


\section{Conceptual Background for Collected Papers}

The theories used to guide and inform this study are Social Identity Theory (Tajfel \& Turner, 1979), Self-Presentation Theory (Goffman, 1959) and Social Penetration Theory (Altman \& Taylor, 1973).

\section{Social Identity Theory and In-Group Bias}

Social identity theory, created in 1979 , is based on the concept that people seek to associate themselves (based on their own self-identification) with others that coincide with their social standing, economic status, racial makeup, ethnic background or other characteristics that serve to reinforce their belief of the in-group's standing as superior to the outside group (Tajfel \& Turner, 1979, 1986). Social identity is defined as "those aspects of an individual's self-image that derives from the social categories to which he sees himself as belonging," (Tajfel \& Turner, 1979, p. 40). Through the assertion of belonging to one group as opposed to another, the in-group and the out-group are formed.

\section{Mental Processes: Social Categorization, Social Identification and Social Comparison/Competition}

Within social identity theory, there are mental processes that foster the in-group and out-group: social categorization, social identification and social comparison/competition (Tajfel \& Turner, 1979, 1986). These mental processes serve to explain the manner in which individuals form their identity through social interaction.

Social categorization speaks to the need to derive understanding of oneself and others through the creation of categories which aid in self-identification and identifying of others as similar or different (Tajfel \& Turner, 1979, 1986). Within society there are 
groups created through categorization due to similar and different attributes, whether that be groups determined by gender, race, ethnicity, nationality, trade, level of academic achievement, etc. Through categorization, social identification occurs when an individual determines their group membership and adopts the behavior and mannerisms that they believe the group embody, thus tying their self-image to their group membership (Tajfel $\&$ Turner, 1979, 1986). During this process, an emotional connection is formed and group membership becomes both significant and an important factor in the individual's self-esteem. Social comparison is the final process and is characterized by the need to differentiate the group from other groups thereby making clear the in-group's favorability and superiority (Tajfel \& Turner, 1979, 1986). In that each group member's sense of self and self-image is tied to the status imparted through group membership, the goal, undertaken through group competition to gain distinction, becomes ensuring that there is homogeneity within the group. For a person with an ethnically identifying name, an act such as the use of a nickname, middle name, or other attempt to normalize their name can be considered as part of efforts to aid in positive social categorization, social identification and social comparison/competition.

When considering these three mental processes: social categorization, social identification and social comparison/competition, a number of themes emerge regarding group selection and its impact on various arenas throughout life (e.g., employment, admission to higher education institutions, organizations, associations, and societies as well spousal and friend selection). Membership within the group has to be selective because those allowed into the group will directly impact the status of the entire group. 
As group membership provides a sense of belonging and pride, to enhance this self-image there becomes a need to ascribe positive attributes to your group (the in-group) and associate negative characteristics to those outside (the out-group) (Tajfel \& Turner, 1979, 1986). Those within the group seek to increase and maintain their group's sense of superiority through group member selection bias (inclusion and exclusion), which can result in racism and discrimination.

\section{Self-Presentation Theory and Impression Management}

\section{Self-Presentation}

Created and developed by Erving Goffman in 1959, self-presentation theory centers around the concept that each person puts forth a public face and undertakes a performance to influence others' perceptions of them to achieve goals, be it professional and/or social (Goffman, 1959). Goffman defines performance, "as all of the activity of a given participant on a given occasion which serves to influence in any way any of the other participants," (Goffman, 1959, p. 15). The idea is that a person will always attempt to influence others' opinions during the initial interaction. The performer has to make clear that they possess and can demonstrate "the officially accredited values of the society" both through word and action, with immediacy and appropriate drama so as to make it both obvious and significant (Goffman, 1959, p. 35). Ethnically identifying names can hinder the performance, particularly if the name assumes characteristics that the performance seeks to downplay. 
Goffman talked about performances as having a front and a back. The front is that which is used to support the performance like a particular setting or backdrop, appearance, manner of speaking and/or actions taken (Goffman, 1959). The front is both the performance and the performer, where the performer becomes more or less credible determined by the social value that both the act and the performer are assigned based on the participants' expectations, opinions and previous experiences (Goffman, 1959). Goffman referred to this as "collective representation" wherein if the performer remains and behaves within the expected frame of reference of the observer, the performance fits the benchmark by which the performer and others will be evaluated (Goffman, 1959). If the performance is credible and accepted, the performer can move from the front to the back, where a truer version of the performer can be presented once the initial barriers are passed. The back, then, can be defined as, "a place, relative to a given performance, where the impression fostered by the performance is knowingly contradicted as a matter of course," (Goffman, 1959, p. 112). If the back is too discordant from the front, the entire performance can be deemed a failure.

\section{Impression Management}

Impression management is concerned with maintaining the performance to continue to influence observers to view the performer in a specific manner (Goffman, 1959). The ability, then to manage one's impression is an essential part of professional and interpersonal efficacy including the forming of friendships, identity formation, career success and group membership success, among others. (Vohs, Baumeister, \& Ciarocco, 2005). When the impression is correctly managed, the observers overlook any small 
actions that may not coincide with the established impression unlike when impression is not maintained.

\section{Social Penetration Theory and Self-Disclosure}

Social penetration theory is based on the idea that there are levels of interpersonal interaction that are traveled as social relationships progress (Altman \& Taylor, 1973). "Social penetration refers to overt interpersonal behaviors which take place in social interaction and internal subjective processes which precede, accompany and follow overt exchange," (Altman \& Taylor, 1973, p. 5). There are four core hypotheses of the social penetration process including, (1) exchanges between persons will begin at a "superficial" level with deeper levels of exchange as interaction progresses, (2) perceived current and future benefits and costs of the interaction will determine how far the interaction advances, (3) if the benefits are perceived to be appropriately acceptable, the interactions will advance to a progressively deeper level where each participant will mutually share, and (4) provided the benefits continue, the interaction will, as well (Altman \& Taylor, 1973). One key element of social penetration theory is the concept of self-disclosure in the initial stages and how one determines what to self-disclose based on how they want the interaction to progress in terms of the social penetration process (Altman \& Taylor, 1973). Characteristics, specific to the individual person like a name, is one of three factors that impact how social penetration progresses; interpersonal rewards and costs, as well as situational and environmental factors are the others. In looking at individual characteristics, there are various groups to consider including personality, demographic-biographical and sociocultural (Altman \& Taylor, 1973). These have 
varying degrees of influence on social penetration, particularly relating to self-disclosure, but all factor to some extent (Altman \& Taylor, 1973).

\section{Connections}

These theories and the associated concepts combine to support the idea of ethnically identifying names. These ethnically identifying names allow for observers to put forth assumptions about another person's characteristics using their group membership as justification. The process of categorization continues along a path from the given name and assumed ties to race and ethnicity to assumptions fueled by negative and positive characteristics made popular through the process of perpetuated stereotypes. Stereotyping and microaggressions are tied to the aforementioned theories and the penchant for persons to present themselves, and closely held details about themselves (including their name), in a manner that allows others to classify them among those who fit inside their group membership. At the point when these individual factors converge there is an increased likelihood of difficulty based largely on the expectation of skill, temperament, and other attributes. When considered in the framework of professional and social interactions, an applicant with a nontraditional name that suggests an ethnicity or race that is associated with unfavorable characteristics may experience more difficulty progressing through the employment process and interacting with others (Pittinsky, Shih \& Ambady, 2000). To achieve a greater understanding of this multi-faceted issue, each of these theories and concepts combine to create a framework that seeks to frame the exploring of the perspectives and experiences of those with ethnically-identifying names 
and their efforts related to self-presentation and social penetration in social and professional settings.

\section{Effects of Names: Supporting Empirical Research}

While there is a gap in the research relating to the perspectives and experiences of those with ethnically-identifying names and their efforts related to self-presentation and social penetration in professional and social settings, there have been studies conducted which empirically examine the relationship between names and employment.

\section{Overview of Bertrand and Mullainathan Study (2004)}

A study, undertaken by Marianne Bertrand and Sendhil Mullainathan (2004), seeking to learn more about the effect of names on the hiring process, tested the notion that an applicant's name influences hiring decisions, specifically the ability for the applicant to receive a call-back and request for interview. In this study undertaken between July 2001 and May 2002, the researchers responded to over 1300 help-wanted advertisements posted in Boston and Chicago newspapers looking to fill positions in sales, administrative support, clerical services and customer services (Bertrand \& Mullainathan, 2004). The positions ranged from retail cashier to positions in management of sales. The researchers sent out four resumes to each of the 1300 posted advertisements, sending out almost 5000 resumes (Bertrand \& Mullainathan, 2004). The responses utilized several variables including varying degrees of qualifications and other markers of employability, creating two "higher-quality" resumes and two "lower-quality" resumes (Bertrand \& Mullainathan, 2004, p. 992). The higher quality resumes were those with more experience in the field and a resume with consistent employment history. 
Experimental methodology also included the random assigning of either "very White sounding names (such as Emily Walsh or Greg Baker) to half the resumes and very Black sounding names (such as Lakisha Washington or Jamal Jones) to the other half" (Bertrand \& Mullainathan, 2004, p. 992). For each of the four resumes created, one highquality and one low-quality were assigned names that indicated that the applicant was Black. Response rate to the submitted resumes were tracked.

\section{Method}

\section{Selection of Names}

The researchers used birth certificates from babies born between 1974 and 1979 in Massachusetts to create a list of names, sorted by race and derived from the names most frequently used to name children during those years (Bertrand \& Mullainathan, 2004). There was an emphasis on determining and selecting names that showed high usage in one race and low usage in another which indicated greater distinction. Once the list of names was gathered, the researchers performed field surveys in public places in Chicago asking participants to attribute specific characteristics, like race, to each of the queried names. Participants were largely able to correctly attribute the race to the name and those with ambiguity in race as determined by the survey participants were discarded. Names such as Aisha, Keisha and Tamika, Jamal, Jermaine and Tyrone were the most frequently used names of Black male and female children, while Allison, Anne, Carrie, Brad, Brendan and Geoffrey accounted for some of the names used for White children (Bertrand \& Mullainathan, 2004). In total, 18 names that are distinctively considered to be White and 18 names distinctively considered to be Black were used in the study 


\section{Creation of Resumes}

To create the resumes, the researchers pulled posted resumes from two online job search websites to create templates for their resumes. Resumes were used from applicants with addresses in Boston and Chicago that were posted within six months of the start of the experiment and were seeking positions within the four established categories of occupations in sales, administrative support, clerical services and customer services (Bertrand \& Mullainathan, 2004). Identifying information such as names, addresses, etc., were removed from the resumes. The resumes were matched to the each of the types of occupation and determined as either high or low quality based on measures such as experience in the field, skills, and continuous employment. To create a greater distinction between the levels of resume quality, additional markers were added such as experience as a volunteer, facility in foreign languages, military service, academic honors, etc., (Bertrand \& Mullainathan, 2004). So as to not closely mimic the qualifications of current job searchers, resume templates from Boston were used to apply for positions advertised in Chicago and vice versa, allowing for changes in educational institutions, civic organizations and other identifiers specific to the region.

\section{Selection of Advertisement/Positions to Submit Applications}

Job advertisements from the Boston Globe and Chicago Tribune Sunday editions were used to find employment opportunities. The researches faxed or mailed resumes as instructed and any advertisement that required the applicant to come in-person or call were disqualified. For each advertisement, the resume bank was used with four resumes submitted with adjustments made to ensure that the applicant is not overqualified or to 
ensure that the applicant meets the basic qualifications. Resumes were randomly assigned an address and telephone numbers were assigned to correspond with age, gender, race, region/city, and quality of resume (Bertrand \& Mullainathan, 2004). Email addresses were given to most high-quality resumes, but not to the resumes configured to be lowquality. Other features of the resume including formatting, font, layout and cover letter were also randomly assigned. Resumes of females were largely used for positions in administrative support and clerical positions, whereas both male and female names were submitted for sales positions.

\section{Results}

The study determined that resumes with White names could expect to receive $50 \%$ more requests to interview than those with Black sounding names; White-sounding applicants had a $9.65 \%$ chance of being called for an interview and Black-sounding applicants $6.45 \%$ chance of callback (Bertrand \& Mullainathan, 2004). White applicants in Chicago were $49 \%$ more likely to receive a callback and 50\% more likely in Boston. Applicant race was not shown to be significant only in the instance where none of the resumes submitted elicited a callback ( $83 \%$ of the ads). When adjusting for quality of the resume, Black applicants with higher-quality resumes received a callback $6.7 \%$ of the time in contrast to a $6.2 \%$ callback of Black applicants with lower quality resumes (Bertrand \& Mullainathan, 2004). The rate for Whites was more substantive, with an $11 \%$ callback rate for higher-quality resumes and $8.5 \%$ for lower-quality resumes. While the study also assesses the impact of addresses, job requirements and characteristics of the employer, they found these variables to have a lesser relationship to the rates of callback 
then the name of the applicant and the assumed/associated race. An additional variable posited is that hiring managers are not only associating responding to the name of the applicant and assuming the race, but associating a specific socioeconomic background to the applicant as well (Bertrand \& Mullainathan, 2004). These results provide an empirical foundation for the notion that applicants with ethnically-identifying names may experience increased difficulty in the personnel selection process. Additionally, with this knowledge, there may be an increase in knowledge of the effects of names which may influence naming decisions.

\section{Overview of Kang, DeCelles, Tilcsik \& Jun Study (2016)}

Drawing upon self-presentation theory put forth by Erving Goffman in 1959, researchers Sonia K. Kang, Katherine A. DeCelles, Andras Tilcsik and Sora Jun sought to understand behaviors undertaken by racial minorities to avoid discrimination when seeking employment (Kang, DeCelles, Tilcsik, \& Jun, 2016). The study was conducted in three parts including qualitative interviews, laboratory experiment and resume audit. The qualitative interviews sought to explore the way in which and the reasoning behind efforts taken by university students to engage in "resume whitening" (Kang et al.). The laboratory experiment was undertaken to explore the manner in which resumes were actually altered to whiten depending on the job posting to which they applied (Kang et al.). The third part of the study worked with results from a resume audit study that looked at how employers responded to resumes both with and without whitening (Kang et al.). 
Study \#1

This study included the conducting 59 total interviews consisting of 29 black and 30 Asian university students from two private universities located in a large "metropolitan" area in North America that were actively engaged in seeking career and internship opportunities whitening (Kang et al., 2016). The researchers conducting the interviews were of the same ethnicity as the participants and were paired accordingly. Participants were recruited from residence hall email listings. Participants who has recently applied for positions within finance, science and medicine, law and government, consulting, education, and information technology (Kang et al.). Of these, $55.9 \%$ were female, and $95 \%$ were in their senior year, with the additional 5\% enrolled in postgraduate programs (Kang et al.). Questions asked over the span of 30-50 minute semi-structured interviews were largely opened-ended.

The data elicited from the interviews indicated that $36 \%$ of those interviewed had engaged in whitening their resume. Of the $36 \%, 31 \%$ of black students and $40 \%$ of Asian students reported whitening their resume. Over $60 \%$ of the 59 students interviewed indicated that awareness of the practice and knowledge of engaging in the practice by friends or family. The participants that personally engaged in resume whitening, identified name changes and the modification of listed information pertaining to employment and experiential activities on the resume as the methods utilized (Kang et al., 2016). Participants, particularly those of Asian ethnicity, reported presenting a different first name on their resume and noticing an uptick in calls related to their employment applications. Black participants who utilized name changes, described using 
a middle name instead of the first name, "if the middle name sounded more white or neutral than the latter" (Kang et al., p. 476). More than $60 \%$ of participants who whitened their resume reported that they changed their resume to reflect activities that were more race neutral and emphasized activities that indicates a higher level of assimilation into the mainstream. These changes were primarily identified by black participants, although the Asian students also mentioned this behavior. The participants that did not whiten their resume reported five main reasons for abstaining from the practice, " (1) the view that the human capital value of experience was too great to omit from the resume; (2) the belief that the presence of minority racial cues on the resume could screen out discriminatory employers; (3) identity-based moral objections to whitening; (4) a belief in the general meritocratic nature of labor markets; and (5) the assumption that a particular targeted employer values racial diversity," (Kang et al., p. 481).

Study \#2

The laboratory experiment utilized resumes submitted by 119 undergraduate business students including 41 men and 78 women of which 87 were East Asian, 18 South Asian and 14 Black to, "experimentally manipulate cues to employers' approach to racial diversity in job postings an measured the resulting effect on job seekers' whitening behaviors," (Kang et al., 2016, p. 483). The participants were not informed that the study was looking at resume whitening. All resume data was analyzed except for any data from white participants as the study's interest was in racial minorities. These participants were from a different university than those who were interviewed in Study \#1. The study participants were provided with a copy of their resume and a job posting that either 
indicated valuing diversity (treatment condition, $N=62$ ) or had no statement indicating diversity at all (control condition, $N=57$ ) and were asked to tailor their resume to the position (Kang et al.). The primary aim of the experiment was to see if participants would respond to the cues of diversity or lack thereof when tailoring their resume to the position. The results indicated that almost $39 \%$ of the overall participants engaged in resume whitening, but only $21 \%$ of those in the treatment group did (Kang et al.).

\section{Study \#3}

This study audit looked at by randomly submitting resumes in response to job postings. Resumes were sent in response to vacancies in large U.S. cities with one resume sent per employer. This experiment, a "correspondence study" aims to, "examine how randomly assigned resume condense such as the name or an experience, affects the probability that an applicant is contacted for a job interview," (Kang et al., 2016, p. 486). The resumes submitted utilized the different levels of whitening indicated in the interviews including, "no whitening, whitened first name, whitened experience or whitened first name and experience," with the degree of resume whitening increasing depending on the race of the participant ( 2 X 4 degree of race to whitening) (Kang et al., p. 487). All of the resumes prepared were of males, who recently graduated with local telephone numbers that indicated residence in the region of the position. The Black male was named Lamar J. Smith and the unwhitened resume indicated participation in a number of university student organizations supporting black students and causes. The whitening of Lamar's resume included using a first initial and middle name and removal of the word black or African American from the names of the student organizations. 
The resumes were sent out from July-September 2015 through large online job websites in response to entry-level position advertisements posted within one month throughout 16 locations in the United States. The advertisements responded to were equally distributed in terms of diversity language inclusion or lack thereof. In total, 1600 postings were responded to with 800 including language indicating diversity language and $267(16.7 \%)$ of these applications resulted in a request for interview (Kang et al., 2016). Overall, patterns from the results indicated that whitened resumes led to more interview requests than unwhitened resumes. For the Black applicants who adjusted their experiences but kept their name, were called back at a higher rate than completely unwhitened resumes (Kang et al.). Whitening only the name for Black applicants did not make a statistically significant difference, although it was statistically significant for Asian applicants (Kang et al.). When applicants whitened only their name, they received call backs 1.8 times more often and 2.5 times more often when both the name and the experiences were whitened. Overall, there was no evidence that employers with diversity language engaged in less discrimination against unwhitened resumes (Kang et al., 2016).

\section{Problem Statement}

The name itself, provides a connection, and grants each child the ability to be recognized, acknowledged, and given a particular identity in its world (Edwards, 2008). The power of the name then is two-fold, as it allows (a) the person to identify themselves and (b) others to identify the person. How these identities are formed, manifested and viewed are largely dependent upon the person. Examples such as the feeling a person experiences when their name is forgotten, mispronounced or incorrect further elucidate 
the deep connection that the name creates to the person and their sense of themselves (Edwards, 2008). For those with ethnically identifying names the process of identification, self-presentation and social penetration can be daunting. In the context of professional and social settings, the process can be seen as being even more daunting.

\section{The Job Seeking Experience}

\section{Self-Identifying and the Applicant}

Applicants are assured of one of two possible outcomes: to be hired or not be hired (Campbell \& Knapp, 2001). While maintaining a format and structure, selection of personnel can be conducted arbitrarily due to enhanced screenings by categories such as skill, work ethic, overall temperament and general fit into the existing organization and its cadre (Pittinsky, Shih \& Ambady, 2000). These screening can develop the potential for stereotyping when race, gender and/or ethnicity are used to better understand an applicant's social frame of reference (Pittinsky et al., 2000). Due to both empirical studies and anecdotal stories, job seekers have increased awareness of the lens through which application reviewers may view and assess their qualifications. The inclination to categorize can include stereotyping and associated discrimination if applicants are assumed to be in categories that are not based on reality (Onwuachi-Willig \& Barnes, 2005).

"Category cues" can be environmental or behavioral attributes of a job applicant that can provide clear clues as to various categories and group memberships (Pittinsky, Shih \& Ambady, 2000). Cues like the name of the applicant can lead to pre-determined 
impressions of the applicant and can positively or negatively shade opinions. Applicant names can be viewed as indicators of education, race, ethnicity or gender, among other categories. While each category can be seen as important, the reviewer's personal experiences and frame of reference can assist in determining which social category is most important to the review.

\section{Whitening or "Whitewashing" the Resume}

Usage of different names on job applications that do not as clearly indicate ethnicity are a sign of job seekers' increased awareness of potential biases (OnwuachiWillig \& Barnes, 2005). Applicants have engaged in "whitening" or "whitewashing" their resume or job application utilizing abbreviated names, middle names, and removal of organizations, higher education institutions and previous work history that can assist in the identification of an applicant's ethnicity, race or gender (Luo, 2009). Applicants with names such as Tahani Thompkins, Ramon Estevez and Kalpen Modi, have begun to go by T. S. Thompkins, Martin Sheen and Kal Penn, respectively, when seeking employment to increase their likelihood of selection (Cotton, O'Neill, \& Griffin, 2008, Luo, 2009; Onwuachi-Willig \& Barnes, 2005).

Researchers at the University of Toronto conducted research related to the practice of whitening resumes to, in part, gain the perspectives of Asian and black students applying for internships and job opportunities; wherein, they discovered that the students were aware of the practice, some had undertaken it and knew of others who changed their resumes (Kang et al., 2016; Lam, 2016). The researchers found that there is more awareness of the need to appear less ethnic and that applicants go to some lengths 
to affect this. Additional studies conducted by various researchers (Bertrand \&

Mullainathan, 2004; Busse \& Seraydarian, 1978; Mehrabian, 1990, 1992) determined that names considered unique like those with unusual spellings create a connotation that suggests characteristics that are less attractive than more common names such as Mary, Patricia, John and James (Cotton et al., 2008; United States Social Security Administration, 2017). This connotation can form an unconscious mental model causing those in charge of personnel selection to attribute certain characteristics to particular individuals which influences their perception of the applicant (King et al., 2006). Unique sounding names can stimulate "discomfort and dislike" from a hiring manager which can result in less opportunities for employment and "early dismissal from the recruitment process" (Cotton et al., 2008, p. 16).

\section{The Social Experience: Self-Presentation in Social and Professional Settings}

According to Goffman (1959):

When an individual enters the presence of others, they commonly seek to acquire information about him or to bring into play information about him already possessed. They will be interested in his general socio-economic status, his conception of self, his attitude toward them, his competence, his trustworthiness, etc...Information about the individual helps to define the situation, enabling others to know in advance what he will expect of them and what they may expect of him...If unacquainted with the individual, observers can glean clues from his conduct and appearance which allow them to apply their previous experiences with individuals roughly similar to the one before them, or more important, to apply untested stereotypes to him (p. 1).

Goffman (1963) theorized that racial minorities may be labeled due to their

membership in a specific "tribe" and therefore become both "stigmatized" and prone to discrimination due to this membership. "Passing" with the intent to appear as much like 
the dominant group, while heavily downplaying characteristics that may indicate outgroup status (Goffman, 1963) is one form of mitigating stigma. A lesser form of concealing stigmatizing characteristics is referred to as "covering," wherein a person does not conceal or pass, but seeks to downplay any characteristics to make them less prominent, possibly to signify conformity to the larger group (Goffman, 1963). For those with ethnically identifying names, then, there can be both an impetus and inclination to both be different as well as need to change to make oneself less obviously different.

\section{The Problem}

Professional and social interactions are among the most important aspects of a person's life. The name that one has is how they relate to the world and how the world relates to them. Although a precise definition of Human Resource Development (HRD) is hard to come by, in general, HRD is concerned with the development of the individual and the organization through learning experiences to effect change or growth (Lee, 2015; Nadler \& Nadler, 1990). As such, HRD practices and the performance of employees can be directly impacted by the professional and social interactions of employees within an organization. There are empirical studies that examine the effect of names and highlight the importance of names on employment and social interaction/inclusion. However, there is a gap in the research related to the experiences of those with ethnically identifying names. Building on the work of Bertrand and Mullainathan (2004), and Kang et al. (2016), this work explored the experiences of those with ethnically identifying names as they navigate professional and personal situations that can impact the organization. 


\section{Purpose of the Collected Papers}

The purpose of the collected papers was to explore the perspectives and experiences related to identity, self-presentation, and social penetration in social and professional setting for persons with ethnically identifying names. Specifically, the research sought to understand the perspectives held and any actions taken by the nameholder related to self-presentation and social penetration strategies including, but not limited to: whitening the resume, use of nicknames and name changes, as well as their perceptions of the quality of their employment opportunities and their initial social interactions when meeting new people, professionally and personally.

\section{Description of Collected Papers}

The fulfillment of this collected papers dissertation took place across two studies related to names and their implications for employment and social-presentation in professional and personal settings. Table 1 presents the running title, method and intended publication outlet for the two studies in this proposed collected papers dissertation. These studies are further described in the sections that follow.

\section{Table 1}

Collected Papers: Studies 1 and 2

\begin{tabular}{lll}
\hline Running Title & Method & Intended Publication Outlet \\
\hline $\begin{array}{l}\text { STUDY \#1. Names, and Self- } \\
\text { Presentation in the Workplace: An } \\
\text { Integrative Literature Review }\end{array}$ & $\begin{array}{l}\text { Integrative } \\
\text { Literature } \\
\text { Review }\end{array}$ & $\begin{array}{l}\text { Human Resource Development } \\
\text { Review } \\
\text { Submitted October 3, 2018 }\end{array}$ \\
$\begin{array}{l}\text { STUDY \#2. Names and } \\
\text { Expectations: What Organizations } \\
\text { Need to Know About People with } \\
\text { Ethnically Identifying Names }\end{array}$ & Phenomenology & Administrative Science Quarterly \\
& & Submitted November 14, 2018 \\
\hline
\end{tabular}


Study \#1: Names, and Self-Presentation: An Integrated Literature Review for Human Resource Development Professionals

Research has been conducted on names, particularly in relation to employment but lesser in relation to self-presentation (Bernard \& Mullainathan, 2004; Kang et al, 2016). However, there was a need to review the existing research to evaluate how it details and informs the convention of naming and the larger implications of names and naming in the context of professional self-presentation. This was accomplished through an integrative literature review, "a distinctive form of research that generates knowledge about a topic by reviewing, critiquing, and synthesizing representative literature on a topic in an integrated way such that new frameworks and perspectives are generated," (Torraco, 2016, p. 62).

Purpose and research question. The purpose of the integrative literature review was to examine the literature on names, and self-presentation in Human Resource Development (HRD) and determine if there are gaps in the research. The study was guided by the research question: How are names and self-presentation in the context of the workplace discussed in the HRD literature?

Method. This utilized an integrative literature review method (Torraco, 2016). Within an integrated literature review, the need, purpose, definition of topic, discussion of research methods, critical analysis, synthesis, logic and conceptual reasoning and implications for further research must be included (Torraco, 2016). To answer the research question, a research librarian was consulted to determine the appropriate number of databases to access searching for key terms related to names, naming, and selfpresentation. As outlined by Fink (2013), articles were selected for inclusion and 
exclusion using a two-step screening process. Articles were first sought using a wide range of pre-established criteria then narrowed based on the strength of the study determined by the design and implementation (Fink, 2013). Two databases were searched, specifically: PsycINFO and Business Source Complete. The search parameters included combining "names" with the following individual terms: "self-presentation," "human resources," "workplace," "employment", and "employee." All publications must be peer-reviewed and published within the United States and Canada.

Publication submission and formatting. The first study of the collected papers will be submitted to Human Resource Development Review (HRDR). HRDR submissions must be prepared according to the American Psychological Association Style Guide $\left(6^{\text {th }}\right.$ ed.) and be no more than 30 double-spaced pages with the exclusion of figures and references.

Study \#2: Behind the name: An Exploration of the Perspectives, Experiences and Behaviors Related to Social Identity, Self-Presentation and Social Penetration in Social and Professional Settings for Persons with Ethnically Identifying Names

Qualitative research is undertaken as a means to bring understanding to a phenomenon in light of the meaning attributed by those involved (Denzin \& Lincoln, 2011). While there have been multiple studies undertaken (largely quantitative) that look at names, naming, employment and self-presentation opportunities within the context of applicant names (Bertrand \& Mullainathan, 2004; Busse \& Seraydarian, 1978; Kang et al., 2016; Mehrabian, 1990, 1992), there is a gap in the research. Qualitative research, in that it, "follow[s] up quantitative research and help[s] explain the mechanisms or linkages in causal theories or models," will aid in bridging the research gap through "telling us 
about the processes that peoples experience, why they responded as they did, the context in which they responded and their deeper thoughts and behaviors that governed their responses," (Creswell, 2013, p. 48). Finally, ethnically identifying names are most often associated with minorities, particularly those of African descent (Fryer \& Levitt, 2004), and as such, qualitative research in its capacity and "sensitivity" to hone in on differences in gender, ethnicity, race socioeconomic background and individuality, is the appropriate research design to examine this phenomenon (Creswell, 2013, p. 48).

Purpose and research question. This phenomenological study was undertaken to explore the perspectives and experiences related to self-presentation and social penetration in social and professional settings for persons with ethnically identifying names. This study was guided by the primary research question: How do persons with ethnically identifying names manage self-presentation and self-disclosure in the context of job seeking and new interpersonal, social interactions? The secondary questions include: (a) What are the perspectives and experiences related to applying for employment and the management of self-presentation and self-disclosure for those with ethnically identifying names? (b) What are the perspectives and experiences related to initial social interactions and the management of self-presentation and self-disclosure for those with ethnically identifying names?

Method. This study used a phenomenological method wherein the goal was to gain greater understanding of the phenomenon both individually and universally while achieving a collective understanding through the participants' shared opinions and experiences (Moustakas, 1994). 


\section{Sampling}

To deeply study the phenomenon that is having an ethnically identifying name, a purposeful sample was needed to ensure that individuals were chosen that can speak to the phenomenon personally (Creswell, 2013). To participate, individuals had to meet the following criteria: 1) at least 18 years of age, 2) employed, 3) have an ethnically identifying first name and 4) be willing to participate in a confidential interview with the possibility of subsequent communication. Having already been approached by individuals who wanted to participate in the study when it took place, initially employed convenience sampling was used to identify these prospective participants (Onwuegbuzie \& Leech, 2007). Snowball sampling, where current participants were asked to recommend additional prospective participants, was used to gather additional participants (Onwuegbuzie \& Leech, 2007).

To ensure that as much knowledge about the experiences and the perspectives of the participants was gained as was possible, sample size was important. For phenomenological research, a smaller sample size was suggested with 6-10 participants (Morse, 2000) or 6-12 (Guest, Bunce, \& Johnson, 2006). While study participants will all have ethnically identifying names, the group was heterogeneous to study the phenomenon across different ethnicities. In total, 15 total participants of Caucasian, African, Asian and Latino/Hispanic ethnicities were interviewed. 


\section{Data Collection}

Data were collected through audio-recorded, semi-structured in-person as well as telephone responsive interviews (Rubin \& Rubin, 2007). Interviews were scheduled for 60-minute increments with approval from the interviewee to up to 120 minutes, if necessary. This allowed for a responsive interview that included carefully framed main questions and probing follow-up questions to discuss the issues involved in names, employment, self-presentation and self-disclosure. The recordings were downloaded and transcribed. Once transcribed, the recordings were listened to checking for accuracy and completeness and undertook any light editing, removing "um", "uh" and the like as well as any repetition in speech as might take place when formatting a thought.

\section{Data Analysis}

To analyze the data inductively, Creswell's (2013) adapted version of Moustakas' (1994) Modification of the Stevick-Colaizzi-Keen Method of Analysis of Phenomenological Data was utilized. Data were analyzed individually and in composite to discover statements that create individual themes that then build into overall themes to aid understanding (Creswell, 2013; Moustakas, 1994).

\section{Integrity Measures}

It is integral that researchers understand and remove their subjectivity to conduct research objectively. Bracketing allows for the acknowledgment and removal of assumptions and possible bias. This effort is an important process in conducting phenomenological research (Moustakas, 1994). Bracketing took place during this research through the inclusion of a brief background and core assumptions relating to the 
research topic as well as a researcher journal, and the use of field notes and rich, detailed descriptions (Creswell, 2013; Ortlipp, 2008).

\section{Researcher Journal}

I am aware that I hold strong opinions about this topic and I aim in some small way to bury my subjectivity, feeling that, "subjectivity is not a badge of honor... and paraded around on special occasion for all to see" (Peshkin, 1988, p. 17). I am conscious that, as researchers, we are expected to exert some level of control over our assumptions in the process of conducting research and approach the research with a fresh perspective (Moustakas, 1994). I came to this subject through my familial history and opinions about naming, specifically the rationale behind the names of myself and my siblings. In discussions of names and naming, I have always been fairly open about my family's approach to naming and the reasons expressed. The overarching rationale has always centered on the desire to avoid names that could provide clues as to ethnicity and, thus, to prevent possible predetermined prejudices to affect the ability to gain meaningful employment and other opportunities. This is an opinion I was presented with at a young age and have wholly subscribed to my entire life. It becomes clear, then, that I cannot be a "neutral participant in the research project ... [and] that I have issues, concerns and opinions..." (Ortlipp, 2008, p. 698). When I realize the length of time that I have held this opinion, I am led to the realization of the effect this has had on my view of myself and in how I choose to interact in various situations where names can be a factor. Through this fresh understanding of my own assumptions, I strive to adopt Rubin and Rubin's (2007) suggestion of, “be[ing] cautious about imposing your own understanding 
in ways that limit the interviewees' freedom to respond" (p. 133).

I believe that I have an understanding of my name and how it was conceived and that I have determined, or at the least, acknowledged my, "experiences, values and assumptions," regarding names (Ortlipp, 2008, p. 698). I recognize that I entered into the research with assumptions that the participants would (a) feel that names were important, (b) each have a story to tell about their experiences with their name, (c) be interested in the opportunity to express their opinion about their name, and (d) have questions about how I came to this research. Due to these assumptions, I chose to keep a researcher journal to document the actual process and my feelings about it. This journal assisted in noting observations, personal feelings, biases and other pieces of information useful in the data analysis stage.

Publication submission and formatting. The second study of the collected papers will be submitted to Administrative Science Quarterly (ASQ). ASQ submissions must be prepared according to the guidelines provided by ASQ in their submission guide. Manuscript page total should be limited to approximately 45 double-spaced pages not including abstract, text, notes, references, tables, figures and appendices.

\section{Structure of Collected Papers Dissertation}

This doctoral dissertation followed Florida International University College of Art, Sciences and Education's guidelines for the "Collected Papers" format. It consists of this introductory chapter and a closing chapter written solely for the dissertation, as well as two related studies outlined above submitted to peer-reviewed journals. Dissertation 
chapters will be as follows:

Chapter 1: Introduction, conceptual framework, empirical research review, problem, purpose, and description of collected papers

Chapter 2: Integrative literature review of names, naming and self-presentation

Chapter 3: Phenomenological study to explore the perspectives and experiences related to employment and self-presentation in social and professional settings for persons with ethnically identifying names.

Chapter 4: Conclusions, cross-cutting implications, directions for further research.

\section{References}

Altman, I. \& Taylor, D. (1973). Social penetration: The development of interpersonal relationships. New York: Holt, Rinehart and Winston, Inc.

Bertrand, M. \& Mullainathan, S. (2004). Are Emily and Greg more employable than Lakisha and Jamal? A field experiment on labor market discrimination. The American Economic Review. 94, 991-1013.

Booker, B. (2015, September 21). How equal is American Opportunity? Survey shows attitudes vary by race. National Public Radio. Retrieved from https://www.npr.org/sections/thetwo-way/2015/09/21/442068004/how-equal-isamerican-opportunity-survey-shows-attitudes-vary-by-race

Busse, T., \& Seraydarian, L. (1978). Frequency and desirability of first names. Journal of Social Psychology, 104, 143-144.

Campbell, J. P. \& Knapp, D. (2001). Exploring the limits in personnel selection and classification. Mahwah, New Jersey: Lawrence Erlbaum Associates, Inc.

Cotton, J., O'Neill, B., \& Griffin, A. (2008). The "name game": Affective and hiring reactions to first names. Journal of Managerial Psychology, 23, 18.39

Creswell, J. (2013). Qualitative inquiry and research Design: Choosing among five perspectives $\left(3^{\text {rd }}\right.$ ed.). Thousand Oaks, CA: Sage

Czopp, A. (2008). When is a compliment not a compliment? Evaluating expressions of positive stereotypes. Journal of Social Psychology, 44, 412-420.

Czopp, A., Kay, A., \& Cheryan, S. (2015). Positive stereotypes are pervasive and powerful. Perspectives on Psychological Science, 10, 451-463. 
Denzin, N. K. \& Lincoln, Y. S. (2011). The Sage handbook of qualitative research $\left(4^{\text {th }}\right.$ ed.). Thousand Oaks, CA: Sage.

Edwards, R. (2008). What's in a name? Chinese learners and the practice of adopting 'English' names. Language, Culture and Curriculum, 19, 90-103

Fink, A. (2013). Conducting research literature reviews: From the Internet to paper. Thousand Oaks, CA: Sage Publications.

Fiske, S. T., \& Taylor, S. E. (1991). Social cognition (2nd ed.). New York: McGraw-Hill.

Fryer, J. R., \& Levitt, S. D. (2004). The causes and consequences of distinctly black names. The Quarterly Journal of Economics, 119, 767-805.

Gaertner, S. \& McLaughlin, J. (1983). Racial stereotypes: Associations and ascriptions of positive and negative characteristics. Social Psychology Quarterly, 46, 23-30.

Goffman, E. (1959). Presentation of self in everyday life. Garden City, NY: Doubleday.

Goffman, E. (1963). Stigma: Notes on the management of spoiled identity. New York, NY: Simon and Schuster.

Guest, G., Bunce, A. \& Johnson, L. (2006). How many interviews is enough? An experiment with data saturation and variability. Field Methods, 18, 59-82,

Kang, S. K., DeCelles, K. A., Tilcsik, A., \& Jun, S. (2016). Whitened resumes: Race and self-presentation in the labor market. Administrative Science Quarterly, 61, 469502.

King, E., Madera, J., Hebl, M., Knight, J., \& Mendoza, S. (2006). What's in a name? A Multiracial investigation of the role of occupational stereotypes in selection decisions. Journal of Applied Social Psychology, 36, 1145-1159.

Lam, B. (2016). When resumes are made 'whiter' to please potential employers. The Atlantic. Retrieved from http://www.theatlantic.com/business/archive/2016/03/white-resumediversity/475032/

Lee, M. (2015). The history, status, and future of HRD. In R. F. Poell, T. S. Rocco, \& G. L. Roth (Eds.), The Routledge companion to human resource development (pp. 312). New York, NY: Routledge.

Lippman, W. (1922). Public opinion. Long Island, NY: Harcourt, Brace and Company. 
Lipton, J.P., O'Connor, M., Terry, C., \& Bellamy, E. (1991). Neutral job titles and occupational stereotypes: When legal and psychological realities conflict. Journal of Psychology, 125, 129-151.

Luo, M. (2009, December 5). 'Whitening' the résumé. New York Times. Retrieved from http://www.cfs.purdue.edu/richardfeinberg/csr\%20309\%20spring\%202011/corner \%20office/Whitening\%20the\%20resume.docx.

Maddux, W. W., Galinsky, A. D., Cuddy, A. J., \& Polifroni, M. (2008). When being a model minority is good... and bad: Realistic threat explains negativity toward Asian Americans. Personality and Social Psychology Bulletin, 34, 74-89.

McGarty, C. Yzerbyt, V., \& Spears, R. (2002). Stereotypes as explanations: The formation of meaningful beliefs about social groups. Cambridge, United Kingdom: Cambridge University Press.

Mehrabian, A. (1990). The name game: The decision that lasts a lifetime. New York, New York: Signet Books.

Mehrabian, A. (1992). Interrelationships among name desirability, name uniqueness, emotion characteristics connoted by names, and temperament. Journal of Applied Social Psychology, 22, 1797-1808.

Morse, J.M. (2000). Determining sample size. Qualitative Health Research, 10(1), 3-5.

Moustakas, C. (1994). Phenomenological research methods. Thousand Oaks, CA: Sage.

Moya, P. M. L., and H. R. Markus. 2010. "Doing Race: An introduction.” In Doing Race: 21 Essays for the 21st Century, edited by H. R. Markus and P. M. L. Moya, 1102. New York: W. W. Norton and Company.

Nadal, K., Sriken, J. Davido, K., Wong, Y., \& McLean, K. (2013). Microaggressions within families: Experiences of multiracial people. Family Relations, 62, 190-201.

Nadler, L., \& Nadler, Z. (1990). Developing human resources: Concepts and a model (3 ${ }^{\text {rd }}$ Ed.) San Francisco: Jossey-Bass.

Onwuachi-Willig, A., \& Barnes, M. L. (2005). By any other name?: On being "regarded as" Black, and why Title VII should apply even if Lakisha and Jamal Are White. UC Davis Legal Studies Research Paper Series: No. 67, 1-53.

Onwuegbuzie, A. J., \& Leech, N. L. (2007). Sampling designs in qualitative research: Making the sampling process more public. The qualitative report, 12, 238-254. 
Ortlipp, M. (2008). Keeping and using reflective journals in the qualitative research process. The Qualitative Report, 13, 695-705.

Peshkin, A. (1988) In search of subjectivity: One's own. Educational Researcher. 19(7), $17-21$

Phelan, J. C., Link, B. G., \& Dovidio, J. F. (2008). Stigma and prejudice: one animal or two? Social Science \& Medicine, 67, 358-367.

Pierce, C. (1970). Offensive mechanisms. In F. Barbour (Ed.), The Black seventies (pp. 265-282). Boston, MA: Porter Sargent.

Pierce, C., Carew, J., Pierce-Gonzalez, D., \& Willis, D. (1978). An experiment in racism:

TV commercials. In C. Pierce (Ed.), Television and education (pp. 62-88). Beverly Hills, CA: Sage.

Pittinsky, T. Shih, M. \& Ambady, N. (2000). Will a category cue affect you? Category cues, positive stereotyped and reviewer recall for applicants. Social Psychology of Education, 4, 53-65.

Powell, G. N., \& Butterfield, D. A. (2002). Exploring the influence of decision makers' race and gender on actual promotions to top management. Personnel Psychology, $55,397-428$.

Rubin, H.J., \& Rubin. I.S. (2012). Qualitative interviewing: The art of hearing data (3rd ed.). Thousand Oaks, CA: Sage.

Sigelman, L. \& Tuch, S. (1997). Metastereotypes: Blacks' perceptions of Whites' stereotypes of Blacks. The Public Opinion Quarterly, 61, 87-101.

Siy, J. \& Cheryan, S. (2013). When compliments fail to flatter: American individualism and responses to positive stereotypes. Journal of Personality and Social Psychology, 104, 87-102.

Sue, D.W., Capodilupo, C., Torino, G., Bucceri, J., Holder, A., Nadal, K. \& Esquilin, M. (2007). Racial microaggressions in everyday life: Implications for clinical practice. American Psychologist, 62, 271-286.

Sue, D.W., Capodilupo, C., \& Holder, A., (2008). Racial microaggressions in the life experience of Black Americans. Professional Psychology: Research and Practice, 39, 329-336.

Tajfel, H., \& Turner, J. (1979). An integrative theory of intergroup conflict. In W. G. Austin \& S. Worchel (Eds.), The social psychology of intergroup relations (pp. 
33-48). Monterey, CA: Brooks/Cole.

Tajfel, H., \& Turner, J. C. (1986). The social identity theory of intergroup behavior. In S. Worchel \& W. G. Austin (Eds.), The psychology of intergroup relations (pp. 724). Chicago: Nelson Hall.

Torraco, R. (2016). Writing integrative reviews of the literature: Methods and Purposes. International Journal of Adult Vocational Education and Technology, 7, 62-70.

Tschaepe. M.D. (2003). Halo of identity: The significance of first names and naming. Janus Head: Journal of Interdisciplinary Studies in Literature, Continental Philosophy, Phenomenological Psychology, and the Arts, 6, 67-78.

Twenge, J., Abebe, E. \& Campbell, W. (2010). Fitting in or standing out: Trends in

American parents' choice for children's names: 1880-2007. Social Psychological and Personality Science, 1, 19-25.

Uhlig, M.A. (1988, January 16). Racial remarks cause furor. The New York Times. Retrieved from http://www.nytimes.com/1988/01/16/sports/racial-remarks-causefuror.html

United States Social Security Administration. (2017). Top names over the last 100 years. Retrieved from https://www.ssa.gov/oact/babynames/decades/century.html.

Van Manen, M. (1990). Researching lived experience: Human science for an action sensitive pedagogy. New York: State University of New York Press.

Vohs, K., Baumeister, R. \& Ciarocco, N. (2005). Self-regulation and self-presentation: Regulatory resource depletion impairs impression management and effortful selfpresentation depletes regulatory resources. Journal of Personality and Social Psychology, 88, 632-657

Wong, F. \& Halgin, R. (2006). The "Model Minority": Bane or Blessing for Asian Americans? Journal of Multicultural Counseling and Development, 34, 38-49.

Young, R. K., Kennedy, A., Newhouse, A., Browne, P \& Thiessen, D. (1993). The effects of names on perception of intelligence, popularity and competence. Journal of Applied Social Psychology, 23, 1770-1788. 


\section{CHAPTER II}

\section{STUDY \#1: NAMES, AND SELF-PRESENTATION IN THE WORKPLACE: AN INTEGRATIVE LITERATURE REVIEW}

When an applicant applies for a position, they are assured one of two outcomes; hired or not hired (Campbell \& Knapp, 2001). While a structured process, personnel selection is also an arbitrary process as applicants are screened not only in terms of skill, work ethic and temperament, but also their ability to fit into the organization (Pittinsky, Shih \& Ambady, 2000).

While looking at the employment process through the lens of possible stereotyping, categorization becomes a factor as people utilize categories such as race, ethnicity and gender to achieve a better understanding of their social experiences (Pittinsky et al., 2000). Applicants are aware that reviewers bring this derived understanding into the review process. It is this impetus to categorize that can lead to stereotyping particularly when persons are placed into categories that are not based on actual knowledge of the person, but through assumptions made about them (OnwuachiWillig \& Barnes, 2005).

\section{Category Cues}

"Category cues" (i.e., "features of the environment or behavior of the applicant that may explicitly or implicitly draw a perceiver to one of a target's many social categories"), like the applicant's name, can shade the impression of the applicant (Pittinsky et al., 2000, p. 55). The applicant's name can be seen as an indication of gender, race, ethnicity, education level, etc. It is, however, a reflection of the experiences 
and understanding of the reviewer as to which category the applicant is ascribed and which captures the reviewer's attention.

\section{Whitening or "Whitewashing” the Resume}

Job applicants who have become aware of employment bias based on names that connote ethnicity have utilized names on their resumes different from their own while applying for jobs (Onwuachi-Willig \& Barnes, 2005). This awareness has led applicants to undertake a process called "whitening" or "whitewashing" their resume using methods like name abbreviations, usage of middle names, and deletions of civic and social organizations listed on resumes that can indicate race, ethnicity, gender, etc. (Luo, 2009). The idea is that an applicant must make themselves appear less ethnic and more racially/ethnically acceptable to proceed past the initial stages of personnel selection.

Goffman (1963) posited racial minorities may seek to "conceal their stigma" by changing the parts of themselves that may make them subject to discrimination due to the ability to easily become identifiable as being outside of the dominant group membership. This is known as "passing" with the intent to appear as much like the dominant group, while heavily downplaying characteristics that may indicate outgroup status (Goffman, 1963). In considering names and self-presentation, a job applicant or an employee may seek to utilize a different name both to fit in and make it more difficult for internal and external partners to pre-form an impression, if hired.

When considering these concepts and the associated behaviors in the context of the workplace, HRD researchers and practitioners need to be aware that naming and selfpresentation may be important considerations as both applicants and employees will 
determine their place within the organization based on what they felt they need(ed) to do to fit in. Altered self-presentation like whitening the resume, has the potential to make the applicant or employee feel that their real self is not valued which can create a situation that stymies interpersonal relationships within the organization. As interpersonal relationships are an integral part of workplace efficacy, organizational goals and performance can be negatively influenced.

\section{Purpose and Research Question}

The purpose of the integrative literature review (Toracco, 2005, 2016) was to examine the literature on names and self-presentation in Human Resource Development (HRD) and determine if there are gaps in the research. An integrative review of the literature was chosen as this type of literature review is "a distinctive form of research that generates knowledge about a topic by reviewing, critiquing, and synthesizing representative literature on a topic in an integrated way such that new frameworks and perspectives are generated," (Torraco, 2016, p. 62).

The study was guided by the research question: How are names and selfpresentation in the context of the workplace discussed in the HRD literature?

\section{Theoretical Framework}

\section{Self-Presentation Theory}

Self-presentation theory guides this study. Self-presentation theory is the concept that people present an official, public face and engage in a performance to exert influence over another's opinions and perceptions of them (Goffman, 1959). At the most basic level, these performances are undertaken with the purpose of achieving professional 
and/or social goals of acceptance. Performers work to ensure that at each stage of their performance they exhibit the acceptable behaviors, mores and values that indicate assimilation within and affinity to the larger society. Both words and actions should be appropriately demonstrative as to make it obvious that the performance is true and accurate to enhance and maintain credibility as well as adherence to the expectations related to the desired category, group membership, etc. In the context of ethnicallyidentifying names, a name which can be considered outside of the mainstream can stymie the performance, particularly if the name can lead to assumptions about the performer that suggest characteristics that the performer and performance desire to restrain. An integral part of the performance is the ability to maintain the performance, known as impression management (Goffman, 1959). Impression management, then, revolves around maintaining the performance for continuous influence over the observers' opinions and expectations (Goffman, 1959). It is an integral piece in friendship formation, group membership, career success, formation of identity and overall efficacy professionally and personally (Vohs, Baumeister, \& Ciarocco, 2005).

\section{Research Design}

The integrative literature review method (Torraco, 2005, 2016) was selected for its ability to both synthesize existing research and develop new approaches and levels of understanding. The topics involved, specifically names, self-presentation and human resource development are studied across a number of disciplines, (e.g., psychology, social psychology, education, and business. PsycINFO and Business Source Complete databases were searched using the key word "names" combined individually with each of the following terms: "self-presentation," "human resources," "workplace," 
"employment", and "employee." There were no delimitations on the length of time since publication, however, this literature review only includes empirical studies up through July 31, 2018. All publications had to be peer-reviewed and published within the United States and Canada. After the removal of 864 duplicates, 1,572 articles remained for selection. Table 2 illustrates the number of articles available from the two databases.

\section{Table 2}

Findings of Research Databases

\begin{tabular}{|l|r|}
\hline Database & Results \\
\hline Business Source Complete & 1338 \\
\hline PsycINFO & 1098 \\
\hline SUBTOTAL & 2436 \\
\hline DUPLICATES REMOVED & 864 \\
\hline TOTAL & 1572 \\
\hline
\end{tabular}

After the initial review using the aforementioned criteria (Fink, 2013), search terms, and the removal of duplications, a staged review was conducted including a review of each of the abstracts for the 1,572 articles (Toracco, 2005). The number was reduced to 141 based on the criteria that each article needed to be directly related to names, selfpresentation, or HRD in the context of the workplace.

Articles removed included those regarding company brand names, rebranding through renaming, employee adherence and management of company branding (Hanin, Stinglhamber \& Delobbe, 2013; Thomson, de Chernatony, Arganbright \& Khan, 1999) as well as a number of empirical articles published outside the United States or conducted within/on international populations (Blommaert, Coenders \& van Tubergen, 2014; Carlsson \& Rooth, 2007; Weichselbaumer, 2017; Wilson, Gahlout, Liu \& Mouly, 2009). 
As the seminal study on names and employment was conducted within the United States and based upon U.S. factors and populations (Bertrand \& Mullainathan, 2004), it was important to limit the research selected to the United States to determine the evolution of research on naming, names, self-presentation and be able to synthesize the research and what it means for the United States. However, to ensure that the sample was not too narrow in scope, as well as for its proximity to the United States and its elated concerns of ethnicity, race, naming and their influences on the employment process, research conducted in Canada was also included. This narrowed the number to 25 .

After an extended review of the remaining articles using the aforementioned criteria, the sample was reduced to 10 articles. Within the United States and Canada, names and self-presentation in the workplace were only specifically researched in three studies (one article). While this literature review was solely interested in empirical studies where names and self-presentation were the main effects/factors, additional articles were included that could also inform the discussion of the literature surrounding names and self-presentation in HRD. Within the final sample, there was only one article that referenced HRD. This article was also from within the HRD discipline. Table 3 outlines the academic disciplines from which the sample of articles was found. 
Table 3

Findings by Discipline of Publication Outlet

\begin{tabular}{|l|r|l|}
\hline \multicolumn{1}{|c|}{ Discipline } & Results & \multicolumn{1}{c|}{ Authors } \\
\hline Business (HR) & 1 & Bendick, Jackson, Reinoso \& Hodges \\
\hline Economics & 4 & $\begin{array}{l}\text { Bertrand \& Mullianathan; Darolia, Koedel, } \\
\text { Martorell, Wilson \& Perez-Arce; Jacquemet \& } \\
\text { Yannelis; Oreopoulos }\end{array}$ \\
\hline Interdisciplinary & 2 & $\begin{array}{l}\text { Kang, DeCelles, Tilcsik \& Jun; Smith, Tabak, } \\
\text { Showail, Parks \& Kleist }\end{array}$ \\
\hline Psychology & 3 & $\begin{array}{l}\text { Cotton \& O’Neill; Segreset Purkiss, Perrewe, } \\
\text { Mayes \& Ferris; Watson, Appiah \& Thornton }\end{array}$ \\
\hline TOTAL & 10 & \\
\hline
\end{tabular}

The search parameters did not include date delimitations for publications to allow for the widest cross section of publications based on date of publication. Business Source Complete includes publications from the year 1886 to the present. PsycINFO includes publications from the year 1998 and forward. The range of publication dates for the selected sample are 1991-2016. Table 4 provides an overview of the publication dates for the sample. The rate of publication is somewhat sporadic, but it does indicate recent interest in the concept of names, if not self-presentation, and linkages to the workplace.

Table 4

Findings by Publication Date (Year)

\begin{tabular}{|r|r|l|}
\hline \multicolumn{1}{|c|}{ (Year) } & Results & \multicolumn{1}{|c|}{ Authors } \\
\hline 2016 & 2 & Darolia, et al.; Kang, et al. \\
\hline 2012 & 1 & Jacquemet \& Yannelis \\
\hline 2011 & 2 & Oreopoulos; Watson, Appiah and Thornton \\
\hline 2008 & 1 & Cotton \& O'Neill \\
\hline 2006 & 1 & Segreset Purkiss, et al. \\
\hline 2005 & 1 & Smith, et al. \\
\hline 2004 & 1 & Bertrand \& Mullianathan \\
\hline 1991 & 1 & Bendick, et al. \\
\hline TOTAL & 10 & \\
\hline
\end{tabular}




\section{Literature Review}

At its most granular level, a person's name can have a strong effect on how they interact with others, professional and personally, through their understanding and belief of what their name says about them and how others react and relate to their name. These everyday interactions can impact the individual and the organization's learning and development affecting change and growth.

Although HRD has theoretical roots in psychology that undergirds research in the field (Reio \& Batista, 2014), names and self-presentation in the workplace do not seem to have yet become a subject of interest for research and study. As previously mentioned, there were only three HRD studies, within one publication with the same authors, which specifically studied names and self-presentation specific to the workplace. However, within the overall sample, the articles roughly fell into 4 categories: (1) resume whitening and self-presentation, (2) names and perceived employability, (3) names, other mitigating factors and perceived employability and (4) reactions to names and perceived suitability for employment.

\section{Resume Whitening and Self-Presentation}

According to Goffman (1959), people will always attempt to present their best self in all situations, particularly professionally. Therefore, those seeking employment or trying to ascend within their current employment structure will attempt to determine what that best self is and present accordingly. Sonia K. Kang, Katherine A. DeCelles, Andras Tilcsik and Sora Jun (2016) conducted both qualitative and quantitative studies exploring resume whitening through in-depth interviews, laboratory experiment and resume manipulation. Two of the three studies looked at resume manipulation and whitening 
behaviors by the applicant. The third study employed resume manipulation by the researchers to gauge labor market behaviors and ascertain if bias exists. The third study will be discussed in a subsequent section of this review.

Of the 59 Asian and black University students interviewed in Study \#1,36\% had participated in activities meant to whiten their resume and remove cues that could indicate race or ethnicity including names, organizations and extra-curricular activities (Kang et al., 2016). Both black and Asian students reported engaging in resume whitening specific to the changing of their first names; however, Asian students noticed an increase in employer follow-up to applications when the applicant's first name was changed. The second study aimed to determine if and how racial minorities (Black, East and South Asian) would or would not attempt to rework their resume to respond to employer cues related to diversity and/or an inclusive workplace (Kang et al., 2016). The research showed that of the 119 undergraduate business students who participated in the laboratory experiment, 39\% engaged in resume whitening. Names and Perceived Employability

There are four studies in the sample (Bertrand \& Mullainathan, 2004; Jacquemet \& Yannelis, 2012; Kang et al., 2016; Oreopolous, 2011) that undertake resume manipulation for the purposes of determining if employer bias against either specific minorities or all ethnic and/or racial minorities exists. Each follows the standardized method of preparing and sending out resumes to posted employment opportunities throughout cities in the United States or Canada. 
Bertrand and Mullainathan's (2004) study is perhaps the best known and the study by which subsequent research assesses their results. Researchers sent out nearly 5000 resumes in response to 1300 job advertisements in Boston and Chicago newspapers. Each advertisement received four resumes manipulated both by names but also by applicable work experience and work history with minimal gaps. The resumes included names that were stereotypically associated with Whites or Blacks, "such as Emily Walsh or Greg Baker or such as Lakisha Washington or Jamal Jones" (Bertrand \& Mullainathan, 2004, p. 992). Responses to the job applications were tracked throughout the experiment and results indicated that there were 50\% more follow-up interview requests for resumes with White names. Additionally, resumes with Black sounding names had a lower chance $(6.45 \%)$ of being called for an interview then resumes with White names $(9.65 \%)$. Quality of the resume also had an impact with higher quality resumes with White names having a callback rate of $11 \%$ and resumes with Black names $6.7 \%$.

A similar study by Philip Oreopoulos in 2011, studied employer bias against immigrants in Canada, specifically noting that the results indicated that immigrants with names that were not English, but had similar qualifications including education and experience, experienced discrimination within the labor market. 12,910 resumes were sent via email to 3,225 job postings in the Greater Toronto Area, Toronto and Montreal from April to November 2008 and February to September 2009. Resumes were manipulated and sent four-at-a-time to employers with different treatments, specifically: 1) English-sounding name, Canadian education and work experience, 2) Foreignsounding name, Canadian education and work experience, 3) Foreign-sounding name, foreign education and Canadian work experience, 4) Foreign-sounding name, education 
and some work experience, and 5) Foreign-sounding name, foreign education and all foreign work experience. The foreign-sounding names were either Chinese, Indian or Pakistani to coincide with the largest source countries for immigration to Canada. Overall, the results indicated that resumes with English-sounding names are 39\% more likely to receive employer follow-up for interviews. Oreopoulos took the research a step further and reached out to a sample of 300 of the employers included in the initial study of resume manipulation to explore why the rates of callback for applicants with Chinese, Indian and Pakistani applicants was lower. Of the 300 queried, 29 responded and indicated that as resume reviewers there is a likelihood that foreign names will be assumed to indicate a lack of proficiency in English communication, including a strong accent and difficulty understanding or being understood. This assumption based on name lends itself to the practice of avoiding these types of applicants.

Jacquemet and Yannelis (2012) also conducted resume manipulation to determine the effects of names on resumes in Chicago. Using three sets of names: Anglo-Saxon, African-American, and names not commonly associated with persons from the United States, specifically names of persons from Georgia, Albania and Armenia, the researchers sent out 330 job applications to 110 posted job advertisements. Resumes with AngloSaxon or African-American names were chosen that were from the name bank of highest callback rates in the Bertrand and Mullianathan (2004) experiment. The experiment was field tested with college students to determine that the names chosen, especially those considered foreign were assumed to be foreign but not ascribed to any particular country, race or ethnicity. Resumes were identical with only the names chosen acting as the treatment. The results indicated that callback rates for African-American resumes were 
lower $(16 \%)$ than those with white names which received callbacks at a rate of $23 \%$. Furthermore, resumes with foreign names that indicate no race or ethnicity, had a callback rate of $16.3 \%$.

Kang et al. (2016) built upon the work of Bertrand and Mullainathan (2004), by sending out manipulated resumes to job vacancies throughout the United States to gauge how whitened resumes fared versus resumes without potential racial and ethnic cues removed. In this third study, resumes had one control and three treatments, specifically, "no whitening, whitened first name, whitened experience or whitened first name and experience," with the degree of resume whitening increasing depending on the race of the participant (2 X 4 degree of race to whitening) (Kang et al., 2016, p. 487). 1600 resumes of males were sent out from July-September 2015 through online job postings at companies which both did and did not include cues regarding workplace diversity. Overall, the results indicated that whitened resumes led to more interview requests than unwhitened resumes. When applicants whitened only their name, they received call backs 1.8 times more often and 2.5 times more often when both the name and the experiences were whitened. Overall, there was no evidence that employers with diversity language engaged in less discrimination against those with unwhitened resumes (Kang et al., 2016).

Names, Other Mitigating Factors and Perceived Employability

Five articles related to studies pairing names with other mitigating factors including gaps in employment history, race, gender, accents and occupational stereotypes do not directly discuss names and self-presentation within the workplace, but provide an important viewpoint for the overall discussion. 
One such study aimed to look at the extent, if any, that Latino job seekers experience discrimination in employment when applying for positions in Washington, D.C. and surrounding areas (Bendick, Jackson, Reinoso \& Hodges, 1991). Researchers applied to or inquired about 468 job openings, using two applicants for each vacancy in February and March of 1992. The two applicants, one Anglo and one Latino, applied for positions either by telephone or by submitting a resume. Telephone applications required that both applicants contact the same employer with the Latino applicant using a slight accent to reinforce the identification. Resumes were similar in style, format and qualifications, however the resumes for the Latino applicant were given slightly higher qualifications. The resumes and associated documentation also included clues to ethnicity such as names (e.g., Juanita Ybarra Alvalrez and Julie Anne Mason) and location of high school education (e.g., Juanita in Texas and Julie in Michigan). In doing this, the researchers utilized the name to reinforce the stereotype and make the differences between the applicants more obvious to observers. Overall, 282 of the vacancies were inquired about and/or applied to via telephone and 186 vacancies applied to via mailing of the resume. In the telephone interactions, Anglo applicants moved forward in the employment process $64.9 \%$ with Latino applicants moving forward $48.6 \%$. For the positions applied for via the mailing of resume and cover letter, when both applicants were contacted, $12.4 \%$ of the time the Anglo applicant was contacted and the higher qualified Latino applicant was not. Researchers also reviewed their findings in the context of human resources activities within an organization, providing methods through which organizations can test their policies and procedures related to employment bias and discrimination and address issues that may arise. 
A similar study also included both names and accents as variables when studying bias related to Hispanic ethnicity in employment judgments and decisions (Segrest Purkiss, Perrewe, Gillespie, Mayes \& Ferris, 2006). 212 students from a University in the southeast, enrolled in management courses, participated in the study whereby they were provided a resume and viewed a job interview. Four treatments 1) Hispanic accent and name, 2) Hispanic accent with non-Hispanic name, 3) "standard" American-English accent with Hispanic name, and 4) "standard" American-English accent with nonHispanic name, were utilized in the form of videotaped, staged interviews. The interviewer was not shown on camera and the interviewee, a White male, was trained in both English and Spanish and confirmed by three linguistics to have both realistic and correct English and Spanish dialects and accents. The interviewee participated in the taping of all four treatments using the same nonverbal cues and wearing the same business suit and tie. Resumes were identical with the name being the treatment (e.g. Miguel Fernandez and Michael Fredrickson). Overall, the applicant was judged as more unfavorable when there was both an ethnic name and an accent present. Conversely, when only an ethnic name was present, the judgment was much more favorable.

A subsequent study used both employment history and applicant name to determine if hiring managers would view applications with a lower amount of employment gaps for male applicants more favorably then female applicants (Smith, Tabak, Showail, Parks \& Kleist, 2005). Researchers used names that were deemed more feminine or masculine to create their resumes to present to 400 randomly selected members of human resource professional organizations. One hundred and sixty-one human resource professionals responded and, once all incomplete questionnaires were 
eliminated, a total of 143 remained from which to test the hypotheses. The questionnaires included a resume, cover letter, a job description and instructions. The resumes and cover letters were identical with the exception of the name of the applicant and the included gaps in the applicants' employment history, although each resume had a similar length of gap in the work history. By manipulating the names of the applicants, the researchers sought to make the difference in gender obvious to the study participants so they could better differentiate when making assessments and forming opinions. Analysis of the data showed that for male applicants, having employment gaps can have a much more negative impact then for female applicants who found these gaps to be either neutral or beneficial when viewed by hiring managers.

A second study, which also used names to indicate gender and race was conducted (Darolia, Koedel, Martotell, Wilson \& Perez-Arce, 2016). Building upon a previously conducted experimental study, researchers, analyzed the date from the dissemination of approximately 9000 resumes in response to job vacancies in Atlanta, Boston, Houston, Philadelphia, Chicago, Seattle and Sacramento. Resumes were created based upon resumes found online for similar positions and required qualifications. On the resume, the first name was used to indicate gender and the last name used to indicate race of black, white, and Hispanic applicants. To reinforce and indicate ethnicity, Hispanic applicants were also provided with Hispanic last names. The first names chosen were Isabella, Megan, Chloe, Brian, Carlos and Ryan. The last names were Hernandez, Garcia, Washington, Jefferson, Anderson and Thompson. By using Hernandez and Garcia, the ethnicity of these applicants is reinforced as well as the usage of Washington and Jefferson for the Black applicants and Anderson and Thompson for the White applicants; 
particularly with census data from 2000 confirming that these last names are most prominently associated with the selected race/ethnicity. Overall, the researchers did not observe any significant results to state that employers favor a specific gender, race or ethnicity, which differs from other research conducted before and after.

Finally, Watson, Appiah and Thornton (2011) studied the effects of names in the specific context of sales positions with either little interaction with the public (inside) or a great deal of interaction with the public (outside). Research was conducted with 192 Caucasian sales professionals from across the United States. Each participant received one of four experimental treatments: 1) ethnic named applicant, inside sales job, 2) “Anglicized"-named applicant, inside sales job, 3) ethnic-named applicant, outside sales job, or 4) "Anglicized"-named applicant, outside sales job. Each treatment was combined with a scenario and a stock photo of the applicant. The scenario stated that senior hiring personnel had already rated the applicant and wanted the participants to provide preinterview judgments of the finalists. All ratings were consistent and positive across the four treatments and the stock photo correctly identified and reinforced the race of the applicant. While the results were mixed, analysis of the data showed that for outside sales jobs where face-to-face interaction with the public would be a large part of the position, Blacks with non-ethnic names were favored.

Reactions to Names and Perceived Suitability for Employment

Cotton, O'Neill and Griffin (2008) conducted three studies to evaluate both opinions about names including "uniqueness and likeability" and subsequent opinions on about uniqueness and likeability related to the intention to hire. Researchers created a name bank of 48 names from four categories (e.g., Russian, African-American, Common 
and 'Unusual'). These names were provided to 505 undergraduate and graduate business students at an upper Midwestern University. A survey with a Likert scale of 1 to 7, strongly disagree to strongly agree, was provided to the participants. Half the survey population received half of the names from the bank and the remainder of the survey population received the other half. Participants in the survey were largely Caucasian ( $81 \%$ ) with $55 \%$ of the population male. Names such as John, Robert, Beth, Mary and Susan were considered most common and highest on the likeability scale. Unusual names like Ajax, Atholl, Magestic and Tangerine were deemed to be most unique and least likeable. Common and unusual names were determined by looking at name data from the Social Security Administration. African-American and Russian names were more unique and less likeable than common names but much more likeable and less unique than unusual names.

In the second study, the name analysis for uniqueness and likeability was replicated, but included the additional variable of likelihood of hiring. This study included 166 participants enrolled in a graduate business degree program. Participants were largely Caucasian (78\%) and male (61\%) and averaged 30 years-of-age. The name bank was reduced to 16 names of which the first study's participants correctly identified as one of the four aforementioned categories and all participants rated the same 16 names. The results indicated that, much like the first study, common names were liked the most and unusual names were liked least. Additionally, those with common names were more likely to be hired followed by those with African-American names. Those with unusual names were least likely to be hired.

The final study aimed to look solely at the intention to hire and did not focus on 
the explicit opinion of the applicant's name itself. In this third laboratory study, 105 employed adults, aged 21 to 47, who were enrolled in a part-time business graduate degree program participated in the study. These participants, who did not participate in either of the previous studies, received eight resumes and eight sets of questions and were asked to act as a hiring manager tasked with selecting a new administrative assistant.

Resumes were provided with one male and one female name from the names and each of the four categories established in Study \#1. After review of the resume and answering of the questions for each applicant, participants were asked to rate the applicant, using a Likert scale, in terms of likelihood to hire. Study \#3 provided results that differed from the previous studies, specifically that name, category, nor gender had a significant effect on the decision to hire.

\section{Implications}

The research, particularly that related to applicant resume manipulation and resume manipulation to test market conditions related to bias, indicates that names and self-presentation are linked either through the name itself and its uniqueness or what the name appears to be saying about the applicant (Bertrand \& Mullainathan, 2004; Cotton et al., 2008; Kang et al., 2016). At its core, each study aimed to manipulate how the applicant appeared to the employer lending support to the linkage between Goffman's self-presentation theory, and names. Although only the Kang studies use self-presentation theory to support and frame the research, as a whole, all of the literature reviewed connects back to this theory. By creating resumes with different types of names and evaluating reactions to them (e.g., interview, likeability, etc.), the research centers in on the concept of how a person is presented and what their presentation says to those they 
encounter. From a practical standpoint, presenting as Greg instead of Jamal, does have an effect on the desired outcomes of that presentation. More than anything else, the studies examined support the notion that awareness of bias is important both in how applicants feel they are being viewed and in how they are actually being viewed.

As was noted by several of the researchers, the studies undertaken illustrate clearly that bias towards certain applicants exists, however, the research ends at the point of a positive or negative action on behalf of the employer; specifically, a callback in response to the application. The research does not go past that point to the interview stage, or the onboarding, which could be equally telling in terms of assimilation and continued self-presentation behaviors for applicants with names that provide racial cues.

\section{Future HRD Research}

The studies reviewed have shown that applicants who do not present with the proper social cues, based on assumptions about their name, will have increased difficulty at the application stage and will likely not make it to the interview or hiring stage of the employment process (Bertrand \& Mullainathan, 2004; Jacquemet \& Yannelis, 2012; Oreopoulos, 2011). Further, when adding in other factors including accent, religious assumptions, and/or gender, the climb becomes that much steeper (Bendick et al., 1991; Darolia et al., 2016; Purkiss et al., 2006; Watson et al., 2011). This is a great starting place for HRD researchers to understand self-presentation, names and its links to the process of the applicant and the review during personnel selection. The research, however, is largely quantitative and focused on two populations based on racial categorization: White and Black. To be sure, this is a gap in the research. 
With the exception of the Kang et al. (2016) qualitative study of graduating Black and Asian students and their behaviors and opinions, within the reviewed literature there is a distinct lack of qualitative research conducted in the United States and Canada related to self-presentation and names. Outside of the United States, the research is also largely quantitative. Additionally, with the exception of the study by Bendick et al. (1991), there is also a lack of research either quantitative, qualitative or mixed-methods on Hispanic populations and self-presentation related to names. With population data indicating a United States Hispanic population that has become the largest minority population in the United States, it only makes sense to extend the previous studies and conduct new studies with a focus on this population (Profile America Facts, 2016). The aforementioned factors, therefore, provide an opportunity for HRD researchers to focus on specific population that may be understudied as well as methods that are possibly underutilized.

When looking at the data provided in the large-scale Canadian employment study (Oreopoulos, 2011), the hiring managers that responded to the follow-up inquiry as to why they did not select applicants with Chinese, Indian or Pakistani names focused upon assumptions of language and speech deficiencies, but also referenced assumptions related to culture and a need to take extended leave due to cultural events and/or long-distance family members. Although this is just one study, it is not inconceivable to posit that other hiring managers may foster these beliefs, which shade their analysis as to the suitability and fit of certain candidates for employment. Whether or not the hiring managers were basing their beliefs on a number of experiences or a few employees, a lack of knowledge may be behind these statements and their associated microaggressions. Future qualitative 
HRD research (e.g., case studies) might be designed to get at this notion and contribute to addressing this information gap.

Additional qualitative as well as mixed-methods studies including populations other than Black and White will help to counteract some of the limitations of previous research and more closely answer questions related to specific opinions and assumptions. To both study new populations using a previous quantitative model (Bertrand \& Mullainathan, 2004) and build upon the quantitative data to create a fuller picture, a mixed-method study utilizing both quantitative and qualitative methods would provide new information and understanding to this area of study. As conducted in the Bertrand and Mullainathan (2004) research, resumes can be created and advertisements responded to, but the resumes would be of applicants with Black, White and Hispanic names to further test the theories therein. The second part of the study could be focused upon speaking with hiring managers about the hiring preferences, if any, that came out of the quantitative research. Additionally, as previous research has utilized the Midwest as a staging ground, new research could be conducted in areas within Florida, California, Texas and New York; states which all have areas of ethnic and racial diversity as well as homogeneity.

Future study, especially qualitative research is needed to better understand the underlying beliefs that spur behavior on the part of the applicant (e.g., whitening) and can lead to biased behavior on the part of hiring professional (e.g., deselection). The ability to more greatly understand the behavior at the granular level can be used to frame the discussion and understanding of the underlying factors and beliefs and influence practice. 
As such, qualitative research and more specifically, a phenomenological approach to qualitative research can be ideal to gain this knowledge. As previously stated, the reviewed research was largely quantitative, and focused on resume creation to gauge the opinions and practices of employers. While researchers were able to draw conclusions through the outcomes observed in the empirical studies, research can always benefit from focusing in on a particular factor or actor, such as specific job applicants. Therefore, additional research should focus on the phenomenology of names and the behaviors, opinions and experiences with specific populations. For instance, five empirical studies using a phenomenological approach could focus on five distinct populations: White, Black, Hispanic (Black, White or mixed-race), Asian, and Arabic and/or Persian. Groups of participants could be gathered within two education levels (e.g., high school diploma or GED and Bachelor's degree) and three age groups (e.g., 18-24, 25-34 and 35-44). Within each population sample, interview or focus groups could be conducted to hear the experiences directly from the participants about their behaviors related to selfpresentation and how /if their name factors into their experiences.

The information that can be derived from both the mixed methods and qualitative studies suggested will build upon the previous research and, through its greater inclusivity, inform about a wider section of the population. It can fill a gap in the current research and provide valuable information to practitioners within HRD and other industries to influence practice.

\section{HRD, Names and Self-Presentation}

In their role, HRD professionals facilitate knowledge and skill acquisition for an organization's personnel (Lee, 2015). HRD professionals, however, also have a role to 
play in how their organization views and assesses applicants and applications as well as how applicants believe they are being viewed and assessed.

Applicants with names that can reveal identity expect discrimination and work to present a different version of themselves through resume whitening (Kang et al., 2016). This can be both based on previous experience and expectation, but can also occur regardless of the organization's public stance on diversity (Kang et al., 2016). This, then, is the other side of the employment experience, but the consequences are much the same (e.g., the best and most qualified could be removed from contention or self-removed through assumptions of characteristics and actions taken to mitigate against these assumptions).

This is where HRD professionals can step in. Besides a wider educational campaign about awareness and the importance of diversity and inclusion (not just focused on the legal requirements), efforts can be made to educate organizational personnel about cultural differences, thereby more clearly illustrating what is and is not true. Educational endeavors like guest speakers, cultural events, and informal mentorships, shadowing and employee pairing cross-culturally could provide a more robust frame of reference. Extending the frame of reference could lend itself to reduced bias and the creation of an actual inclusive workplace where applicants and employees do not feel the need to selfpresent through their names to reach some ideal.

\section{Conclusions}

The set of studies conducted by Kang et al. (2016) was largely unique in that it discussed the activity of resume whitening, and specifically self-presentation and selfdisclosure, from the standpoint of the potential applicants. By including the qualitative 
study and the subsequent laboratory experiment in their paper, it allowed the researchers to more closely monitor applicant behavior for cues.

On a whole, self-presentation and names are not discussed within HRD's literature, although the empirical studies reviewed indicated research within the associated fields of human resources/business, and psychology, as well as economics, and cross-disciplinary. It is obvious that both applicants and hiring managers have a story to tell, both in how they see themselves and their role as either prospective employee or figurative gatekeeper. As both a leader of change and a steward of an organization's collective and individual culture competencies, HRD researchers should be thoughtleaders engaging in the discussion of names, self-presentation, possible and perceived bias, etc. Learning from past research and new knowledge that can be created through the studies suggested, human resources, in general, and HRD professionals specifically can gather information and understanding about the beliefs and expectations of bias that persist despite efforts to present and facilitate inclusivity and diversity.

\section{References}

Bendick, M., Jackson, C., Reinoso, V., \& Hodges, L. (1991). Discrimination against latino job applicants: A controlled experiment. Human Resource Management, 30, 469-484.

Bertrand, M. \& Mullainathan, S. (2004). Are Emily and Greg more employable than Lakisha and Jamal? A field experiment on labor market discrimination. The American Economic Review, 94, 991-1013.

Blommart, L., Coenders, M., \& van Tubergen, F. (2014). Discrimination of Arabicnamed applicants in the Netherlands: An internet-based field experiment examining different phases in online recruitment procedures. Social Forces, 92, 957-982.

Campbell, J. P. \& Knapp, D. (2001). Exploring the limits in personnel selection and classification. Mahwah, New Jersey: Lawrence Erlbaum Associates, Inc. 
Carlsson, M., \& Rooth, D. (2007). Evidence of ethnic discrimination in the Swedish labor market using experimental data. Labour Economics, 14, 716-729.

Cotton, J., O'Neill, B., \& Griffin, A. (2008). The "name game": Affective and hiring reactions to first names. Journal of Managerial Psychology, 23, 18-39

Creswell, J. (2013). Qualitative inquiry and research Design: Choosing among five perspectives $\left(3^{\text {rd }}\right.$ ed.). Thousand Oaks, CA: Sage.

Darolia, R., Koedel, C., Martorell, P., Wilson, K., \& Perez-Arce, F. (2016). Race and gender effects on employer interest in job applicants: New evidence from a resume field experiment. Applied Economics Letters, 23, 853-856.

Fink, A. (2013). Conducting research literature reviews: From the Internet to paper. Thousand Oaks, CA: Sage Publications.

Hanin, D., Stinglhamber, F., \& Delobbe, N. (2013). The impact of employer branding on employees: The role of employment offering in the prediction of their affective commitment. Psychological Belgica, 53, 57-83

Jacquemet, N. \& Yannelis, C. (2012). Indiscriminate discrimination: A correspondence test for ethnic homophily in the Chicago labor market. Labour Economics, 19, 824-832.

Kang, S. K., DeCelles, K. A., Tilcsik, A., \& Jun, S. (2016). Whitened resumes: Race and self- presentation in the labor market. Administrative Science Quarterly, 61, 469502.

Lee, M. (2015). The history, status, and future of HRD. In R. F. Poell, T. S. Rocco, \& G. L. Roth (Eds.), The Routledge companion to human resource development (pp. 312). New York, NY: Routledge.

Luo, M. (2009, December 5). 'Whitening' the résumé. New York Times. Retrieved from http://www.cfs.purdue.edu/richardfeinberg/csr\%20309\%20spring\%202011/corner \%20office/Whitening\%20the\%20resume.docx.

Nadler, L., \& Nadler, Z. (1990). Developing human resources: Concepts and a model (3 $3^{\text {rd }}$ Ed.). San Francisco: Jossey-Bass.

Onwuachi-Willig, A., \& Barnes, M. L. (2005). By any other name?: On being "regarded as" Black, and why Title VII should apply even if Lakisha and Jamal Are White. UC Davis Legal Studies Research Paper Series: No. 67, 1-53.

Oreopoulos, P. (2011). Why do skilled immigrants struggle in the labor market? A field 
experiment with thirteen thousand resumes. American Economic Journal: Economic Policy, 3, 148-171.

Pittinsky, T., Shih, M., \& Ambady, N. (2000). Will a category cue affect you? Category cues, positive stereotyped and reviewer recall for applicants. Social Psychology of Education, 4, 53-65.

Profile America Facts. (2017, October 17). Retrieved from https://www.census.gov/content/dam/Census/newsroom/facts-forfeatures/2017/cb17-ff17.pdf

Segrest Purkiss, S. L., Perrewe, P. L., Mayes, B. T., \& Ferris, G. R. (2006). Implicit sources of bias in employment interview judgment and decisions. Organizational Behavior and Human Decision Processes, 101, 152-167.

Smith, F. I., Tabak, F. Showail, S., Parks, J. M., \& Kleist, J. S. (2005). The name game: Employability evaluations of prototypical applicants with stereotypical feminine and masculine first names. Sex Roles: A Journal of Research, 52, 63-82.

Thomson, K., de Charnatony, L. Arganbright, L. \& Khan, S. (1999). The buy-in benchmark: How staff understanding and commitment impact brand and business performance. Journal of Marketing Management, 15, 819-835.

Toracco, R. J. (2005). Writing integrative literature reviews: Guidelines and examples. Human Resource Development Review, 4, 356-367.

Torraco, R. J. (2016). Writing integrative reviews of the literature: Methods and purposes. International Journal of Adult Vocational Education and Technology, 7, 62-70.

Vohs, K., Baumeister, R. \& Ciarocco, N. (2005). Self-regulation and self-presentation: Regulatory resource depletion impairs impression management and effortful selfpresentation depletes regulatory resources. Journal of Personality and Social Psychology, 88, 632-657

Watson, S. Appiah, O. \& Thornton, C.G. (2011). The effect of name on pre-interview impressions and occupational stereotypes: The case of black sales job applicants. Journal of Applied Psychology, 41, 2405-2420.

Weichselbaumer, D. (2017). Discrimination against migrant job applicants in Austria: An experimental study. German Economic Review, 18, 237-265.

Wilson, M.G., Gahlout, P., Liu, L. \& Mouly, S. (2005). A rose by any other name: The effect of ethnicity and name on access to employment. University of Auckland Business Review, 7, 65-72. 


\section{CHAPTER III}

\section{STUDY \#2, NAMES AND EXPECTATIONS: WHAT ORGANIZATIONS NEED TO KNOW ABOUT PEOPLE WITH ETHNICALLY IDENTIFYING NAMES}

Naming is the manifestation of various factors including familial traditions, socioeconomic status, identification within groups and subgroups, and cultural biases (Young, Kennedy, Newhouse, Brown \& Thiessen, 1993). A name is how a person presents to the world around them. As it relates to ethnic identification, names are thought to be especially telling and can be utilized to aid in ethnic classification (King, Madera, Hebl, Knight, \& Mendoza, 2006). "Names are clearly not arbitrary labels, used simply for recognition and identification. They often convey information about age, sex, ethnicity...thus names are potentially heavy with meaning, and can act as referents for quick identification of social and demographic categories" (Young et al., 1993, p. 1772). It becomes evident then, that names are significant not only to assist in organization and in creating one's identity, but to classify, stratify, and identify one's race and ethnicity. Inasmuch as the name can be highly influential in terms of internal and external loci of identity, the employment recruitment process and simple everyday interactions, the research sought to understand the opinions and behaviors undertaken by the name-holder related to self-presentation and social-penetration strategies including, but not limited to: whitening the resume, use of nicknames and name changes, as well as their perceptions of the quality of their employment opportunities and their initial social interactions when meeting new people, professionally and personally. 


\section{Ethnically Identifying Names}

A name that can provide information upon which to base assumptions of group membership of specific races, ethnicities and/or gender and perceived associated characteristics can be considered ethnically identifying. For the purposes of this study, ethnicity is defined as, "a dynamic set of historically derived and institutionalized ideas and practices that allows people to identify or be identified with groupings or people on the basis of presumed (and usually claimed) commonalities including language, history, nation or region of origin, customs, ways of being, religion, names, physical appearance, and/or genealogy or ancestry (Moya \& Markus, 2010). Examples of ethnically identifying names most often associated with Black or White children include: Mary, Linda, James and Michael as well as names like Connor, Cody, Jake, Molly, Abigail and Caitlin (Fryer \& Levitt, 2004). DeShawn, Tyrone, Reginald, Shanice, Precious, Kiara, and Deja are prevalent among Black male and female children. As research on names tends to focus most often on the names of Black and White children, there is a lack of research that looks closely at names and impacts for Asian or Latino children.

One of the major points regarding ethnically identifying names is they have been associated with various kinds of stereotyping; that is, positive and negative stereotypes, and occupational stereotyping. Ethnically identifying names can lead also to being labeled as part of a model minority, and being the target of microaggressions.

\section{Theoretical Framework}

Social identity theory (Tajfel \& Turner, 1979), self-presentation theory (Goffman, 1959) and social penetration theory (Altman \& Taylor, 1973) were used to inform this 
study. The combination of the three theoretical perspectives, and associated concepts, afforded support for richer understandings of the naming phenomenon in organizations.

Social Identity Theory and In-Group Bias

Under social identity theory, people desire to align themselves with those that meet the standards of society, economics, race, ethnic make-up and other characteristics to which they themselves want to belong and reinforce their notions of superiority over those outside of the desired group (Tajfel \& Turner, 1979, 1986). For a person with an ethnically identifying name, their individual and social characteristics may be predetermined and their group membership decided by virtue of their name and the characteristics assumed therein.

Connected to this theory are the concepts of stereotyping, negative and positive stereotyping, and occupational stereotyping. Stereotypes are steeped in preconceived notions which directly inform perception and opinion, "mark[ing] out certain objects as familiar or strange, emphasizing the difference, so that the slightly familiar is seen as very familiar, and the somewhat strange as sharply alien" (Lippmann, 1922, pp. 89-90). When operating under the assumption that every member of this group has those characteristics, this furthers the belief that every member of that group can be interacted with, judged and identified using those assumptions (Gaertner \& McLaughlin, 1983).

Positive stereotypes can be traits attributed to a particular social group, such as the notion that all Asians are intelligent, all Jewish people are good in business and all women are nice (Siy \& Cheryan, 2013). Much like negative stereotypes such as "women 
are perceived as warm but weak, Asians as competent but cold, and Blacks as athletic but unintelligent," (Czopp, 2008, p. 414), positive stereotypes can become widespread and, in their pervasiveness, provide support for the belief of information which may or may not have a factual basis (Kay, Day, Zanna \& Nussbaum, 2013). Unlike negative stereotypes which most often have a negative connotation, positive stereotypes as defined are, "subjectively favorable beliefs about members of a social group that directly or indirectly connote or confer domain-specific advantage, favorability, or superiority based on category membership,” (Czopp, Kay \& Cheryan, 2015, p. 451). When positive and negative stereotypes relating to social placement, race, and ethnicity are bought into and propagated by one group upon another, there is a likelihood that racism and prejudice can result (Phelan, Link \& Dovidio, 2008). Finally, occupational stereotyping is the, "preconceived attitude about a particular occupation, about people who are employed in that occupation, or about one's suitability for that occupation,', (Lipton, O'Connor, Terry, \& Bellamy, 1991, p. 129). Occupational stereotyping, then, is another factor that applicants must consider when applying for employment.

In terms of social identity theory, is it the act of stereotyping that largely informs the opinions that lead the observer in determining the values to ascribe to the observed and to which group the observed belongs.

\section{Self-Presentation Theory and Impression Management}

Self-Presentation. Erving Goffman's theory details the performance a person puts forth to present their public face in order to influence the perceptions of others to achieve goals (Goffman, 1959). The idea is that a person will always attempt to influence others' 
opinions during the initial interaction. Ethnically identifying names can hinder the performance, particularly if the name assumes characteristics that the performance seeks to downplay.

Impression Management. Impression management centers on the maintenance of the performance and the continued influence over the observers to view the performer favorably (Goffman, 1959). Managing impressions is a critical component of efficacy, both professional and interpersonal, affecting the formation of identity, friendships, career and group membership success, etc. (Vohs, Baumeister, \& Ciarocco, 2005).

\section{Social Penetration Theory and Self-Disclosure}

Within social penetration theory is the concept that levels of interpersonal interaction are traversed during the progression of social relationships (Altman \& Taylor, 1973). A fundamental component of social penetration theory is the assertion that the goals of the interaction and desired social penetration determine what to disclose in those initial stages (Altman \& Taylor, 1973). Specific characteristics, such as an ethnically identifying name, can spur stereotypes, which manifest themselves in microaggressions related to one's opinions about comportment, temperament, work ethic, socioeconomic status, background, etc., connected to the assigned ethnicity that the name implies. A person's desire to move past the initial self-disclosure stage may decide to adjust their name if it aids in the meeting of their social and/or employment goals. While also connected to social identity theory, central to the self-presentation and social penetration theories are the concepts of the model minority and microaggressions. 
Created in 1966 to refer to the achievements of Japanese Americans and their position as a model for minorities of other races and ethnicities to follow, "model minority” is a label that persists today (Wong \& Halgin, 2006). Through widespread beliefs about the superior abilities of Asian Americans and the effect of their upward mobility of others (e.g., concepts relating to lower grades and lesser job opportunities for others outside the model minority group), ethnic and employment discrimination as well as victimization can occur (Maddux, Galinsky, Cuddy \& Polifroni, 2008). This belief about the model minority can lead Asian applicants to attempt to alter their selfpresentation and how much they disclose about their ethnic and cultural backgrounds in hopes of increasing their perceived suitability for employment and lengthen their progression in the employment recruitment process.

Microaggressions, derived from stereotyping, stem from the perpetuation of preconceived and subconscious notions of ability, status, and worth indicated by the individual's assumed or actual membership in a specific group (Pierce, 1970; Pierce, Carew, Pierce-Gonzalez, \& Willis, 1978). Microaggressions can be telling a Black person that they speak well, asking a Latino or Asian person where they are really from or the avoidance of a minority on an elevator or other space due to belief of criminality (Wing, Capodilupo, Torino, Bucceri, Holder, Nadal \& Esquilin, 2007). Much like Asians who may desire to dispel the notion of the model minority, for other persons with ethnically identifying names, the microaggressions they may experience can hamper their job search, their perceived suitability for employment and their progression through the employment recruitment process as well. 
To achieve a higher level of understanding of what is a complicated issue, each of these theories and concepts converge to create a context to frame the exploration of the perspectives and experiences of those with ethnically identifying names and their efforts related to self-presentation and social penetration in social and professional settings.

\section{Connections}

These theories and the associated concepts of names and name selection, stereotyping, and microaggressions lend support to the idea of a name being an ethnic identifier, which allows someone to make determinations about another person's individual characteristics based on group membership. This process of identifying and categorizing follows a path from the given name and its assumed linkages to race, and ethnicity, to the associated negative and/or positive characteristics assumed through the process of stereotyping. The perpetuation of stereotyping and microaggressions is tied to the aforementioned theories and the inclination for people to self-present and selfdisclose those characteristics (including their name) which will allow others to identify and categorize them as one who fits inside (or outside) of their group membership. When these individual factors converge, there is an increased likelihood of difficulty based largely on the expectation of skill, temperament, and other attributes. When taken in the context of professional and social interactions, an applicant with a nontraditional name that suggests an ethnicity or race that is associated with unfavorable characteristics may have a more difficult time progressing through the employment process and interacting with others (Pittinsky, Shih \& Ambady, 2000). To gain a greater understanding of what is a multi-faceted issue, each of these theories and concepts combine to create a framework 
that seeks to frame the exploring of the perspectives and experiences of those with ethnically identifying names and their efforts related to self-presentation and social penetration in social and professional settings.

\section{Statement of the Problem}

Professional and social interactions are among the most important aspects of a person's life. The name that one has is how they relate to the world and how the world relates to them. Human Resource Development (HRD) practices and the performance of employees can be directly impacted by the professional and social interactions of employees within an organization. There are empirical studies that examine the effect of names and highlight the importance of names on employment and social interaction/inclusion. However, there is a gap in the research related to the experiences of those with ethnically identifying names. Building on the work of Bertrand \& Mullainathan (2004), and Kang, DeCelles, Tilcsik \& Jun (2016), this work explored the experiences of those with ethnically identifying names as they navigate professional and personal situations that can affect the organization.

\section{Purpose and Research Question}

The purpose of this phenomenological study was to explore the perspectives and experiences related to self-presentation and social penetration in social and professional settings for persons with ethnically identifying names. This study was guided by the primary research question: How do persons with ethnically identifying names manage self-presentation and self-disclosure in the context of job seeking and new interpersonal, social interactions? The secondary questions include: (a) What are the perspectives and 
experiences related to applying for employment and the management of self-presentation and self-disclosure for those with ethnically identifying names? (b) What are the perspectives and experiences related to initial social interactions and the management of self-presentation and self-disclosure for those with ethnically identifying names?

\section{Research Design}

This study utilized a phenomenological method of qualitative research (Moustakas, 1994). In the context of the perspectives of those with ethnically identifying names, a phenomenology allowed for the collection of data related to what the participants experienced and how that experience was undertaken (Moustakas, 1994). Those with ethnically identifying names may experience stereotyping and be subject to microaggressions wherein the, "specific acts of microaggression experienced...are based on stereotypes and prejudice unique to each particular racial or ethnic group" (ForrestBank \& Jenson, 2015, p. 145). Having an ethnically identifying name, therefore, is a phenomenon of which there is a lack of understanding of the perspectives and experiences of those with the name. Therefore, there is a need for a greater understanding of these persons, which could only be achieved through in-depth discussion and the ability to detail their experiences and perspectives in their own words (Creswell, 2013). The participants were able to detail how their names were chosen, how their names resonated within their individual, social, and professional identities, and how they managed these identities, and in doing so brought the world into closer alignment and interrelation (van Manen, 1990). 


\section{Sampling}

Eligible participants had to meet the following criteria: 1) at least 18 years of age, 2) employed, 3) have an ethnically identifying first name and 4) be willing to participate in a confidential interview with the possibility of subsequent communication. Convenience sampling was first used to recruit nine of the participants. Participants were then asked to recommend additional participants (snowball sampling) that met the criteria of the study; an additional six participants (Onwuegbuzie \& Leech, 2007). To attempt to achieve data saturation, the group was heterogeneous to study the phenomenon across different ethnicities. As such, interviews of 15 participants of Caucasian, African, Asian and Latino/Hispanic ethnicities were conducted.

\section{Participants}

Fifteen participants agreed to be interviewed with an average of 31.26 years-ofage; 3 were male and 12 were female. Two participants identified as Caucasian (13.3\%). Three participants identified as multi-ethnic (20.0\%). Three participants identified as African ethnicity (20.0\%). Three participants identified as Latino/Hispanic ethnicity (20.0\%). Finally, three participants identified as Asian ethnicity (20.0\%). Eighty percent of the participants were female and $20 \%$ male.

All participants reported earning a Bachelor's degree, while several reported advanced degrees. Each participant agreed to be identified by first name, ethnicity, gender, and age range. Table 1 provides a summary of the participants. 
Table 1

Summary of Participants

\begin{tabular}{|c|c|c|c|}
\hline $\begin{array}{l}\text { Participant } \\
\text { Name }\end{array}$ & $\begin{array}{l}\text { Age } \\
\text { Range }\end{array}$ & $\begin{array}{l}\text { Ethnicity (As Identified by } \\
\text { Participant) }\end{array}$ & Sex \\
\hline April & $40-50$ & Caucasian & $\mathrm{F}$ \\
\hline Cory & $25-35$ & Caucasian & $\mathrm{M}$ \\
\hline El pagnier & $50-60$ & African & $\mathrm{F}$ \\
\hline Elizabeth & $40-50$ & Latina/Hispanic & $\mathrm{F}$ \\
\hline Haki & $45-55$ & African & $\mathrm{M}$ \\
\hline Hazel & $35-45$ & Latina/Hispanic & $\mathrm{F}$ \\
\hline Heidi & $30-40$ & African & $\mathrm{F}$ \\
\hline Hillary & $30-40$ & African & $\mathrm{F}$ \\
\hline Jade & $20-30$ & Asian & $\mathrm{F}$ \\
\hline Jia & $25-35$ & Asian & $\mathrm{F}$ \\
\hline John & $35-45$ & Latino/Hispanic & $\bar{M}$ \\
\hline Kenyeta & $25-35$ & $\begin{array}{l}\text { Multi-ethnic: African \& } \\
\text { Latina/Hispanic }\end{array}$ & $\mathrm{F}$ \\
\hline Nicole & $20-30$ & Asian & $\mathrm{F}$ \\
\hline Mercedes & $35-45$ & $\begin{array}{c}\text { Multi-ethnic: Latina/Hispanic \& } \\
\text { African }\end{array}$ & $\mathrm{F}$ \\
\hline Simone & $40-50$ & $\begin{array}{l}\text { Multi-ethnic: African, Asian, } \\
\text { Anglo/Caucasian }\end{array}$ & $\mathrm{F}$ \\
\hline
\end{tabular}




\section{Data Collection}

\section{Interviewing}

Guided by the FIU Institutional Review Board, data was collected through semistructured, in-person responsive interviews (Rubin \& Rubin, 2007). When in-person interviews were not possible, telephone interviews for seven of the participants were substituted. Interviews were scheduled for 60-minute increments with approval from the interviewee for up to 120 minutes, if necessary. The length and format of the interviews allowed for a responsive interview that reached the goals of the study (Rubin \& Rubin, 2007). The average length of the 15 interviews was 54 minutes with the longest interview lasting 72 minutes and the shortest lasting 34 minutes. Interview questions fell under four categories and were asked sequentially in a manner that made the connection apparent and worded in a way that did not bias or place limitations on the interviewee's responses (Rubin \& Rubin, 2007). The categories of questions were: 1) Perspectives about their name and associated connotations, 2) Name selection and associated meanings/historical and/or ethnic references, 3) Self-presentation and self-disclosure related to employment, and 4) Self-presentation and self-disclosure related to social interaction. Questions asked specific to each category included: 1) What do you think your name says about you, if anything? 2) Do you think there is such a thing as an ethnically identifying name that can indicate to others that person's race or ethnicity without meeting them? 3) When you meet someone new in a professional setting, how do you introduce yourself? and 4) When you meet someone new in a social setting, how do you introduce yourself? The full interview guide can be found in Appendix A. 


\section{Instrumentation}

Interviews were captured both through audiotaping and field notes. To ensure that the field notes were descriptive and accurate, they were kept during the interview (Bogdan \& Biklen, 2007). However, when the taking of notes hindered the flow of two interviews, field notes were written immediately after the interview had ended and the participant departed.

\section{Data Analysis}

Creswell's (2013) adapted version of Moustakas' (1994) Modification of the Stevick-Colaizzi-Keen Method of Analysis of Phenomenological Data was utilized to analyze the date inductively. To assist in analysis, NVivo 12 was used. Through an initial reading, then rereading of each transcript, data were analyzed individually and in composite, allowing for multiple layers of meaning. During the individual analysis each transcript was read, then reread to tease out lists of significant statements that grouped together to create themes (Creswell, 2013; Moustakas, 1994). These themes built into the textural description and using specific, "verbatim" examples from the data provided a rich description of what the participants experienced (Creswell, 2013, p. 193). After the textural description, a structural description was written following the same process as before to determine "how" the experiences occurred (Creswell, 2013, p. 194). The textural and structural descriptions were combined to create a composite description, which, "serves as the essence of the experience... [and]...explains the how and what in context" (Creswell, 2013, p. 194; Moustakas, 1994). 


\section{Integrity Measures}

An understanding of possible researcher subjectivity and the removal of subjectivity from the process allows the research to be conducted objectively and assures research integrity. Acknowledging assumptions and removing bias (bracketing), while not often fully accomplished, is an integral part of phenomenological research (Moustakas, 1994). I am conscious that, as researchers, we are expected to exert some level of control over our assumptions in the process of conducting research and approach the research with a fresh perspective (Moustakas, 1994). In qualitative study, the actual words of the participants are what is important. By keeping field notes and including detailed passages of participant responses, a clear picture of their specific opinions and support for the conclusions reached through the analysis of the data can be achieved. By asking each participant the same standard set of questions and allowing them to respond at their own pace, in their own words and when ready (e.g., skipping a question to answer at the end), the research is strengthened and bias diminished.

Bracketing was attempted through the inclusion of core assumptions relating to ethnically identifying names and through the use of a researcher journal (Creswell, 2013; Ortlipp, 2008). Additionally, semi-structured interviews were undertaken with the goal of gathering data direct from the participant, utilizing their words verbatim whenever possible. Throughout the interviews, I kept extensive field notes to highlight those areas of special importance such as when a participant came to a breakthrough (e.g., realizing that they have inadvertently created a speech to use when explaining their name). I noted when questions were answered at length, as well as when questions were skipped and/or when the participants were energetic, uncomfortable, reflective, etc., during the 
interviews and on specific questions. Additionally, I utilized detailed passages and rich descriptions of the specific words and phrases of the participants and noted expressions, and emphasis where important to further expand on the experiences, and opinions of the participants. Finally, critical reflection, specifically the connections I have to the research and how the research has evolved my viewpoints and understanding of the topic were also included through a researcher journal.

\section{Researcher Journal}

I believe that I have an understanding of my name and how it was conceived and that I have determined, or at the least, acknowledged my, "experiences, values and assumptions," regarding names (Ortlipp, 2008, p. 698). I recognize that I entered into the research with assumptions that the participants would (a) would feel that names were important, (b) each have a story to tell about their experiences with their name, (c) would be interested in the opportunity to express their opinion about their name, and (d) have questions about how I came to this research. Due to these assumptions, I chose to keep a researcher journal to document the actual process and my feelings about it. This journal assisted in noting observations, personal feelings, biases and other pieces of information useful in the data analysis stage. Of particular note, I found that in speaking with other women of African descent that were given names most often associated with persons of Caucasian descent (e.g., Heidi and Hillary), my journal entries were longer and more in depth. This is likely due to my name and the need to note words and/or descriptions and experiences that heightened my awareness of possible similarities without allowing those to color the analysis of the data. Of particular note was the concept of "blackness" 
referenced by a number of participants and the concept that those with names that are not usually associated with those of African descent may have to "prove" their group membership to be accepted. Heidi and Hillary were told that they "talk White" or participated in activities like White people (e.g., reading books, writing, etc.). They described feeling a need to defend themselves to a certain extent and prove their blackness through organizations joined, friends, etc. These experiences were also described by Simone and Mercedes who are multi-ethnic. In my journal, I noted that these experiences were similar to mine, but did not notate the similarities in my field notes to ensure that the thought process was kept separate from the tools I would be using to analyze the data (e.g., the transcripts and field notes).

\section{Findings}

In the analysis and coding process, one overarching theme emerged which was reinforced throughout the interviews. It was the idea of curiosity surrounding names and the concept that there has to be a good story behind an interesting name to almost excuse the uniqueness and any resulting difficulty. From this overarching theme/context, three main themes and eleven subthemes emerged. Figure 1 provides a summary of the themes and sub-themes. 
Figure 1. Summary of themes and subthemes

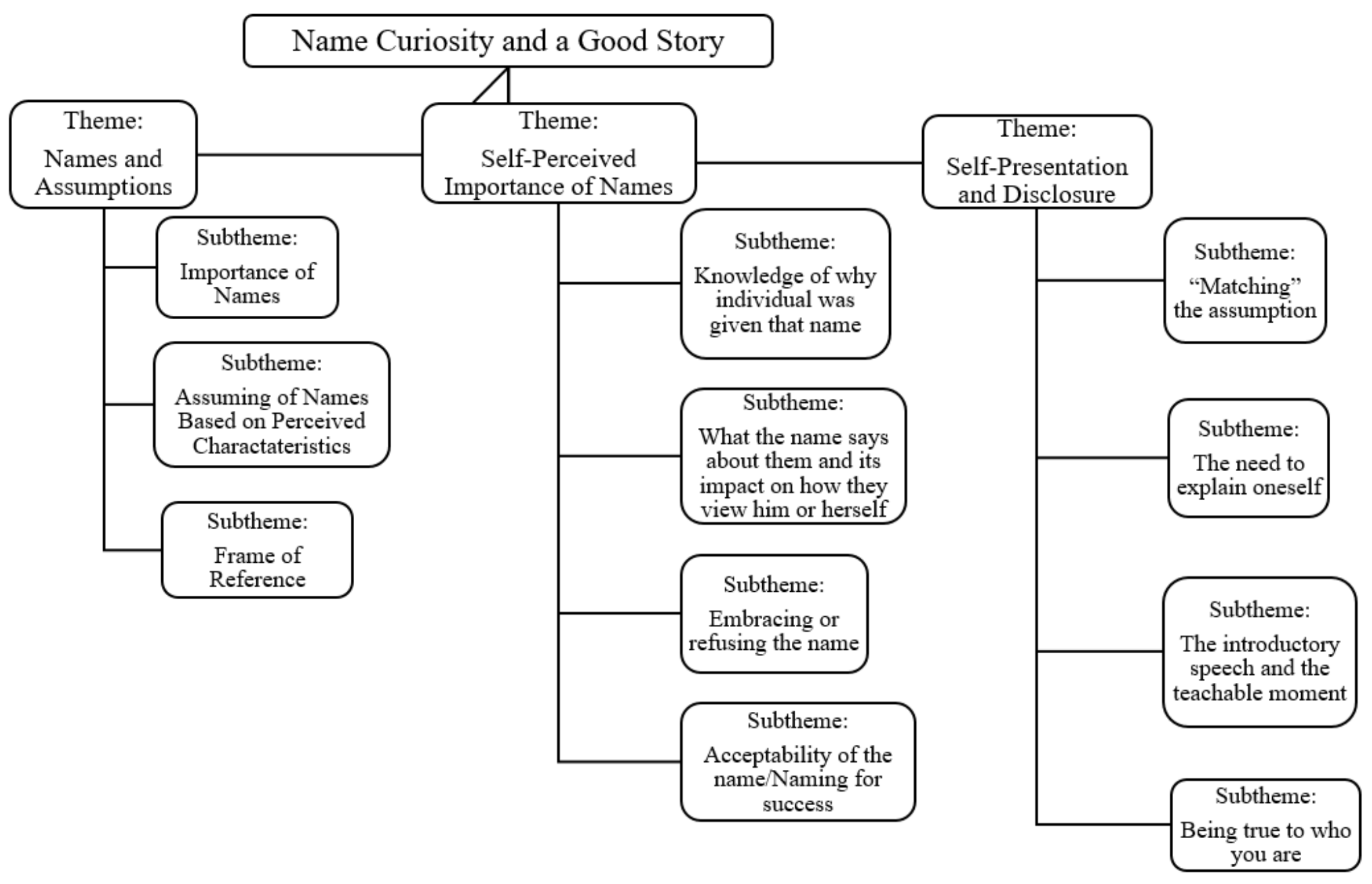




\section{Theme \#1: Names and Assumptions}

\section{Importance of Names and Frame of Reference}

A recurring theme throughout the interviews was the idea of the importance of a person's name. As it relates to the overall question of the importance of names, specifically, "do you think that what a person is named matters or is important?," all but two respondents said "yes." The participants that said, "no," Elizabeth and Jade of Hispanic and Asian ethnicity, respectively, said that names are interesting, but not as important as who the person is as a whole. When participants were asked to expand on their answer, the affirmative answers became more concrete and the "no" became less of a no and more of a maybe. Elizabeth initially responded that unequivocally that names were not important, but later added that she found names "interesting" and is, "sometimes curious of why you were names [sic] this such thing." As examples of concrete answers, respondents referred to familial ties and being named after a loved one, as well as the importance of keeping a name provided by parents even if it is not preferred. Other participants discussed the need for a name to mean something to be important. Finally, Haki and Kenyeta discussed the importance of names from a professional standpoint as the main arena where the name carries weight. April and John brought in the perspective of the name and how it shapes the identity of the name holder.

"First, primarily what jumps at me is how others will treat you based on your name and their perception of that name, or whatever feeling they have of that name, or their prior experiences. They might treat you a certain way because of that. Secondly, there's no academic studies that I'm going to cite here, but, I have read or heard that depending on the name you have growing up you build certain expectations or emotions tied to that name in terms of the way you'll perform or what you're gonna [sic], I guess live up to, in a sense." (John) 
Ethnicities, Name Association, and Assumptions

The overarching consensus among participants was that names could suggest ethnicity; however, it is the person's frame of reference that points them in one direction over another.

"I think that's something depending on the culture that you're talking about or depending on who, it's like beauty is in the eyes of the beholder. So depending on who's viewing that name, they're going to make a particular impression based on what they're used to...Yeah, definitely, your name is your identifier, both ethnically and to a certain extent, it makes other statements about who you are... When I send out that resume the first thing they see is my name, so even if you try to eliminate internal biases and what have you, human nature is going to give you an impression about something that you read, something that you see. So you're going to make up an opinion about it." (Haki)

"Yes and no, because like I said, take for example, my name, most people that probably call me assume that I am probably Caucasian. Then when they see me they see that I'm African American. But then again, I've heard hiring managers say that they've gotten resumes of someone with a African American name and just totally assume that is an African American person, and not think that, "Oh, that person might be Caucasian." Like I said, I've experienced it. I have heard stories. Unfortunately, it happens more often than not. They just automatically see the name and just assume that they know that person's ethnicity.” (Heidi)

To better assess the participants' thinking as it relates to names and associated characteristics that could impact self-presentation and social penetration, study participants were asked to provide the first name that comes to mind that they associated with specific ethnicities.

Across the spectrum of participants, Maria was the most commonly mentioned as most closely associated with a Hispanic/Latina female. Jose, Jesus, and Juan were the most often mentioned across all 15 participants when a name for a Hispanic/Latino male was provided. The only participant who did not provide the names Jose, Jesus and Juan was Cory (Caucasian male), who named Pedro, Marcos and Raul. 
The interviewees seemed to have particular difficulty providing names that they most closely associated with Asian persons with only five respondents, three of African ethnicity, one of Hispanic ethnicity and one of Asian ethnicity, able to provide a name (e.g., Kwan, Fong, Liu, Sanjeet and Ming). Respondents who did provide a name that they associated with Asian ethnicity did not differentiate between genders. The names of Caucasian males and females were in abundance with Emily, Becky, Blair, Mary, Sue, Kelly, Amanda, Alicia, David, Richard, William, Bruce, Dylan, Tyler, Jim and Michael being named. Alicia, was a name provided as associated with both Caucasian and Hispanic females with the pronunciation being the method of differentiation (e.g., Hispanic: Ah-lee-sea-ah and Caucasian: Ah-lee-shuh).

Name associations for those of African ethnicity varied by respondent ethnicity, however, respondents reported that names ending in "Sha" and/or beginning with "La" were clear indicators. Specific names provided included LaTonya, Antonique, Jamal, Tamar, Keyon, Leonard, Winston, Tyrone, LaShawn, Mar'Quan, Shaquana, Tanisha, and Keisha. Of particular note are the African names provided by two of the Asian participants, Jia and Jade. They noted Derrick and Jose as names of males of African ethnicity and Kim and Samantha for females. It is difficult to determine if these were actually the names that came to mind or those that felt "safe" to say, as the Asian participants seem to be choosing their words very carefully.

The Mysterious Case of Shanequa and the Influence of the Media

Hillary was the only participant to provide the name Shanequa within the context of name association during the aforementioned exercise. However, a number of participants across the various ethnicities referred to the name Shanequa as their example 
of a quintessential ethnic name and referenced the name when providing responses to other questions. Throughout each interview when the name Shanequa was mentioned, each interviewee was asked if they personally knew someone named Shanequa. All said no, and confirmed that they did not know where they had heard the name. April, however, pinpointed that her knowledge of the name Shanequa comes from a series of Saturday Night Live skits featuring "Queen Shanequa" performed by comedian Ellen Cleghorne in the early 1990s. This concept of frame of reference, then, and specifically aided by portrayals in the media further reinforces the notion that context is important both in how we see ourselves and see each other. A number of participants asserted that their frame of reference when it comes to certain types of names had been influenced by media stories and portrayals. Even among those within each specific ethnic group who knew firsthand that media portrayals can take some creative license, participants still referenced the media accounts as a factor in their opinions about how they view themselves.

"I think it (frame of reference) plays little. But again, I think it's the context. Sometimes if you don't have a frame of reference, then that's how people are going to - people fear what they don't know. So instead of taking a chance on them it is like, okay, well you know what? Maybe-I'm not even going to go there because what you've seen, maybe in the media or those different images may have tainted your opinion or whatever. But again, if you haven't had that direct experience, you're just going to be assuming in terms of something that you've heard." (Hillary)

\section{Theme \#2: Self-Perceived Importance of Names}

\section{Names and Origins}

The emphasis placed by each interviewee on knowing the origins of their name and knowing the meaning brought forth an interesting understanding of how they 
attached their names and that knowledge to their identity, and in some cases, to their place in their family. Some respondents talked about how they felt their name was a perfect fit. Simone and Hillary, in particular, felt that they were perfect representations of their name and had never questioned it. Elizabeth, of Hispanic ethnicity, was named after Queen Elizabeth and Elizabeth Taylor. She believes that her naming was "a combination of the power of the queen, and infatuation with Elizabeth Taylor" on the part of her parents.

El pagnier reflected that she had asked her parents about the origins of her name; she knew what it meant, but she had never asked why she received the name. She admits, however, to disliking the name early in life.

"So what I've been told all my days, [is] my uncle who was a teacher in Georgia, had heard it and he gave it to my parents and they liked it, and they gave it to me. So they didn't have the same concern about what names meant, they just oh, that sounds good...I haven't always liked it because it's, I guess, it's just too much work, 'cause it was just too much correcting it...It was too different for a little girl...And I never complained like, 'Mommy, why did you give me that name?' I never did that, but in my mind I'm like, ughhh, again."

Heidi's parents had two options when it came to her name, choosing between Inga and Heidi, who was a college friend of Heidi's mother. More important than the actual name, however, is the reasoning behind choosing a name so ethnically discordant to Heidi's own. In the discussion, Heidi reflected that she knew the reasoning and had had that conversation with her parents, in particular her father, often.

"My dad has-we've had the discussion about this before. He said that when he and my mom were naming me and my sister, it was important to them...But their thing was they had an understanding of racism and they felt they didn't want anyone to automatically judge us by just hearing our names on paper. They wanted us to be able to go to a job interview because they felt that if given a very ethnic name, your chances are lowered a lot. We have that conversation all the time. He mentions that all the time, that they did that on purpose." 
Hazel, Jia, John and Jade also discussed their naming and the meanings behind their name. John was named after both his father and mother, with his first name coming directly from his father and his middle name a very close derivative of his mother's name. Hazel was named after her grandmother. Jade is not Jade's first name, nor is it the name her grandfather provided, which is Manichahn. Manichahn means "Blessed Monday" in Lao, from where Jade's family hails in Laos. Jade chooses to go by Jade, her middle name, almost exclusively and reflected that had she a choice, she would switch her names making Jade her first name and Manichahn her middle name. Her use of Jade stems both from the ease others have in its pronunciation, but also because she likes the name better. Jade believes that her name signifies her dual identities of Laotian and American.

Jia, who is of Asian ethnicity, and specifically Chinese, brought in the perspective of Western names and Chinese children in the overarching discussion of naming practices within China. In her culture, the name selection is a rigorous process that includes both the name selection, but also the character(s) used to spell out the name as different characters have different meanings and she believes that her name is a perfect example of that cultural awareness.

"... A lot of Chinese names, even if they have the same pronunciation, if you give the name traditionally, they all have different meaning, or different way to interpret it and even those who have been given an English name. When the baby's first born, the first thing they were asked, like from the experts to check the kids' birthday, zodiac, and the five element combination of the kids and then they want to provide characters that come from the world compatible with the five elements so that they have a balance and a well last name for the future." 
Haki was born with a different first name (Germanic in origin) and last name and made a conscious effort to select new names that better fit his identity and his cultural ties. His research led him to the name Haki, which means justice in Swahili. Haki is also the chosen name of Haki R. Madhubuti, a prominent African-American poet, educator and author from whom Haki draws inspiration.

"I went to the library \{Moorland-Spingarn Research Center\} and the librarian there, I told him what I was trying to do, and he helped me. He suggested that I choose a Swahili name, because that's the predominant language of most of the slaves that came to America. So that's most likely something that would represent you and would have been your name had we not come to America, through slavery. He suggested I look into this Swahili book and after some consideration and some dialogue between he and I, I chose the name Haki, and Haki in Swahili means justice...That's really what I'm all about...That's exactly who I am, I'm all about justice. I'm all about integrity..."

In contrast to the other study participants, Haki chose a name that clearly indicates his ethnicity because he wanted it to be known and understood. He wanted those associations and ties to be clear, because he wanted his name to speak for him before he ever said a word or walked into a room. This is the clearest example of the link between naming and identity of the interviewees, possibly because this respondent chose their own name.

\section{Perceived Identity and Naming: What does your name say about you?}

Each participant reflected for a longer time when they had to consider what they thought their name said to others. Elizabeth, April, Cory, Hazel, Simone, John, Heidi and Hillary quickly asserted that the main assumption would be that they were of Caucasian ethnicity, which could be both an advantage and a disadvantage. An advantage in that in society, it may be perceived that this person is a better candidate professionally and may get them a foot in the door. The perceived disadvantage then, particularly for Elizabeth, 
John, Heidi and Hillary, however, is that by being assumed to be of Caucasian ethnicity, they may not be considered for opportunities where diversity is desired.

El pagnier, Haki and Kenyeta acknowledged that they would likely be assumed to be of African ethnicity, however, El pagnier pointed out that people assume that she is male based on her name, which may serve as an advantage.

In looking at their names as whole, Jia, Jade, and Nicole reflected that they would likely be assumed to be of Asian ethnicity, but it was unlikely that the correct country of origin would be identified.

Finally, Mercedes asserted that her name was more likely to be assumed and associated with Hispanic ethnicity, however, she reported that she uses that to her advantage.

"My first name is Mercedes, my middle name is Maria. I play it up on my resume, I don't go by it, but on my resume I have my full government name. Because I understand the market I'm in. And I also understand that employers will look at it and say, 'Okay she speaks two languages.'...But putting that out there, overHispanicizing as it were, helps me."

\section{Acceptability of Names and Naming for Success}

Across the respondents, there was this concept that within society some names can be considered unacceptable. That unacceptability could be based on social constructs, but also the assumed characteristics of that persona and where they could go in life with that name. Each interviewee lamented the possible discrimination that could result but acknowledged that it could happen and likely has happened. When discussing the naming of possible progeny, each reflected that they had considered the possible ramifications, as it were. El pagnier, in particular, asserted that a name had to have meaning, both a literal meaning and a meaning in that person's life and she discussed naming her children with 
that mindset. Simone mentioned the need for a strong name, that has a positive frame of reference but not a name too prevalent within society. She spoke of a naming exercise that she and a friend undertook recently to name a male.

" $\{$ David and George $\}$, they're strong names, in that regard. I think it's a cultural reference perhaps. One of my friends, recently was, we were going over names for her son, and as we sat there, we're just like, 'Does this look like somebody who's going to end up on Wall Street?' When we were looking at his name, that's what we were saying. 'Would they take that name as somebody's who's on Wall Street or maybe a lawyer?'."

This concept of names and the naming exercise is a form of occupational stereotyping in

reverse, where the parent tries to determine the industry and choose a name for the industry where they want their child(ren) to succeed (Lipton et al., 1991).

Jia reflected on names and naming in Chinese society reflecting that having both a Western and a Chinese name is now seen an indication of the dual education of the person and their place in society.

"It's more like the pop culture trend thing, because it's more like global influence, and more and more middle class families will realize the importance of understanding the different culture...like Western culture...And a good way for them to make their children better understand those cultures is to give them, we call it a bi-culture education since they were young...Like bi-culture education system, they usually give their kids a Western or English name so that it's easier for them to pick up the language."

\section{Theme \#3: Self-Presentation and Self-Disclosure}

\section{The Face of Confusion}

Throughout the interviews, respondents discussed the confusion they spotted on others' faces when they met for the first time or when additional details or characteristics were disclosed after the initial meeting. The respondents described the awkward pause, utter confusion, the slightly tilted head and other body language that indicated confusion. That initial public face and the associated disclosure allows the observer to read into the 
interaction what they would like and create their own impression; an impression which can be different then the reality. It becomes clearer, then, that the person who makes an assumption is somewhat befuddled when the name and associated picture formed does not match the reality (e.g., Heidi not being Caucasian, Mercedes being of Hispanic ethnicity and Kenyeta being of African ethnicity).

"The faces I get when people meet me and realize I'm African American, is like...I want to take a photo of it. I want to say, 'Can you hold that face for a second. Let me just take a quick picture.' It's insane actually. It's pretty insane.” (Heidi)

Those of multi-ethnic ethnicity, like Mercedes and Kenyeta, also reported experiencing assumptions, questioning and confusion over their actual versus assumed identities. Mercedes, who is Afro-Latina, discussed the dual identities and group memberships that someone named Mercedes can have, just based on frame of reference, pronunciation, and assumption.

"I think there's more of an appropriation to it. If black people see me, they're like oh Mercedes, Porsche. That's just a name. There's no assumption that you must be Hispanic...Hispanic or Latina people are like, oh you must be Hispanic. Everyone adopts it as their own. Well, not everyone, but those two communities, ironically adopt it as their own."

When existing within a Latin ecosystem that accepts her group membership, her name is pronounced in the traditional Spanish fashion (i.e. Mur-sed-ehs) and the assumption (correctly) is that she is named after Our Lady of Mercy in the Roman Catholic religion. However, for those who assume her group membership to be African ethnicity, Mercedes is pronounced Mer-say-dees (like the car), and she is assumed to be named after the car, or to be using Mercedes as a stage name in her career as an exotic dancer. To be clear, Mercedes is not an exotic dancer, however, this is the frame of reference and name 
association from those who used their own brand of math, put $1+1+2$ together and arrived at five. Mercedes discussed what seems to be a hidden Latina identity, which comes into the conversation only when she self-identifies or someone hears her speaking fluent Spanish. On this Mercedes reflected:

"I think the assumption is more for the black than the Hispanic even in the Hispanic community...So, I think in the black community they're surprised when there's more to it...typically it'll be something like someone will say something in Spanish and I'll respond, or my mom will call me in the presence of someone, and I will talk to her in Spanish. When I hang up, the look on someone's face is...If I started speaking Mandarin, it wouldn't have been any more shocking to them."

Kenyeta, who is of mixed African and Hispanic ethnicity, has similar experiences to Mercedes, however, Kenyeta does not speak Spanish and has only recently more readily identified as being of both African and Hispanic ethnicity. Kenyeta has what can be considered a "black" first name and a Hispanic last name and this has led to the assumption, particularly professionally, that she is of Hispanic ethnicity, only, with the associated expectations of language proficiency and cultural affinity. In her interview, Kenyeta described a series of successful telephone job interviews with a company that culminated in a final in-person interview with the same persons from the telephone interview sessions.

"These three people are all a different race from me. And, literally, the first person that walked in... without them even knowing that they did it, they kinda [sic] looked shocked. Body language was like "Whoa, this is not the person that we called'...He asked, 'What's your name", and I said Kenyeta (last name redacted). And he was like, you're, uh, Kenyeta (last name redacted)? And I said, 'yes'. And, the other person didn't say much, but I was pretty much at this point now I'm scanning everyone's body language 'cause they don't want to be disrespectful. They don't want to come off as discriminatory, but I'm scanning body language. I'm really trying to figure out, 'do you even want me here'?" 


\section{Unwanted Curiosity and the Teachable Moment}

More so than any of the other respondents, those of African ethnicity reported being asked to explain their name, including the correct pronunciation and its origins, whether or not the name was stereotypically associated with those of African descent. While the assumption may be that someone named Kenyeta, El pagnier, or Haki would be questioned due to the perceived "unusualness" of their name within society, Heidi also talked about the questions she has faced about her name.

From this, a subtheme that emerged was this concept of the introductory speech and the teachable moment. A number of respondents reported having a speech that they use when meeting new people and the subject of their name is brought up. Nicole, John, Heidi, Haki, and El pagnier, in particular, saw the conversation as an opportunity to teach and inform, helping others to be more culturally competent. They have each decided what face they want to put forward, through the carefully chosen disclosure of personal information regarding their name, its meaning and origins. This is done both to expedite the name discussion, but also to satisfy curiosity and further the interaction. John and Nicole, named after their parents, simply indicate the parental origins of their name. Nicole, however, does not mention that she also has a Chinese name and a Taiwanese name. Heidi's name is assumed to be from either the movie of the same name or from the infamous madam Heidi Fleiss. These questions typically occur more often in social settings with Heidi providing her speech.

"I usually just explain how I was named and that a friend of my mom's, that they grew up together and she just loved that name and I think people want more explanation than that. I don't really know how to go into it further." 
Heidi's assertion that she didn't really know what else to say about her name, along with other interviewees creation of a narrative brings forth a possible conundrum where if you're going to be named " $\mathrm{X}$ " you need to have a good reason/story as to why and be willing to tell that story reliably and at will. Almost as if there is an emphasis on the legitimacy of the name because of the story and through that the legitimizing of the person.

Haki's experience is somewhat different largely because, as he reported, he has often worked and socialized among those of African ethnicity, be it American, West Indian, etc. As Haki's name is the Swahili word for justice and also has meaning in Arabic (as Hakim, it means wise), he is often questioned as to his understanding of his name and his embodiment of its meaning as well as the pronunciation. Haki choose his first and last name and is comfortable with the questions about his name and enjoys the ability to teach and share. For those who are not familiar with the origins of the name Haki and the correct pronunciation, he utilizes his standard, "It's Hakim without the m."

" $90 \%$ of the time I'm explaining something. Not necessarily be it pronunciation or... what does it mean. So, I've giving something based on the name. It's not always pronunciation...the bank teller experience, she was from Senegal, but she spoke Swahili. So immediately she was like, 'Do you know what your name means?' Like yeah, of course, I know."

El pagnier's experience with self-presentation and her name began in elementary school when she would provide her name phonetically on her school work when asked to, to ease other's ability to pronounce her name and identify her correctly. As an adult, El pagnier discussed her experience with her name both personally and professionally. Because El pagnier is a derivative of De pagnier, there is also the assumption that she 
speaks French and in South Florida, that also sometimes includes the assumption that she is from Haiti. El pagnier stated that about $98 \%$ of the time she is asked about and explains her name in both professional and social settings. Until the discussion, she was not aware that she possessed a standard speech for response to the inquiry. Although El pagnier has often been asked about her name, she believes that the questions are largely innocent because "people don't know what they don't know" and they wish to better understand. In this respect, she largely enjoys the ensuing conversation and the opportunity to enlighten. In situations where she does not want to have to explain, El pagnier either her middle name or the initials for her first and middle name. In her speech, she weaves both the tale of her name but also a bit of her personality.

"'Wow, that's a different name, what does it mean?' 'I knew you were going to ask me that...the correct pronunciation is De pagnier (day pon-ya), and day means the and pagnier is a basket of bread or fruit, and I don't like to consider myself a basket case, I'm a centerpiece.' I always say that. [I add] It's De pagnier but my father changed the prefix to El. It's French, and that the only French I speak'."

Although Kenyeta's name is a derivation of Kenyatta (a nod to Jomo Kenyatta, the first indigenous Prime Minister of Kenya and President of the decolonized Republic of Kenya), Kenyeta discussed that she does not enjoy being questioned about her name; particularly when the inquiry is prefaced by comments regarding the "uniqueness" of the name. To avoid the discussion entirely, Kenyeta goes by her last name, even going so far as to introduce herself as such. This is a practice that she has undertaken since the first grade.

"But I don't go by my first name not because I don't like it. I don't go by my first name because I' $m$ tired of always correcting people... But, another reason why I stop going by my first name was because every time I correct someone, after we go through the whole phase of 'It's-no, it's Ken-ye-ta', someone always asks, 
'What is that? That's so different, that's unique'...And I don't know how to explain it and people are like, 'Oh that's so different and so unique." I never understood what unique and different meant when they said it to me. What were your definitions of unique and different? Is that, you know, ethnic? Is it just a name that's really different? Is it something that like, 'Oh, I've never heard of that before'. I don't know. And for me, it made me uncomfortable so I honestly would just tell people (last name redacted). Like James Bond, when he's like, "Bond. James Bond...Let's just, we'll just go with (last name redacted). And it stuck with me."

\section{Side A or Side B: "Professional" Presentation in Employment}

Although none of the study participants reported that they engaged or had engaged in using a different name on a resume or employment application, some knew others that had. The opinion of the practice in terms of self-presentation and selfdisclosure, however, was largely that people should do what they feel is needed to get their foot in the door. As a person with duties that include reviewing resumes, Simone reflected that she knows of those who use a different name but, she prefers to view resumes with no names included and she recommends that this be a practice more heavily taught and adopted.

Mercedes expressed a divergent opinion, based both on her professional experience and her personal practice. When working in a previous position, she met with students frequently who wanted to know if they should abbreviate or change their names on their resume for fear of discrimination due to names that they felt were too "ethnically revealing." The students wanted to know what a person would think when they saw their name and if it would lessen their opportunities as a result. Mercedes did not personally advocate the use of a different name and she advised the students to think about it in terms of their values and the values of the company. 
"My biggest thing was what kind of environment do you want to work in? So if an organization would make a judgment based on your name and decide not to hire you on that, is that somewhere where you want to work? How important is it to your own identity? Is it a big piece of your identity? Don't "normalize" it just to fit in somewhere that you don't fit in. At the end of the day, I would leave it to them to make a judgment on their own value systems and what was important to them."

Hillary, like Mercedes, does not advocate using a different name, but frames it as

a possible disconnect with family and who they are on the inside.

“They are just not happy. They haven't been able to look outside of themselves and just understand that this is the name that their parents thought was going to be precious and bestowed it unto them and for them to go forth and conquer the world..."I believe that names do make a person. However, people can decide whether or not they want to embody those characteristics or be something different in spite of. They know that they have this name. They're knowledgeable that this is something that could actually typecast them for being this type of person and then consciously make an effort to go above and beyond to say, 'okay, well let me prove this person wrong.' 'Cause I know when they see my name on this application, they're gonna [sic] assume I'm just this type of person."

\section{Discussion}

By exploring the data inductively, this phenomenological research revealed significant responses to the research question, "How do persons with ethnically identifying names manage self-presentation and self-disclosure in the context of job seeking and new interpersonal, social interactions?" as well as the secondary questions. One overarching concept, three themes and eleven subthemes emerged (see Figure 1). The overarching theme revolved around this concept of names being an item of curiosity and the need for a good story that explains the name and makes it more acceptable. Participants were largely in agreement that names were important, particularly in terms of how a person is viewed, however interviewees displayed opinions steeped in stereotypes when thinking of names they felt were ethnically identifying, how that person might be 
seen and how they should/could manage their self-presentation. Second, participants demonstrated a heightened sense of awareness of their name, its origins, and meanings in the construct of their identity and how their name could and has shaped their experiences, both professional and socially. Finally, some of the interviewees demonstrated a, largely subconscious, configuring and reconfiguring of their name narrative when discussing presenting themselves to new people. With the "speech" and the way that it was discussed, it felt almost as if the respondents thought that they needed a good story to make an "unusual" name and, through association, themselves acceptable.

The concepts, themes and subthemes that emerged largely supported previous research as well as the conceptual framework of stereotyping, microaggressions, model minorities, and the referenced theories: social identity, self-presentation and social penetration. Furthermore, previous research findings were extended through this research, which also filled in research gaps left by previous studies.

\section{Implications for Theory, Research and Practice}

\section{Theory}

What was most often described by interview participants may be best identified as stereotyping and microaggressions (Lippmann, 1922; Pierce, 1970; Pierce, Carew, Pierce-Gonzalez, \& Willis, 1978). Although the participants did not use the language “microaggressions," many including Mercedes, Kenyeta, John, and Heidi described that

moment of awkward silence as the person confronted with the reality comes to terms with their assumptions (Fiske \& Taylor, 1991; Lipton et al., 1991; Pierce, 1970; Pierce et al., 1978). This concept was repeated among the African, Asian, Latino and multi-ethnic 
participants, lending support to the concept of microaggressions more widely impacting minorities. Additionally, these specific participants exhibited an expectation that they would be judged differently and seemed to expect the microaggressions to play out and be responded to before the interaction could move forward. For some of the participants like John, El pagnier, Heidi, Hazel, and Haki, the meanings behind their names, the circumstances of the bestowal and the impact of their name on their identity overcome most negative thoughts and potential positive or negative stereotypes (Czopp et al., 2015). For others, such as Kenyeta, their name will always open them up to unwanted attention and scrutiny.

Among the interviewees of Asian ethnicity, both Jia and Nicole referenced the specter of the model minority paradigm, and how this type of thinking could both be an advantage and a disadvantage particularly in the technology or communication industries (Wong \& Halgin, 2006). Although the concept of model minorities was introduced many decades prior, the participants of Asian descent described the pressure from others to embody the characteristics expected of them. Specifically, Nicole discussed being very Americanized, which she uses to explain why she is not more "Asian" when questioned.

Participants described a feeling of perceived disconnect between what an observer pre-determined about them and the reality. As previously mentioned, the participants described an awkward pause, utter confusion and a tilted head position as well as other body language that suggested confusion. Throughout the interviews, participants discussed a perceived need for others to figure them out so that they would know how to respond. More specifically, the participants of African descent with names most often 
associated with Caucasian women, described efforts on the part of other to categorize them by race based on their name. With the exception of Mercedes and John, participants did not discuss their individual efforts to achieve a specific group membership. John, a male of Hispanic ethnicity, discussed the notion of being a "chameleon" wherein he is John with the assumed characteristics of someone with that name (associated largely with those of Caucasians) when the occasion calls for it and a more laid-back version of himself when interacting with those within his identified social membership (Hispanic). However, John's characterization of himself as a chameleon able to move between the Caucasian and Latino worlds that he inhabits and Mercedes assertion that she plays up her Latina heritage, link back to Tajfel and Turner's (1979) positing that individuals seek to align themselves with the group with the most desirable characteristics based on their individual needs. In addition, this assuming and/or or "playing up" of characteristics also links back to Goffman's (1959) concept of the public face and the associated performance to convince observers, in this case Latino observers, that they belong.

Self-presentation and disclosure (Allman \& Taylor, 1973; Goffman, 1959), and its associated goals of progressive social penetration were viewed differently by Mercedes and Hillary, multi-ethnic and African ethnicity females, respectively. Both Mercedes and Hillary's viewpoint of the subject stemmed from the position of the individual's values and the perceived values of the potential place of employment. Hillary's point of view may be shaded by her stated lack of experience in having to consider the potential negative ramifications of her name and ways to mitigate negative outcomes. By virtue of being named Hillary, she may have been able to bypass much of the questions and 
confusion experienced by Kenyeta or El pagnier. Conversely, Mercedes through her embracing of her Latin roots and its associated group membership, may also be able to largely avoid any negative repercussions simply by virtue of her physical location (Tajfel \& Turner, 1979, 1986).

Self-disclosure as a means of moving the interaction forward and telling the inquisitor only the important information was of particular importance for those participants who have created and use prepared speeches to respond to questions about their name. Haki, in particular, discussed the idea that through his name and his explanation of it, he can inform others of his desirable characteristics (e.g., wisdom, justice, self-pride) at the beginning of the interaction while also moving the interaction to its latter stages. Haki's usage of his positive characteristics in response to questions about his name harken back to the concept of social penetration and, more specifically, self-disclosure for the purposes of continued interaction with others (Altman \& Taylor, 1973).

Several respondents were not aware until their interview that they had been performing acts of self-presentation and self-disclosure through the use of a formal narrative to explain their name. On a conscious level, they were aware only that they had been asked questions about their name so often that they wanted to present the information in a manner that was quick but not off-putting, thereby preserving the interaction (Allman \& Taylor, 1973). El pagnier, Haki, John and Heidi referenced what they came to realize were their introductory speeches to be brought out when their names were brought up. For El pagnier, Haki, John and Heidi, their individual speeches hit the high points of the topic (e.g., origin, meaning, pronunciation), but also attempted to put 
the inquirer at ease and move the conversation forward. While the respondents did not feel that this was particularly stressful, when looking at their interviews as a whole, a larger picture forms about their overarching identity and its reduction down to the sum of its parts, through feeling a need to provide an explanation of who they are that others may not experience.

\section{Research}

Prior to the conducting of this research, concepts of the effects of naming were largely informed through quantitative empirical studies including resume manipulation and focused primarily on names indicating applicants of African or Caucasian ethnicity (e.g., Bertrand \& Mullainathan, 2004; Jacquemet \& Yannelis, 2012; Kang, DeCelles, Tilcsik \& Jun, 2016). Overall, the findings of this study supported the prior qualitative research on behaviors of minorities related to self-presentation and self-disclosure when applying for a job (Kang et al., 2016). More specifically, these findings are similar to that of Kang et al., (2016) who sought to understand the behaviors and opinions associated with resume whitening among Black and Asian students. Unlike the aforementioned study, which found that $36 \%$ of the respondents engaged in whitening their resume, none of the interviewees in the present study claimed to have participated in these behaviors for the purposes of concealing their ethnicity. However, respondents across the range of ethnicities in the present study felt that the likelihood of discrimination partly based on an applicant's name, particularly for professional opportunities, warranted the practice, even if they themselves did not feel a personal need to do so. This heightened awareness of the participants' need to present themselves in a manner deemed acceptable within society, manifests itself in the knowledge and understanding of their individual names as well as 
what people may assume about their suitability for certain types of employment in reference to their name (Lipton, O'Connor, Terry, \& Bellamy, 1991).

Respondents described being stereotyped as well as experiencing microaggressions related to questions about their country of origin, the meaning of their name and the expectations that they would have a good story, have the ability to speak Spanish, be good at math, have the ability to speak French or be a practicing Muslim. These experiences provide strong support for the concepts of positive and negative stereotyping put forth by Lippmann (1922); Pierce (1970); Pierce, Carew, PierceGonzalez, \& Willis (1978).

Respondents including John, Kenyeta and Heidi talked about hearing stories of studies conducted like Bertrand and Mullainathan's (2004) quantitative research on the effect of names on the hiring process, as well as anecdotal and personal stories of perceived discrimination based on names, which informed their beliefs that names do matter; if only as a topic of interest. Interestingly, through the individual discussions, it became clear that each participant was aware that they are more than their name. They are aware of their personality traits and individual characteristics as well as strengths and weaknesses. Nonetheless, the interviewees still felt that the name was important, even going so far as to consider the possible advantages and disadvantages and how the name can be worked to their advantage. Much like the participants in the qualitative portion of the Kang et al. (2016) study, with the exception of Cory, April, Hazel and Hillary, the participants exhibited an expectation of a challenge regarding their name to be overcome. 
By building upon the assumptions put forth by Bertand and Mullainathan (2004) and Kang et al. (2016), this study fills a gap in the research by providing perspectives heretofore not heard (e.g., the perspectives and experiences from people who have ethnically identifying names in their own words using their actual names) and allowing those without ethnically identifying names to better understand and assist with navigating professional and social interactions.

\section{Practice}

When considering the diverse nature of the United States population (United States Census Bureau, 2010), it becomes important to further engage in research to obtain a clearer understanding of the perspectives of a wider swath of the population. By utilizing the research to create and implement learning activities and trainings, employee development, particularly for employees involved in recruitment and selection can be enhanced. Furthermore, it is important to note, that it is not just the appearance or assumption of overt bias that must be trained out of the process. It is also the perceived marginalization surrounding an applicant's identity that can be manifested through facial expressions, questioning of the applicant's or employees name, the emphasis placed on pushing or adopting an "easier" name and other behaviors that can lead to feelings of being an outsider or anomaly. Trainings on microaggressions and stereotyping (both positive and negative) would be useful to bring to light these subconscious behaviors which may affect professional and social interactions and provide strategies to counteract them. A starting point for HRD professionals, then is to begin understanding the 
experiences and opinions of those with ethnically identifying names. By and large, participants felt they had been evaluated and pre-judged based on the impressions formed by their name particularly, within the professional arena. Therefore, it is important for HRD professionals to understand the implications of these beliefs and work to mitigate against them both inside and outside of their organization.

\section{Strengths and Limitations of the Study}

The strengths of this study drew upon the measures undertaken to ensure the integrity of the data. At the outset, I worked to suspend my opinions and judgments to focus on analysis of the experiences of the participants by seeking first to understand my areas of subjectivity. One method was to keep a researcher journal whereby I noted items that particularly caught my attention. In this journal, I also wrote out and worked through assumptions that I may have expected going into the interviews to ensure that my interview questions were not leading or alluding to any of the assumptions I may have held. I included rich, detailed descriptions and passages from the participants in their own words to guide and support conclusions to ensure that they were based solely on the data provided. I kept field notes that allowed me to make note of actions, word choice or other indications of strong feelings or emotions, or a lack thereof on the part of the interviewees. In conducting my analysis, I drew heavily upon the conceptual framework to put into perspective the words of the participants to create a larger framework of their experiences, opinions and behaviors.

One of the limitations of this study was related to the make-up of the group interviewed. While there was an effort to have representatives from different ethnicities, 
ages and educational levels, there were factors, specifically related to ethnicity and education, which could affect the data. All participants had achieved a minimum of a Bachelor's degree, and a number of participants had earned a doctoral degree. It is possible, and likely, that these additional levels of educational achievement will have influenced their perceived and actual employability as well as their opinions related to self-presentation and self-disclosure. Additionally, among the Asian participants, there was no distinction made between an Asian participant from China and an Asian participant from Thailand. Undoubtedly, even with shared cultural ties, there would be cultural differences that would influence opinions and experiences related to names and self-presentation. In future research, homogeneity among participants, would create even stronger research to hone more closely in on the naming phenomenon.

A general limitation of any first-person research on naming, ethnicity and race will include very personal and sensitive topics. A person's experiences and perspectives will be psychologically driven and delving into that level will require that participants attempt to understand and acknowledge factors that they might not have considered or understand all that well. The experience of a participant of Caucasian or Asian descent may be much different from a participant of Spanish or African descent. While there will likely be common themes, there is an expectation of divergent themes, as well. Convenience sampling may create a homogenous group when none is intended, particularly in terms of educational level and this can affect the effect of the phenomenon being studied. These limitations will have to be guarded against to create the strongest data in future research. 


\section{Recommendations for Future Research}

To further study the naming phenomenon, there are a number of avenues that could be traversed. Throughout the study, participants discussed frame of reference and how they formed their opinions and their expectations of who is a Maria, Jose, Juan, DeKesha, Sarah, etc. Much of these frames of reference, particularly related to the name Shanequa as a quintessential ethnic name, have come from portrayals in the media. Even though the participants recognized that portrayals could often be drawn-out caricatures, these portrayals still had influence both in how they see themselves and how they chose to and may choose to name their offspring. A quantitative survey study, therefore, could look more closely at the impact of media portrayals focusing on three types: news, satirical and dramatic. These portrayals could be studied for their possible impacts on the behaviors and opinions of minorities and more specifically, minorities with ethnically identifying names (self-identified).

As studies related to impacts of ethnically identifying names on Asian and Latino population are not abundant, separate mixed-methods studies focusing on these populations could provide additional levels of knowledge on the subject of naming particularly related to the adoption of Westernized names for children; both formally and informally. The survey portion of the study could focus upon the opinions and behaviors relates to naming and self-presentation. More specifically, opinions about the giving of traditional names versus westernized names to children, the formal or informal use of Western names in social and professional settings, and behaviors related to resume whitening and other behaviors to obfuscate one's identity. Based on those results, the 
second qualitative portion of the study could focus more heavily on the reasons behind the reported behaviors, and opinions as well as the experiences that inform these behaviors and opinions. This research, while proposed to be initially undertaken in the United States, would lend itself well to replication abroad, specifically selecting Asian and Latino countries with populations that immigrate in large numbers to the United States or other westernized countries. Through this replication, it would be useful to compare the findings to that of the U.S.-based study to determine if opinions and behaviors of names, naming and self-presentation are similar or different.

Within the research, there were participants who considered themselves to be multi-ethnic, which influenced their opinions and viewpoints. Mercedes, who is of Latino and African descent spoke about her dual identities, which heavily influenced decisions and opportunities in her life. Qualitative, phenomenological research, specifically related to the viewpoints of multi-ethnic persons would be a valuable contribution to the research to see how multiple identities provide influence when there is more than one factor to consider in ethnic identity.

The research indicated three main subthemes: naming and assumptions, selfperceived importance of naming and self-presentation and disclosure. It is possible that the person-to-person nature of the interview process might have inadvertently encouraged reticence on the part of some of the participants. Therefore, a quantitative study that looked more closely at the established subthemes anonymously would be an option to address this. More specifically, an experimental study could provide respondents with various scenarios and questions which would elicit their opinions on behaviors related to 
the subthemes as well as their personal behaviors and opinions on their own efforts related to self-presentation and self-disclosure and their experiences and behaviors related to stereotyping, microaggressions, and related topics such as incivility and workplace bullying.

While not studied directly, factors such as organizational commitment, satisfaction and the intention to leave an organization can be linked to the phenomenon of names and naming. Research that more closely studied those ties in terms of the opinions and experiences of employees who may feel that their names or the assumptions about them, their background, abilities, etc., which may be exacerbated by their name is also important. A quantitative study, specifically a survey, could elicit responses useful to better understand these linkages. Furthermore, through inquiring about the perspectives of employees including their opinions about how they are perceived, their expected professional growth within the company and their intention to leave or reason for leaving would be useful information to better inform both $\mathrm{HR}$ as well as HRD practices within the organization.

Finally, name research often compares Black names to other ethnicities, typically the names most often associated with Caucasian persons, when looking at opinions, experiences and predicted life outcomes. It would be useful to compare and contrast the experiences and opinions of black persons with names most associated with Caucasian persons against the experiences and opinions of Black persons with names most often associated with their own ethnicity. At their core, both groups would have the same racial and/or ethnic foundation, however, the issue of self-presentation from the naming 
standpoint could be different. These studies would be best undertaken as separate qualitative studies, utilizing a phenomenological approach with individual interviews and/or focus groups. These two studies could be included under the umbrella of one focus of research, but have similar populations in terms of age, educational level, and current employment. There may also need to be some differentiation between the those of African descent with West Indian familial/cultural ties and those of African descent within the United States without West Indian familial/cultural ties as these experiences could also vary.

\section{Conclusions}

A main benefit of this study is that it lends itself to a larger conversation both for professionals in the HRD community as well as within and throughout society. The inclusion of actual interviewee names shows how the experience differs for those, who on paper, may be considered to be mostly equal in terms of age, education level, gender, and ethnicity (e.g. Heidi, Kenyeta and Hillary). Through the inclusion of actual names and the phenomenological approach of qualitative study, the study was able to both illuminate the experiences and opinions of the participants across various ethnicities, ages, and educational levels.

From a larger standpoint, the overall takeaway from this research is that names and naming matters. Names and naming matters because race, ethnicity and nationality matter. Names and naming also matter in terms of the name recipient's internal and external loci of identity, how they are viewed by others, and how they choose to be seen. Additionally, the name matters when the recipient constructs their resume, and applies for 
a job, as well as when that application or resume is reviewed. From the research, it is clear that applicants believe strongly that they will be judged on their suitability for employment based partly on their name and they actively work to present the best version of themselves to work around what they view as a possible hindrance to their success. The participants described experiencing stereotyping and microaggressions related to their name which influenced how they introduce themselves and how they self-disclose when interacting with others. Furthermore, participants described feeling a need to explain themselves. While some participants decided to handle the situation as a teachable moment with aplomb, others described a feeling of bitterness and distress when asked about their name. These nuances, teased out through this research, can be used to better understand interactions in organizations and inform recruitment practices including applicant review and interviewing. Once inside the organization, these insights can also better inform and direct every day interactions as simple as introductions which, if handled incorrectly, could negatively impact organizational behavior and the overall culture of the organization.

\section{References}

Altman, I. \& Taylor, D. (1973). Social penetration: The development of interpersonal relationships. New York: Holt, Rinehart and Winston, Inc.

Bogdan, R., \& Biklen, S. (2007). Qualitative research for education: An introduction to theory and practice (5th ed.). New York: Pearson Education, Inc.

Creswell, J. (2013). Qualitative inquiry and research design: Choosing among five perspectives $\left(3^{\text {rd }}\right.$ ed.). Thousand Oaks, CA: Sage

Czopp, A. (2008). When is a compliment not a compliment? Evaluating expressions of positive stereotypes. Journal of Social Psychology, 44, 412-420.

Czopp, A., Kay, A., \& Cheryan, S. (2015). Positive stereotypes are pervasive and 
powerful. Perspectives on Psychological Science, 10, 451-463.

Forest-Bank, S. \& Jenson, J. (2015). Difference in the experiences of racial and ethnic microaggression among Asian, Latino/Hispanic, Black, and White young adults, The Journal of Sociology and Welfare, 42, 141-161.

Fryer, J. R., \& Levitt, S. D. (2004). The causes and consequences of distinctly black names. The Quarterly Journal of Economics, 119, 767-805.

Gaertner, S. \& McLaughlin, J. (1983). Racial stereotypes: Associations and ascriptions of positive and negative characteristics. Social Psychology Quarterly, 46, 23-30.

Goffman, E. (1959). Presentation of self in everyday life. Garden City, NY: Doubleday.

Kay, A., Day, M., Zanna, M., \& Nussbaum, A. (2013). The insidious (and ironic) effects of positive stereotypes. Journal of Experimental Social Psychology, 49, 287-291.

King, E., Madera, J., Hebl, M., Knight, J., \& Mendoza, S. (2006). What's in a name? A Multiracial investigation of the role of occupational stereotypes in selection decisions. Journal of Applied Social Psychology, 36, 1145-1159.

Lippman, W. (1922). Public opinion. Long Island, NY: Harcourt, Brace and Company.

Lipton, J.P., O'Connor, M., Terry, C., \& Bellamy, E. (1991). Neutral job titles and occupational stereotypes: When legal and psychological realities conflict. Journal of Psychology, 125, 129-151.

Maddux, W. W., Galinsky, A. D., Cuddy, A. J., \& Polifroni, M. (2008). When being a model minority is good... and bad: Realistic threat explains negativity toward

Asian Americans. Personality and Social Psychology Bulletin, 34, 74-89.

Moustakas, C. (1994). Phenomenological research methods. Thousand Oaks, CA: Sage.

Moya, P. M. L., and H. R. Markus. 2010. "Doing Race: An introduction.” In Doing Race: 21 Essays for the 21st Century, edited by H. R. Markus and P. M. L. Moya, 1102. New York: W. W. Norton and Company.

Onwuegbuzie, A. J., \& Leech, N. L. (2007). Sampling designs in qualitative research: Making the sampling process more public. The Qualitative Report, 12, 238-254.

Ortlipp, M. (2008). Keeping and using reflective journals in the qualitative research process. The Qualitative Report, 13, 695-705.

Phelan, J. C., Link, B. G., \& Dovidio, J. F. (2008). Stigma and prejudice: one animal or 
two? Social Science \& Medicine, 67, 358-367.

Pierce, C. (1970). Offensive mechanisms. In F. Barbour (Ed.), The Black seventies (pp. 265-282). Boston, MA: Porter Sargent.

Pierce, C., Carew, J., Pierce-Gonzalez, D., \& Willis, D. (1978). An experiment in racism: TV commercials. In C. Pierce (Ed.), Television and education (pp. 62-88). Beverly Hills, CA: Sage.

Rubin, H.J., \& Rubin. I.S. (2012). Qualitative interviewing: The art of hearing data (3rd ed.). Thousand Oaks, CA: Sage.

Siy, J., \& Cheryan, S. (2013). When compliments fail to flatter: American individualism and responses to positive stereotypes. Journal of Personality and Social Psychology, 104, 87-102.

Tajfel, H., \& Turner, J. (1979). An integrative theory of intergroup conflict. In W. G. Austin \& S. Worchel (Eds.), The social psychology of intergroup relations (pp. 33-48). Monterey, CA: Brooks/Cole.

Tajfel, H., \& Turner, J. C. (1986). The social identity theory of intergroup behavior. In S. Worchel \& W. G. Austin (Eds.), The psychology of intergroup relations (pp. 724). Chicago: Nelson Hall.

Van Manen, M. (1990). Researching lived experience: Human science for an action sensitive pedagogy. New York: State University of New York Press.

Vohs, K., Baumeister, R. \& Ciarocco, N. (2005). Self-regulation and self-presentation: Regulatory resource depletion impairs impression management and effortful selfpresentation depletes regulatory resources. Journal of Personality and Social Psychology, 88, 632-657

Wong, F. \& Halgin, R. (2006). The "Model Minority": Bane or Blessing for Asian Americans? Journal of Multicultural Counseling and Development, 34, 38-49.

Young, R. K., Kennedy, A., Newhouse, A., Browne, P \& Thiessen, D. (1993). The effects of names on perception of intelligence, popularity and competence. Journal of Applied Social Psychology, 23, 1770-1788. 


\section{CHAPTER IV}

\section{CONCLUSIONS}

This concluding chapter is divided into four parts. Summaries of Study \#1 and Study \#2, respectively, will comprise the first two sections. The third section will discuss the findings of the two studies in relation to the overarching purpose for this collected papers dissertation. The final section is a discussion of the overarching theoretical, practical and research implications of the collected papers dissertation.

\section{Summary of Study \#1}

The purpose of the study was to examine the literature related to names and selfpresentation in Human Resource Development (HRD), discover if there were gaps, and recommend research that can work towards filling those gaps. Self-presentation theory, which asserts that people display their best face through a performance to influence observers that they possess desirable characteristics, guided this study and the analysis of the research (Goffman, 1959).

PsycINFO and Business Source Complete databases were utilized to gather the studies. The search parameters included combining "names" with the following individual terms: "self-presentation," "human resources," "workplace," “employment", and "employee." All publications were peer-reviewed and published within the United States and Canada. No time delimitation of study publication was set. The search yielded 1,572 articles and additional review lowered that number to 10 . Only one article was found that referenced or included human resource development. The final selection of 
articles came from a number of disciplines including: Business/Human Resources, Economics, Interdisciplinary Studies and Psychology. Economics with four articles and Psychology with three articles were the academic fields with the largest number of contributions to the research on this subject. Four categories of research emerged: resume whitening and self-presentation, names and perceived employability, names, other mitigating factors and perceived employability and reactions to names and perceived suitability for employment.

Within the literature reviewed, there is only one article within HRD and it is from 1991. It is likely that HRD professionals are aware of the concerns related to names, employment and bias or discrimination. However, it is possible that the assumption is that these issues are addressed through policies, both within the organization as well as federal mandates, which could lead to a lack of attention to underlying causes and opportunities for study and improved practice.

Overall, the research on names and self-presentation is centered on the concept of suitability for employment, specifically the suitability indicated by an applicant's name (Bertrand \& Mullainathan, 2004; Jaquemet \& Yannelis, 2012; Kang, DeCelles, Tilcsik \& Jun, 2016; Oreopoulos, 2011). Included research also studied suitability for employment, but in the context of names and other factors including accent, facial features, employment history, gender, likeability, and race (Bendick, Jackson, Reinoso \& Hodges, 1991; Cotton, O’Neill \& Griffin, 2008; Darolia, Koedel, Martotell, Wilson \& Perez-Arce, 2016; Segrest Purkiss, Perrewe, Gillespie, Mayes \& Ferris, 2006; Smith, Tabak, Showail, Parks \& Kleist, 2005; Watson, Appiah \& Thornton, 2011). 
The literature indicated that applicants with names that are more unique are lower in likeability, which can negatively impact the perception of the applicant's suitability for employment (Cotton et al,, 2008). A number of studies have tested and found evidence to support the theory that applicants with names that indicate African ethnicity will experience more difficulty in progressing through the employment process with a lower rate of being selected for interviews (Bertrand \& Mullainathan, 2004; Kang et al., 2016). Another study indicated that potential bias due to names is not limited to Black applicants, but all ethnic minorities regardless of race (Jacquemet \& Yannelis, 2012). Additional research showed that accents have a negative impact on the concept of suitability for employment when paired with ethnic names, and applicants with foreign backgrounds will have more difficulty finding employment even when they have been living in the desired country of employment for a length of time (Bendick et al., 1991; Darolia et al., 2016; Oreopoulos, 2011; Segrest Purkiss, et al., 2006). Gender was also introduced as factor in addition to names, specifically how a name could indicate gender and how that would influence a hiring manager's opinion when the applicant has a sporadic employment history. The findings of the study showed that female applicants fared better than male applicants when gaps in employments history were present (Smith, et al., 2005). Finally, applicants with names that suggest African ethnicity will be less favored for public-facing positions (Watson, Appiah \& Thornton, 2011).

\section{Summary of Study \#2}

The purpose of this phenomenological study was to explore the perspectives and experiences related to self-presentation and social penetration in social and professional settings for persons with ethnically identifying names. This study was guided by the 
primary research question: How do persons with ethnically identifying names manage self-presentation and self-disclosure in the context of job seeking and new interpersonal, social interactions?

A conceptual framework including concepts of ethnicity, stereotyping, model minority, microaggressions and marginalized identities as well as social identity theory (Tajfel \& Turner, 1979: 1986), self-presentation theory (Goffman, 1959; 1963) and social penetration theory (Altman \& Taylor, 1973) guided this study. Social identity theory posits that every person categorizes others and once categorized, seeks to align themselves with the desirable category to the exclusion of others to maintain perceived superiority. Social penetration theory centers around self-disclosure and the concept that a person will determine which details to disclose in initial interactions based on how they wish the relationship to proceed. Self-presentation theory was also used to guide Study \#1. The concepts and theories come together to create a framework to support the study of behaviors, opinions and experiences of participants with ethnically identifying names.

The study was a set of semi-structured interviews with 15 participants ranging in age from 20-50 and from four ethnicities: African, Asian, Caucasian, and Latino/Hispanic. All participants had earned a minimum of a Bachelor's degree. While not a requirement to participate, this is how the sample turned out. Participants were recruited through convenience and snowball sampling. Interviews were an average of 54 minutes and took place either in person or via telephone, when in-person was not an option. Interviewees were initially asked the same set of questions, however, as the discussion progressed additional questions were added when necessary.

The majority of participants felt that names did matter, that people were judged by 
their names, and that they have been judged by their names. They were able to provide assumed names for different ethnicities, but asserted that these were often based on either stereotypes or actual people in their lives. Participants of African ethnicity with names not usually associated with that ethnicity (e.g., Hillary and Heidi) asserted that they have found their names to be helpful in their career progression, but still faced questions as to the origin of their names and surprise when meeting someone for the first time and presenting as someone of African ethnicity. Interviewees of Asian descent (e.g., Jia and Nicole) described frequent mispronunciations and misspelling of their given names and/or adoption of different names when interacting with other outside family and close friends. The findings from participants of African ethnicity who had what would be assumed to an African name (e.g., El pagnier, Haki, Kenyeta), spoke of very different experiences with their names. El pagnier considers her name as an opportunity to inform others and increase their frame of reference when asked. Kenyeta has ceased to use her first name since the first grade and only goes by her last name in almost all situations; both professionally and personally. Haki sees his name as a sense of pride and is quicker to teach others how it is spelled and pronounced, as well as the underlying meanings. Mercedes, Hazel, Simone and John: Latinax, Latina, Multi-ethnic, and Latino, respectively, felt that names could help or hinder, but used their names as an extension of their personality and to play-up attributes (e.g., Hispanic heritage in South Florida). Finally, Cory and April acknowledged that their experience was different from others as their names would be considered mainstream or normal. However, they lamented the societal constructs that create the circumstances where these things matter. Participants varied on the concept of using different names in professional or personal settings to ease 
other's discomfort with their name or to present a more socially desirable picture to others who may be biased. Furthermore, multiple participants discussed the use of a "speech" to use when asked about their name as a way to politely answer the question and end that line of questioning. The overall findings indicated that these issues matter to the applicants and that they maneuver throughout their life with their name as part of their existence, even when it is not overtly discussed.

\section{Findings Related to Overarching Purpose of Collected Papers Dissertation}

The purpose of the collected papers was to explore the perspectives and experiences related to identity, self-presentation, and social penetration in social and professional setting for persons with ethnically identifying names. Specifically, the research sought to understand the perspectives held and any actions taken by the nameholder related to self-presentation and social-penetration strategies including, but not limited to: whitening the resume, use of nicknames and name changes, as well as their perceptions of the quality of their employment opportunities and their initial social interactions when meeting new people, professionally and personally.

The literature review, supported and guided by self-presentation theory (Goffman, 1959), showed that names do matter which coincides with, and is further supported by the qualitative study (Study \#2). Additionally, different types of self-presentation (using a middle name or selecting a name for a resume different from one's own ethnicity) can have a positive effect on employment prospects and how far an applicant proceeds in the employment process (Bertrand \& Mullainathan, 2004; Jaquemet \& Yannelis, 2012; Kang, DeCelles, Tilcsik \& Jun, 2016; Oreopoulos, 2011). Only one study related directly to HRD and utilizing the research to inform HRD practices. Furthermore, only one study 
directly used self-presentation theory to guide their study. However, at its core, each study is using various forms of self-presentation related to names and other factors to improve upon the characteristics that can work against an applicant when applying for a job. The prior research, which was largely quantitative, did not delve directly into the behaviors of applicants. Instead, the research assumed applicant behavior and conducted the studies based on those assumptions. Increased qualitative study with the inclusion of Hispanic, Asian and Arabic and/or Persian populations, as well as additional mixedmethods studies replicating previous experiments, but including Hispanic populations, might fill some of the gaps in the literature and better inform HRD practices.

The findings of Study \#2 delved deeply into the behaviors of participants with ethnically identifying names. This research provided additional insight into behaviors related to self-presentation and social penetration/self-disclosure from the direct perspective of the applicant. Participants do consider how they will present themselves professionally and personally, asserting that professional considerations hold more sway in their self-presentation related to their name. Self-disclosure was of particular importance for those participants who have created and use prepared speeches to respond to questions about their name. Overall, the findings are supported by other research on behaviors of minorities related to self-presentation and self-disclosure when applying for a job (Kang et al., 2016).

\section{Overarching Implications}

Findings in Studies 1 and 2 found that persons with ethnically identifying names do benefit from self-presentation that minimizes characteristics that may work against them. This aligns with self-presentation theory (Goffman, 1959), which asserts that 
people always attempt to present positive, desirable attributes to influence observers that they are similar, and as such, acceptable. In the context of names, when researchers (e.g., Bertrand \& Mullainathan, 2004; Jaquemet \& Yannelis, 2012; Kang et al., 2016; Oreopoulos, 2011) sent out resumes with the same qualifications but a name more closely associated with Caucasian ethnicity, the results indicated that the outcomes were much more favorable then for those with names with ties to African ethnicity. While the research indicates that self-presentation could be at the core of research into the influence of names on employment and potential bias, only one study from the literature review actually utilizes self-presentation theory to guide the research. From both a theoretical and research standpoint, utilizing self-presentation theory to guide future empirical research could open up new avenues of research and knowledge that can influence HRD practices. Self-presentation theory, through its ability to explain the motivations that influence decision-making related to how a person chooses to be seen, can be useful in guiding studies where the goal is to better understand how people will behave. Better understanding behavior and the motivations behind the behaviors can create better policies, more effective training and better dialogue to further evolve HRD practices. While there is important research that has been conducted on names and self-presentation (e.g., Bertrand \& Mullainathan, 2004; Jacquemet \& Yannelis, 2012; Kang et al., 2016; Oreopoulos, 2011), the research tends to follow the methods related to resume creation and responding to job advertisements used by Bertrand \& Mullainathan in 2004. As a seminal study in the field, the hypothesis and results have been replicated by subsequent researchers with close adherence to the established populations used by this initial study.

Finding similar results within different parts of the United States does strengthen a 
study's impact, yet it may lessen its generalizability as population changes take place.

Future research that includes Hispanic, Asian and Arabic and/or Persian populations will strengthen the research and open up new avenues of inquiry.

Study \#2 utilized social identity theory (Tajfel \& Turner, 1977) and social penetration theory (Altman \& Taylor, 1973), in addition to self-presentation theory (Goffman, 1959), and the theories were largely supported by the findings. In finding that participants also engage in the categorizing of others and seek to join the most desirable groups, social identity theory works to explain the behavior in terms of social conditioning. By selecting and manipulating the information to present to others based on the interaction and the desired, the findings also indicate clear support for selfpresentation and social penetration theories and the underlying concept of self-disclosure. Specific to self-presentation and social penetration, the participants discussed the crafting of explanations to questions about their names. They chose specific information to highlight desirable characteristics and tailored what they shared based on the audience and the desired level of interaction.

Taking all of the information into account, then lends itself to the assertion that additional research is needed within the HRD field to better understand the behaviors of internal and external actors within the organization. Internal actors, such as hiring managers, should be more closely studied to determine underlying beliefs or assumptions that may cloud their judgment and make their assessment of potential candidates subconsciously subjective. External actors, like the applicants and those with ethnically identifying names already inside or interacting with those inside the organization, can also contribute important knowledge as to their behaviors related to their self- 
presentation and how it can affect how they work with and interact with others inside the organization.

\section{Emerging Themes for Possible Future Research}

Unexpected themes emerged from the research that could benefit from future study to gain understanding. In Study \#2, often when participants talked about ethnically identifying names, they mentioned names most often stereotypically associated with those of African and Hispanic ethnicities. Participants discussed their frame of reference and the influence of the media on their opinions. Although the participants were aware that media portrayals can be exaggerated, participants still referenced these accounts in the media as factors in their viewpoints about themselves and others. A greater understanding of the impact of the media in self-presentation and identity could provide some insight into any underlying factors at play.

Participants in Study \#2 frequently referenced ethnically identifying names in the context of names most closely aligned with those of African descent. After further discussion, interviewees had a better understanding that Caucasian and Asian ethnicities are in fact ethnicities. Their initial inclination, however, was to focus upon names tied to those of African ethnicity like LaShonda, Keisha, Shanequa, etc., as their frames of reference for those overarching ethnically identifying names that said that this person is blank to them and the rest of the world. Perhaps this is a byproduct of stereotyping in the United States that assets that if a name is unusual, the person must be of African descent. However, a lack of understanding about ethnic ties, and cultural competence could also be behind these assumptions. Additional research into bias, both among different ethnicities as well as within ethnicities, would also provide new knowledge. 


\section{Conclusions}

This research aimed to better inform HRD researchers and practitioners of the important and influence of names and naming, on self-presentation, and self-disclosure for both job applicants as well as employees inside an organization. The research indicated that names are important and they matter both for the applicant, employee and the organization when recruiting new employees and interacting with current employees. Research findings also indicated that stereotyping and microaggressions based on assumptions related to the name and assigned characteristics can be professionally detrimental to those with names that can indicate or reveal ethnicity.

These findings provide a framework to begin additional research on the linkages between names, naming, employment, incivility and workplace bullying while broadening the current research to include understudied Asian and Latino populations. This research also informed the dialogue around what really makes a person employable and the formal and informal standards by which an applicant is judged. Through this information, the dialogue can evolve and be more inclusive which will benefit applicants, employees and employers.

\section{References}

Altman, I. \& Taylor, D. (1973). Social penetration: The development of interpersonal relationships. New York: Holt, Rinehart and Winston, Inc.

Bendick, M., Jackson, C., Reinoso, V., \& Hodges, L. (1991). Discrimination against latino job applicants: A controlled experiment. Human Resource Management, 30, 469-484.

Bertrand, M. \& Mullainathan, S. (2004). Are Emily and Greg more employable than Lakisha and Jamal? A field experiment on labor market discrimination. The American Economic Review. 94, 991-1013. 
Cotton, J., O'Neill, B., \& Griffin, A. (2008). The "name game": Affective and hiring reactions to first names. Journal of Managerial Psychology, 23, 18.39

Darolia, R., Koedel, C., Martorell, P., Wilson, K., \& Perez-Arce, F. (2016). Race and gender effects on employer interest in job applicants: New evidence from a resume field experiment. Applied Economics Letters, 23, 853-856.

Goffman, E. (1959). Presentation of self in everyday life. Garden City, NY: Doubleday.

Goffman, E. (1963). Stigma: Notes on the management of spoiled identity. New York, NY: Simon and Schuster.

Jacquemet, N. \& Yannelis, C. (2012). Indiscriminate discrimination: A correspondence test for ethnic homophily in the Chicago labor market. Labour Economics, 19), 824-832.

Kang, S. K., DeCelles, K. A., Tilcsik, A., \& Jun, S. (2016). Whitened resumes: Race and self- presentation in the labor market. Administrative Science Quarterly, 61, 469502.

Moya, P. M. L., and H. R. Markus. 2010. “Doing Race: An introduction.” In Doing Race: 21 Essays for the 21st Century, edited by H. R. Markus and P. M. L. Moya, 1102. New York: W. W. Norton and Company.

Oreopoulos, P. Why do skilled immigrants struggle in the labor market? A field experiment with thirteen thousand resumes. American Economic Journal: Economic Policy, 3(4), 148-171.

Segrest Purkiss, S. L., Perrewe, P. L., Mayes, B. T., \& Ferris, G. R. (2006). Implicit sources of bias in employment interview judgment and decisions. Organizational Behavior and Human Decision Processes, 101, 152-167.

Smith, F. I., Tabak, F. Showail, S., Parks, J. M., \& Kleist, J. S. (2005). The name game: Employability evaluations of prototypical applicants with stereotypical feminine and masculine first names. Sex Roles: A Journal of Research, 52 (1-2), 63-82.

Tajfel, H., \& Turner, J. (1979). An integrative theory of intergroup conflict. In W. G. Austin \& S. Worchel (Eds.), The social psychology of intergroup relations (pp. 33-48). Monterey, CA: Brooks/Cole.

Tajfel, H., \& Turner, J. C. (1986). The social identity theory of intergroup behavior. In S. Worchel \& W. G. Austin (Eds.), The psychology of intergroup relations (pp. 724). Chicago: Nelson Hall. 
Watson, S. Appiah, O. \& Thornton, C.G. (2011). The effect of name on pre-interview impressions and occupational stereotypes: The case of black sales job applicants. Journal of Applied Psychology, 41, 2405-2420. 


\section{APPENDIX A}

\section{INTERVIEW GUIDE}

\section{OVERARCHING QUESTIONS}

1. Do you think what a person is named matters or is important?

2. Do you think there is such a thing as an ethnically identifying name that can indicate to others that person's race and/or ethnicity without meeting them?

a. If so, can you give me examples of such names and their associated race or ethnicity?

3. Do you think that there are names that are more "acceptable" than others?

\section{NAMES AND NAMING}

1. Tell me your first name.

a. Is this the name you were given at birth?

2. Tell me about the background of your name.

a. Are you named after someone?

b. Is it an ethnic name?

c. Does it have a specific meaning?

3. Has your name ever been mispronounced?

a. In what context?

b. By whom?

c. How do/did you handle it?

4. What is your opinion about your name?

a. Do you like your name?

b. Do you think it fits who you are or who you want to be?

c. If so, why?

d. If not, why not?

5. Have you ever been asked to, or felt the need to, explain your name to someone (outside of this interview)?
a. In what context?
b. To whom?
c. How do/did you handle it?

6. Have your ever been ridiculed because of your name?

a. In what context?

b. By whom?

c. How do/did you handle it?

d. Why do you think you were ridiculed?

7. Do you know of anyone else who has your name?
a. What is their gender?
b. Race?
c. Ethnicity? 
8. If you could permanently change your name, would you?

a. If so, to what and why?

b. If not, why not?

\section{NAMES AND ASSUMED CHARACTERISTICS}

1. What do you think your name says about you, if anything?

2. Do you think people can assume characteristics about you, like your race or ethnicity based on your name?

a. If so, what race and/or ethnicity?

3. Do you think people actually make assumptions about you and your characteristics, such as your race or ethnicity, because of your name?

a. If so, what are some of the assumptions you think people make about you?

4. If you had to assume your race and/or ethnicity from your name, what do you think it would be?

a. Why?

5. Do you think that a person could be discriminated against based, in full or in part, on their name and what others may assume about them?

\section{NAMES, SELF-PRESENTATION AND DISCLOSURE IN PROFESSIONAL SETTINGS}

1. Have you or anyone that you know ever considered using a different name, middle name or nickname on your/their resume or employment application?

a. Why or why not?

2. Have you or anyone that you know actually used a different name, middle name or nickname on your/their resume or employment application?

a. If so, what was the name?

b. Is this still practiced?

c. Do you have any opinions or feelings about the practice?

3. When you meet someone new in a professional setting, how do you introduce yourself?

a. Do you use your entire name?

b. Middle Name?

c. Nickname?

4. Have you ever felt that your name gave you an advantage or put you at a disadvantage professionally?

5. Do you think those with ethnically identifying names experience any additional stressors in professional settings?

NAMES, SELF-PRESENTATION AND DISCLOSURE IN SOCIAL SETTINGS

1. When you meet someone new in a social setting, how do you introduce yourself? 
a. Do you use your entire name?

b. Middle Name?

c. Nickname?

2. Have you ever felt that your name gave you an advantage or put you at a disadvantage socially?

3. Do you think those with ethnically identifying names experience any additional stressors in social settings? 


\section{CONSENT FORM EXAMPLE}

\begin{tabular}{|l|l|}
\hline FIU IRB Approval: & $3 / 22 / 18$ \\
\hline FIU IRB Expiration: & $3 / 22 / 19$ \\
\hline FIU IRB Number: & IRB-18-0114 \\
\hline
\end{tabular}

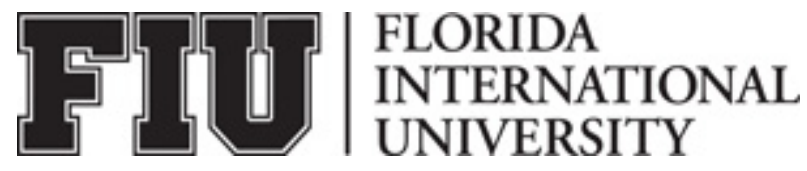

\section{ADULT CONSENT TO PARTICIPATE IN A RESEARCH STUDY}

Opinions and experiences about identity, presentation, and disclosure in work and society for persons with names that can reveal ethnicity.

\section{PURPOSE OF THE STUDY}

You are being asked to participate in a research study. The purpose of this study is to discover the opinions and experiences related to self-presentation and social penetration in work and society for persons with names that can reveal ethnicity.

\section{NUMBER OF STUDY PARTICIPANTS}

If you decide to be in this study, you will be one of 15 people in this research study.

\section{DURATION OF THE STUDY}

Your participation will require one (1) interview of around an hour, but no longer than two hours, as well as willingness to answer possible short follow-up questions via phone or email.

\section{PROCEDURES}

If you agree to be in the study, we will ask you to do the following things:

1. Participate in the interview process mentioned previously.

2. Allow researchers to make an audio recording of the interview.

3. Communicate with researchers regarding concerns prior to the publication of the research article.

\section{RISKS AND/OR DISCOMFORTS}

We expect minimal risk to you as a participant in this study. Still, although the information about you will remain strictly confidential, there may be a potential risk. As this is a study about first names and ethnicity, your first name and ethnicity will be included in any publication of the research, which may make it possible, although unlikely, to identify you.

Because some of the questions in the interview could seem personal or make you 
uncomfortable, you can opt out of answering any questions in the interview if that is the case. You have the right to withdraw from the study at any time if you perceive personal risk or discomfort.

\section{BENEFITS}

While we anticipate no direct benefits to your participation in this research study, the information gleaned from this research may be useful to further what we know about ethnic naming and its possible link to identity, presentation, and disclosure in work settings in particular and ultimately society. This new information could better inform organizational practice about how to avoid stereotypes in recruitment and hiring practices based simply upon one's name.

\section{ALTERNATIVES}

There are no known alternatives available to you other than not taking part in this study. However, any significant new findings developed during the course of the research, if so desired, would be communicated to you.

\section{CONFIDENTIALITY}

The records of this study will be kept private and protected to the fullest extent of the law. In any sort of report that might be published from this research, we will only include the first name and ethnicity of any participant.

Research records will be stored securely in a locked office where only the research team will have access to the records. However, authorized University or other agents, bound by the same provisions of confidentiality, may review your records for audit purposes.

\section{COMPENSATION \& COSTS}

You will not receive a payment for your participation, nor will you be responsible for any costs to participate in this study.

\section{RIGHT TO DECLINE OR WITHDRAW}

Your participation in this study is voluntary. You are free to participate or withdraw your consent at any time during the study. Your withdrawal or lack of participation will not affect any benefits to which you are otherwise entitled. The investigator reserves the right to remove you without your consent at such time that they feel it is in the best interest.

\section{RESEARCHER CONTACT INFORMATION}

If you have any questions about the purpose, procedures, or any other issues relating to this research study you may contact Dr. Thomas Reio, at Florida International University, 305.348.2382,reiot@fiu.edu.

\section{IRB CONTACT INFORMATION}

If you would like to talk with someone about your rights of being a subject in this research study or about ethical issues with this research study, you may contact the FIU 
Office of Research Integrity by phone at 305-348-2494 or by email at ori@fiu.edu.

\section{PARTICIPANT AGREEMENT}

I have read the information in this consent form and agree to participate in this study. I have had a chance to ask any questions I have about this study, and they have been answered for me. I understand that I will be given a copy of this form for my records.

Signature of Participant

Date

Printed Name of Participant

Signature of Person Obtaining Consent

Date 
VITA

\section{PAIGE JOHNSON}

B.A., International Relations

Florida International University

Miami, Florida

2009

Master of Public Administration

Florida State University

Tallahassee, Florida

2011

Academic Advisor

Florida International University

Miami, Florida

2014-2018

Doctoral Candidate

Florida International University

Miami, Florida

2016-2017

Academic Advisor-Lead Advisor

Florida International University

Miami, Florida

2016-

Instructor, Department of Communication

Florida International University

Miami, Florida

$2017-$

Manager of Academic Advising Services

Florida International University

Miami, Florida 